\title{
Teleostean Phylogeny Based on Osteological and Myological Characters
}

\author{
Filogenia de Teleosteos Basada en Características Osteológicas y Miológicas
}

*,******Rui Diogo; **Ignacio Doadrio \& ****Pierre Vandewalle

DIOGO, R.; DOADRIO, I. \& VANDEWALLE, P. Teleostean phylogeny based on osteological and myological characters. Int. J. Morphol., 26(3):463-522, 2008.

SUMMARY: Despite the progresses done in the field of teleostean phylogeny in the last decades, recent studies continue to raise questions concerning the higher-level relationships of this remarkably diverse group of fishes. The main aim of the present work is to help to clarify teleostean higher-level relationships. For that purpose, we undertook a cladistic analysis including 70 terminal taxa of 20 different orders and 271 morphological characters, concerning mainly osteological and myological structures of the cephalic region, pectoral girdle and fins and anterior vertebrae. In the consensus cladogram obtained, the elopomorphs appear as the most basal extant teleosts. The osteoglossomorphs included in the analysis are grouped in a monophyletic clade, which is the sister-group of the remaining non-elopomorph teleosts. The Otocephala, the Clupeiformes, and the Ostariophysi appear as monophyletic clades, thus contradicting the results of some recent molecular cladistic analyses placing the Alepocephaloidea inside the Otocephala. In fact, the monophyly of the Argentiniformes (Alepocephaloidea + Argentinoidea) is well supported by the cladistic analysis of the present work. This cladistic analysis also provides support for the monophyly of the Alepocephaloidea, of the Argentinoidea, of the Galaxioidea + Osmeroidea, and of the Esociformes. However, it does not provide strong evidence to resolve the relationships between the Argentiniformes, Salmoniformes, Esociformes, Osmeriformes and Neoteleostei, although it does indicate that the salmoniforms might be closely related to the Neoteleostei and that the Esociformes and the Osmeriformes might constitute a monophyletic unit. The monophyly of the Cypriniformes + Characiformes + Gymnotiformes + Siluriformes, of the Characiformes + Gymnotiformes + Siluriformes and of the Gymnotiformes + Siluriformes is well supported.

KEY WORDS: Elopomorpha; Euteleostei; Myology; Otocephala; Osteoglossomorpha; Osteology; Phylogeny; Teleostei.

\section{INTRODUCTION}

The Teleostei, with an estimated of about 28000 living valid species, is the most speciose group of vertebrates (Nelson, 2006). The extraordinary taxonomic diversity of teleosts is accompanied by a remarkably variety of morphological features and adaptations to very different freshwater, brackish, and marine habitats, from high elevation mountain springs over 5000 meters above sea level to the ocean abyss almost 8500 meters below (e.g. Arratia, 2000; Stiassny et al., 2004).

Due to restrictions of size and to the high number of characters described and of clades diagnosed in the present paper, the Introduction, as the other Sections of the paper, will be short and concise and, thus, it is not possible to provide here a detailed historical account of all the works dealing with teleostean phylogenetic relationships. Such a detailed account was provided, for instance, by Arratia (2000). Springer \& Johnson (2004) have recently presented, in their figure 3 (i.e. in the introduction of their work), a cladogram that summarizes what they consider to be, in face of a comprehensive review of the literature, the most supported scenario regarding teleostean higher-level phylogeny (see Fig. 1). However, as stressed by those authors, this scenario is far from being consensual among teleostean specialists. For instance, some authors argue that the most basal extant teleostean group is the Elopomorpha and not the Osteoglossomorpha (e.g. Arratia, 1997, 1999), while other authors argue that the Elopomorpha is not even a monophyletic unit (e.g. Filleul, 2000; Filleul \& Lavoué, 2001). Researchers such as Ishiguro et al. (2003) defend that

\footnotetext{
* Department of Anthropology, George Washington University, Washington DC, USA.

** Museo Nacional de Ciencias Naturales, Madrid, Spain.

*** Laboratory of Functional and Evolutionary Morphology, University of Liège, Liège, Belgium.
} 
some otocephalans are more closely related to the 'protacanthopterygian' alepocephaloids than to other otocephalans (e.g. Ishiguro et al.). This has major implications for teleostean higher-level phylogeny, because this would mean that two of the four major extant teleostean groups, i.e. the Neoteleostei and Otocephala (the two other groups being the Osteoglossomorpha and Elopomorpha: Fig. 1) are in fact not natural groups. These latter researchers also defend that the remaining, non-alepocephaloid 'protacanthopterygian' groups (i.e. their Esociformes,
Salmoniformes, Osmeriformes and Argentinoidea) do form a monophyletic 'Protacanthopterygii' clade, contrary to what is accepted by most authors nowadays (see Fig. 1). These are just a few examples to illustrate that, despite the progresses done in the field of teleostean phylogeny in the last decades, recent studies continue to raise controversial questions about the higher-level relationships of this remarkably diverse group of fishes. A more extensive analysis of the major current controversies concerning teleostean phylogeny will be provided in the discussion below.

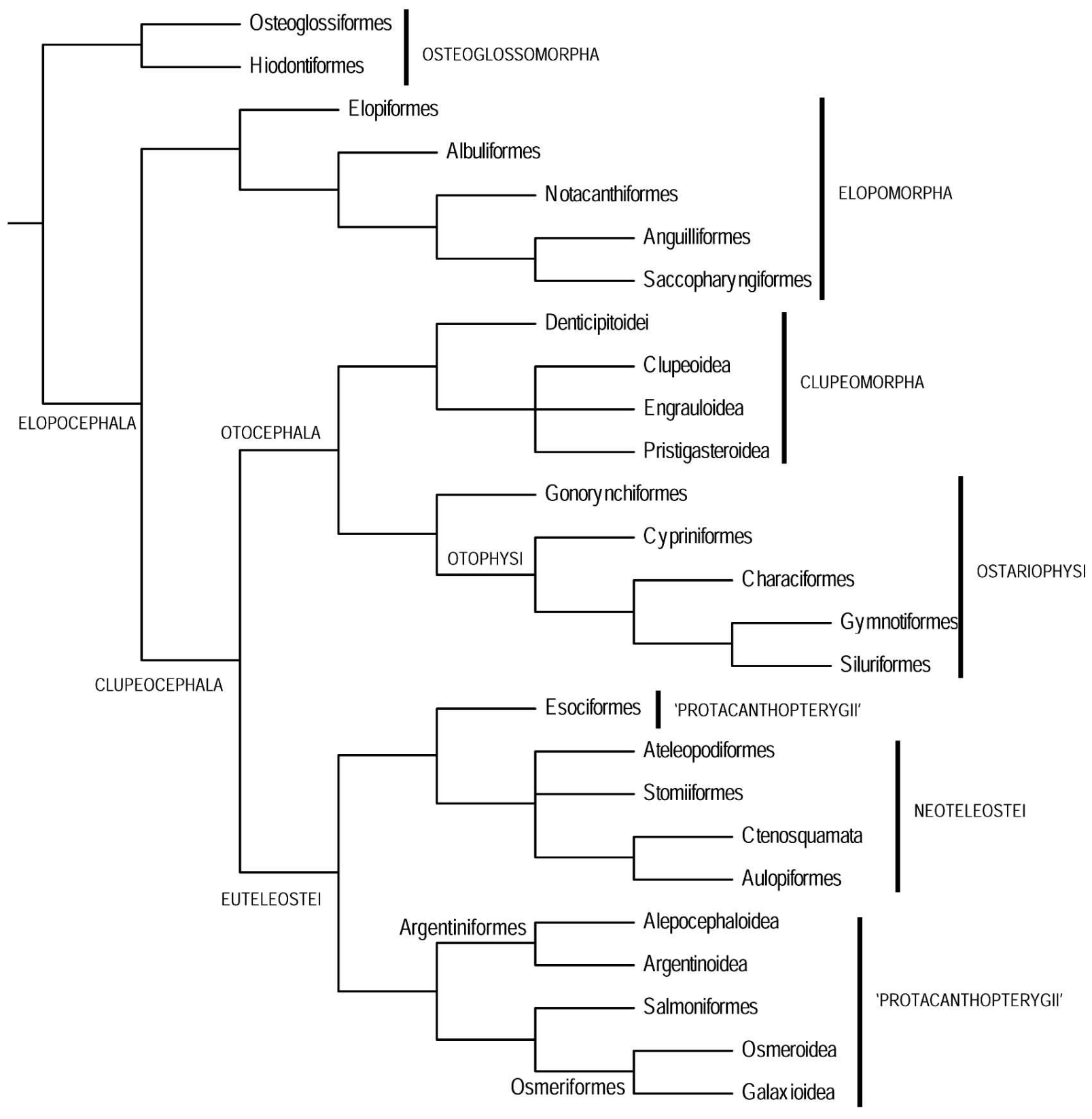

Fig. 1. Relationships between the major teleostean groups, modified from Springer \& Johnson's (2004) figure 3; the 'protacanthopterygian' groups shown in the tree correspond to those of Ishiguro et al.'s (2003) paper (for more details, see text). 
The main aim of the present work is to help to clarify the higher-level relationships of lower teleosts, because a basic understanding of this subject is crucial to pave the way for analyses on the evolutionary history of these fishes.

\section{MATERIAL AND METHOD}

In order to clarify the higher-level phylogeny of teleosts we undertook a cladistic analysis based in numerous osteological and myological characters. The inclusion of a large number of myological characters is one of the main differences between the present study and previous morphological cladistic analyses on teleostean relationships, as these latter were almost exclusively based on osteological features (see e.g. Stiassny et al.). The use of numerous myological characters in the cladistic analysis allows testing if these characters support, or not, the results of previous studies based essentially on osteological characters. With these myological characters, the present cladistic embraces a total of 271 phylogenetic characters, a number that is significantly higher than that used in previous morphological cladistic analyses of Teleostei higher-level phylogeny. The other main difference with previous analyses is the attempt to include, in a same cladistic analysis, representatives of all the major non-Neoteleostei groups (see Fig. 2). The necessity of including representatives of taxa such as the Anguilliformes, the Saccopharyngiformes or the Alepocephaloidea in a cladistic analysis of teleostean higherlevel phylogeny been stressed by authors such as Forey et al. (1996), Arratia (1999, 2004), Filleul (2000), Belouze (2002), Filleul \& Lavoué, Ishiguro et al., Diogo (2004) and Stiassny et al.

Although it is not possible to explain with much detail the reasons for the choice of each of the 70 terminal taxa included in the cladistic analysis, the most relevant points concerning this choice are briefly summarized. First of all it is important to note that the great majority of these terminal taxa concern extant groups, although some fossils are also included. The main reason for this is precisely the fact that we use a great number of characters referring to the configuration and presence of muscles, ligaments and cartilages. Thus, the fossil taxa that were included in the cladistic analysis of the present work, i.e. $\dagger$ Chanoides macropoma, $\dagger$ Clupavus maroccanus, $\uparrow$ Santanichthys diasii, $\dagger$ Lusitanichthys characiformis and $\dagger$ Sorbininardus apuliensis were chosen for a major, precise reason: authors such as Gayet (1981, 1985, 1986), Taverne (1977a, 1995, 1999) and Filleul \& Maisey (2004) have argued that these are particularly 'problematic' fossil taxa that, if included in an explicit cladistic analysis together with other ostariophysan and non-ostariophysan taxa, could well show that the four extant otophysan orders, and possibly the clade Ostariophysi, as currently recognized, do not form monophyletic groups. As the ostariophysan fishes play an important, central role for a proper understanding of the higher-level phylogeny and evolution of lower teleosts (e.g. Fink \& Fink, 1981, 1996), and as the testing of the monophyly of the otophysan, ostariophysan and otocephalan fishes was precisely among the main aims of the present work, we decided to include these five fossil taxa in the cladistic analysis. The inclusion of these fossils in an explicit cladistic analysis is also crucial to clarify a major question in the evolution of teleosts: if the characteristic Weberian apparatus of extant otophysans was, or not, acquired just once in the evolutionary history of these fishes (see e.g. Gayet, 1981, 1985; Fink \& Fink, 1981, 1986; Taverne, 1995; Filleul \& Maisey). The reason for including these five fossil taxa and not, for example, other 'problematic' otophysan fossil taxa sensu e.g. Gayet (1981, 1985, 1986), such as $\dagger$ Salminops ibericus, is that these five taxa are particularly well-conserved, what is clearly not the case of taxa such as $\dagger$ S. ibericus.

Concerning the 65 extant taxa included in the cladistic analysis (see Fig. 2), Amia and Lepisosteus were chosen in order to have two extant outgroup taxa in the analysis representing both the Halecomorphi and the Ginglymodi (see Fig. 1), which can thus help to polarize both the osteological and myological characters used. Representatives of each of the four osteoglossiform extant families sensu Hilton (2003) are included in the cladistic analysis: Hiodon (Hiodontidae), Pantodon (Osteoglossidae), Xenomystus (Notopteridae) and Mormyrus (Mormyridae). Representatives of all five extant elopomorph orders (see Fig. 1) are also included: Elops and Megalops (Elopiformes), Albula (Albuliformes), Notacanthus (Nothacanthiformes), Anguilla and Conger (Anguilliformes) and Eurypharynx (Saccopharyngiformes). The five extant ostariophysan orders are also covered in the analysis, including all extant gonorynchiform genera: Chanos, Gonorynchus, Phractolaemus, Kneria, Parakneria, Cromeria and Grasseichthys (Gonorynchiformes), Opsariichthys, Barbus, Danio, Cobitis and Catostomus (Cypriniformes), Xenocharax, Distichodus, Citharinus and Brycon (Characiformes), Sternopygus, Gymnotus and Brachyhypopomus (Gymnotiformes) and Diplomystes, Nematogenys, Trichomycterus, Callichthys, Cetopsis, Silurus, Pimelodus, Bagrus and Chrysichthys (Siluriformes). The four major extant clupeomorph groups (see Fig. 1) are also represented: Denticeps (Denticipitoidei), Ilisha (Pristigasteroidea), Ethmalosa (Clupeoidea) and Thryssa and Engraulis (Engrauloidea). All the major extant groups of 'Protacanthopterygii' sensu Ishiguro et al. (see Fig. 1) are represented: Coregonus, Thymallus and Salmo 


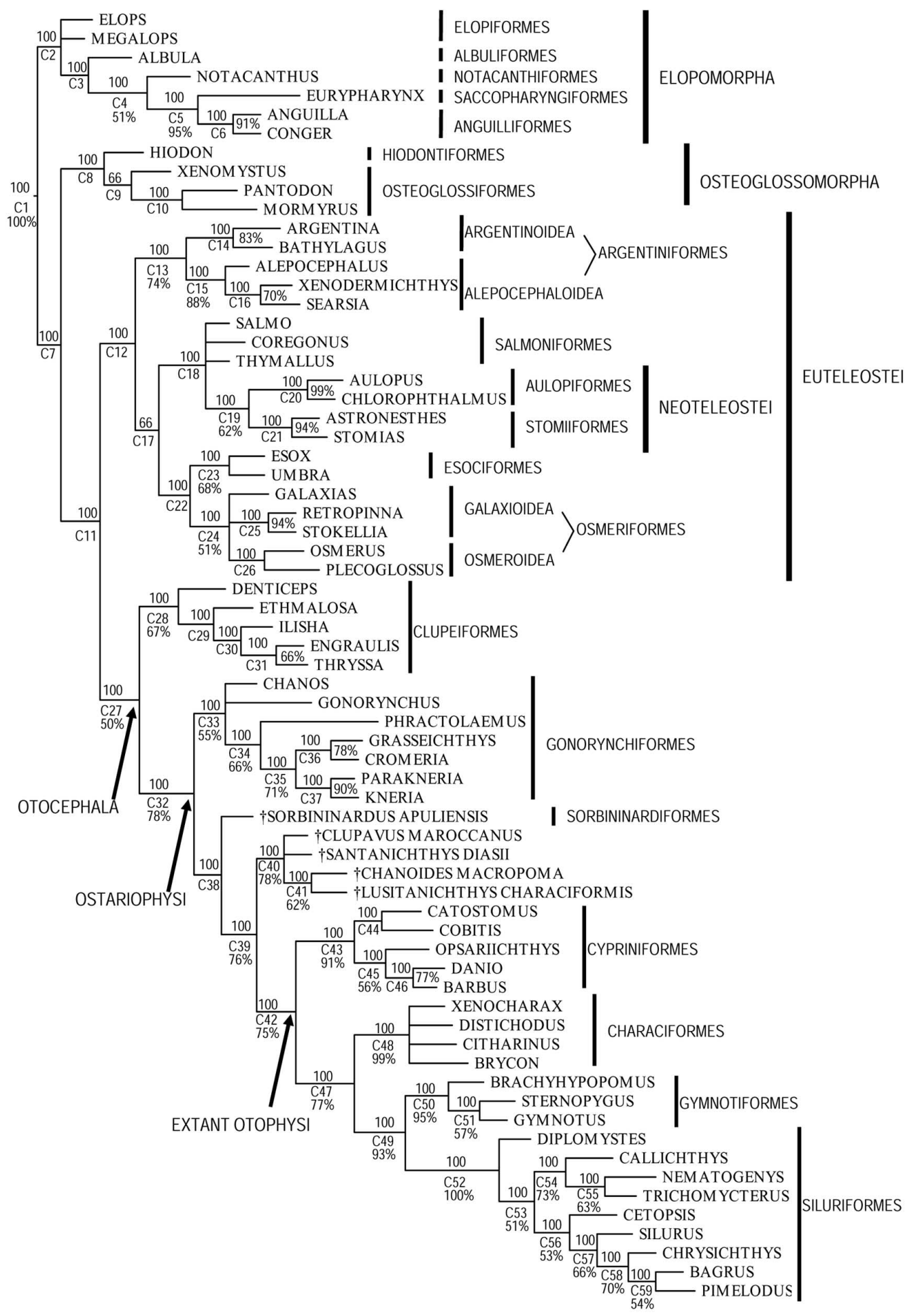

Fig. 2. Phylogenetic relationships between the teleostean groups included in the cladistic analysis, according to the results obtained by applying the 'majority fools' option of Nona \& Winclada to the 48 most parsimonious trees $(\mathrm{CI}=0.39$; RI $=0.76)$ obtained in the present work. The terms from 'C1' to 'C59' indicate the number of the clades, following the order given in the synapomorphy list provided in the text. The numbers 100 and 66 (not followed by a "\%") shown just above the numbers of the clades indicate the percentage of most parsimonious trees supporting each clade. Bootstrap values for 1000 replicates are shown (below or in front the number of the respective clade, in percentage, i.e. followed by a "\%") on branches for which these values are $\geq 50 \%$. The branch lengths illustrated are proportional to the number of unambiguous evolutionary transitions leading to the different nodes represented in the tree (for more details, see text). 
(Salmoniformes), Stokellia, Retropinna and Galaxias (Galaxioidea), Osmerus and Plecoglossus (Osmeroidea), Searsia, Xenodermichthys and Alepocephalus (Alepocephaloidea), Argentina and Bathylagus (Argentinoidea) and Umbra and Esox (Esociformes). Lastly, in order to test the monophyly versus paraphyly of the 'Protacanthopterygii' (see above), we have included in the cladistic analysis four representatives of two of the most basal neoteleostean orders, i.e. Stomias and Astronesthes (Stomiiformes) and Aulopus and Chlorophthalmus (Aulopiformes) (see Fig. 1).

With exception to the five fossil taxa included in the cladistic analysis, which were not directly examined by us and are thus coded following exclusively their descriptions in the literature (i.e. Taverne, 1977a, 1995: †Clupavus maroccanus; Gayet, 1981, 1985: †Lusitanichthys characiformis; Patterson, 1984: †Chanoides macropoma; Taverne, 1999; † Sorbininardus apuliensis; Filleul \& Maisey: $\dagger$ Santanichthys diasii), we have personally checked the characters listed in the Appendix 2 for all extant taxa included in the analysis. The phylogenetic procedure employed for proposing hypotheses of relationships is the cladistic methodology: parsimony was employed to find the hypothesis best supported by the analyzed data, using both the Hennig86 (Farris, 1988) and the Nona \& Winclada (Nixon, 2002) computer programs. The Implicit Enumeration algorithm (ie*) was employed in the search for the most parsimonious cladograms, with Nona \& Winclada used to check the most parsimonious results found with this algorithm. Tree manipulations and diagnostics were done with the help of Nona \& Winclada. Multistate characters were ordered, following Diogo (2004). As explained above, Amia and Lepisosteus were used as outgroups; the descriptions given in the literature concerning numerous other basal actinopterygians, either fossil or living, were also taken into account in the polarization of the characters. Autapomorphies for the different taxa examined were actively searched for and included in the analysis. The complete list of the 271 morphological characters included in the cladistic analysis is given in the Appendix 2.

\section{RESULTS AND DISCUSSION}

\section{Diagnoses for clades obtained and comparison with previous hypotheses.}

The characters listed in Appendix 2 were coded for each of the taxa included in the cladistic analysis, resulting in the data matrix shown in Table I. The phylogenetic analysis of these characters resulted in 48 equally parsimonious trees with a length of $680, \mathrm{CI}=0.39$, and $\mathrm{RI}=0.76$. Fig. 2 shows the phylogenetic relationships between the teleostean groups included in the analysis according to the results obtained by using the 'majority fools' option of Nona \& Winclada, which shows all clades that are supported by more than $50 \%$ of these 48 most parsimonious trees and thus provides more information than that given by the use of the 'strict consensus' option (Nixon). The terms from 'C1' to 'C59' indicate the number of the clades, following the order given in the synapomorphy list provided below. The numbers 100 and 66 (not followed by a "\%") shown above the numbers of the clades indicate the percentage of most parsimonious trees supporting the respective clades. Bootstrap values for 1000 replicates are shown (below or in front of the number of the respective clade, in percentage, i.e. followed by a "\%") on branches for which these values are $\geq 50 \%$. As can be seen in Fig. 2, of the 59 clades obtained, 43 (i.e. about $73 \%$ ) have bootstrap values $\geq 50 \%$, and, within these 43 clades, 26 (i.e. about $60 \%$ ) have bootstrap values $\geq 70 \%$ (these values need to be interpreted in the context of a morphological cladistic analysis including 271 characters; when a higher number of phylogenetic characters is used to perform a bootstrap analysis - e.g. genomic level sequence cladistic analyses may include several thousands of characters - the bootstrap values obtained tend to be higher: e.g. Hillis \& Bull, 1993; Rokas et al., 2003). The synapomorphy list provided below includes, for most clades, a commentary and a comparison with previous hypotheses; the numbering for diagnostic characters follows that of Appendix 2. Character state changes mentioned in this list are restricted to those unambiguous character states changes occurring in the different nodes, and can be included in two main categories: 1) state changes occurring exclusively in a certain node (in bold); 2) state changes subsequently reversed in a more terminal node and/or independently acquired in another node (non-bold).

Clade C1: $[2: 0 \rightarrow 1],[16: 0 \rightarrow 1],[\mathbf{1 7}: \mathbf{0} \rightarrow \mathbf{1}],[\mathbf{2 0 : 0} \rightarrow \mathbf{1}]$, $[22: 0 \rightarrow 1],[23: 0 \rightarrow 1],[\mathbf{4 0 : 0} \rightarrow \mathbf{1}],[66: 0 \rightarrow 1],[105: 0 \rightarrow 1]$, $[110: 0 \rightarrow 1],[132: 0 \rightarrow 1],[163: 0 \rightarrow 1],[167: 0 \rightarrow 1],[181: 0 \rightarrow 1]$, $[236: 0 \rightarrow 1],[244: 0 \rightarrow 1],[245: 0 \rightarrow 1]$

As expected, the teleostean taxa included in the cladistic analysis appear more closely related to each other than to Amia and Lepisosteus. In all the 48 most parsimonious trees obtained, the teleostean taxa examined appear more closely related to Amia than to Lepisosteus (the clade including Amia and these teleostean taxa is supported by a bootstrap value of $82 \%$ ). However, the relationships between the Teleostei, the Halecomorphi and the Ginglymodi are of course beyond the scope of the present work: such relationships can only be seriously addressed in an analysis including a great number of other neopterygian and non- 


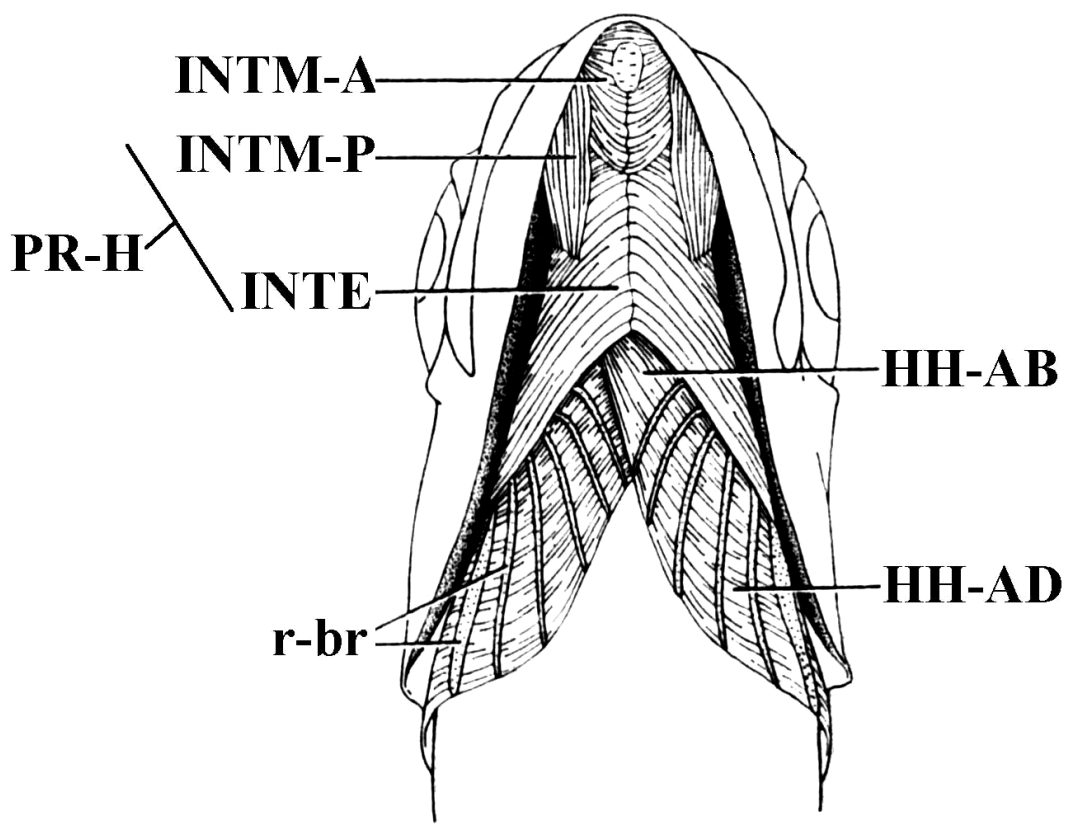

Fig. 3. Ventral view of the ventral cephalic musculature of Hiodon alosoides (modified from Greenwood, 1971). HH-AB, hyohyoideus abductor; HH-AD, hyohyoidei adductores; INTE, interhyoideus; INTM-A, INTM-P, anterior and posterior sections of intermandibularis; PR-H, protractor hyoidei; r-br, branchiostegal rays.

Fig. 4. Ventral view of the ventral cephalic musculature of Danio rerio. On the right side a portion of the hyohyoidei adductores, as well as of the mandible, was cut, and the opercle, interopercle, subopercle and preopercle are not represented. ch-a, ch-p, anterior and posterior ceratohyals; $\mathbf{H H}-\mathbf{A B}$, hyohyoideus abductor; HH-AD, hyohyoidei adductores; HH-INF, hyohyoideus inferior; hyh-v, ventral hypohyal; ih, interhyal; INTM-A, anterior intermandibularis; iop, interopercle; mnd, mandible; op, opercle; pop, preopercle; PR-H-D, PR$\mathbf{H}-\mathbf{V}$, sections of protractor hyoidei; $\mathbf{r}-$ br-I, branchiostegal ray I; SH, sternohyoideus; sop, subopercle.

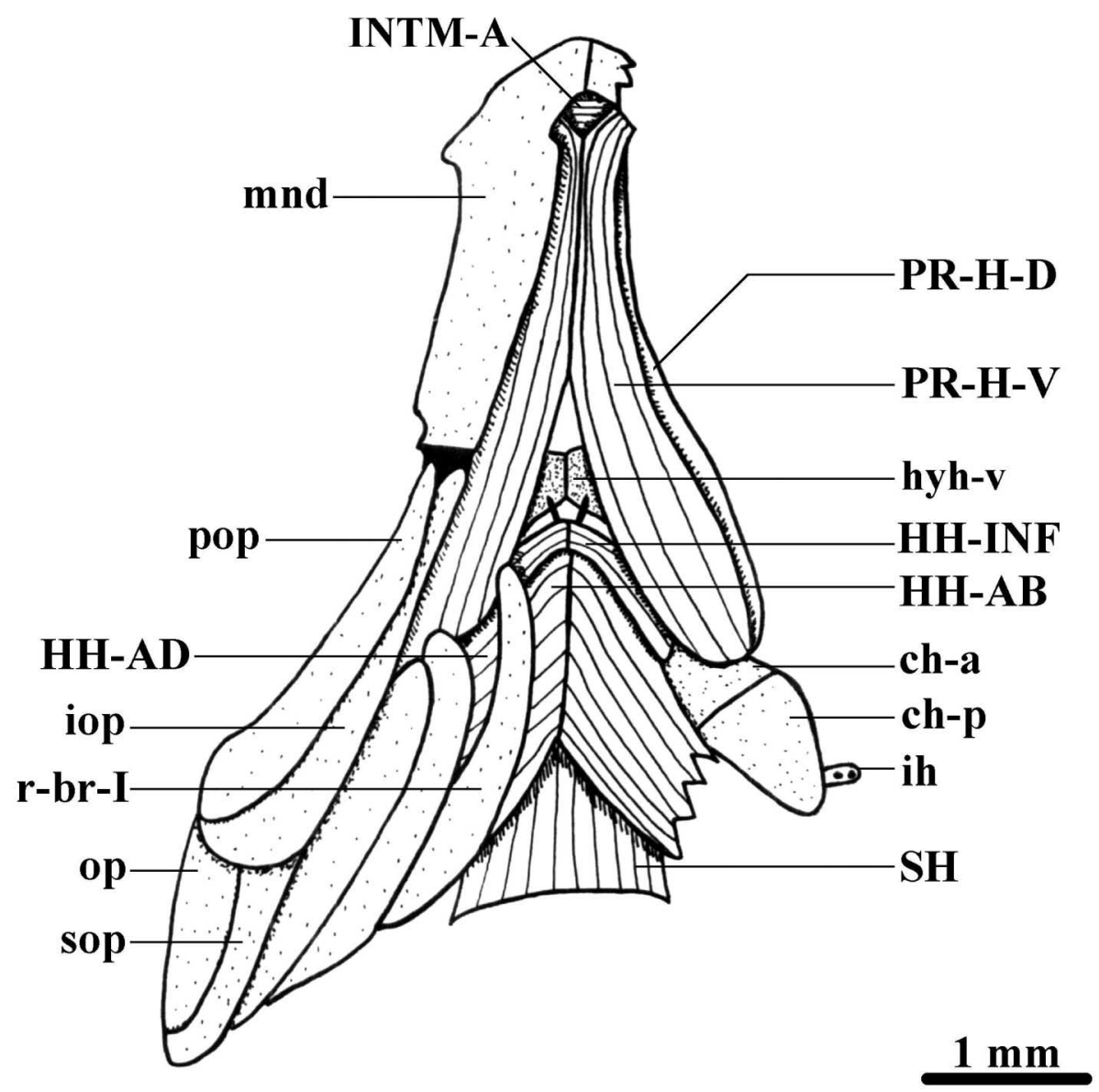


neopterygian fishes (e.g. Arratia, 2004; Cloutier \& Arratia, 2004). Among the unambiguous synapomorphies of the clade including all the teleosts examined in the present work, which is supported by a bootstrap value of $100 \%$ (Fig. 1), those concerning characters 2 (posterior intermandibularis integrated in protractor hyoidei, but also deeply associated with anterior intermandibularis), 16 (anteroventromesial portion of hypoaxialis continuous with posteroventromesial portion of sternohyoideus), 17 (sternohyoideus consolidated into a single median muscle), 20 (presence of distinct muscle arrector ventralis), 40 (prevomer unpaired), 66 (ossification of supraoccipital), 105 (mesocoracoid arch ossified), 110 (first pectoral ray articulating directly with scapula and/or possibly coracoid), 163 (premaxillae not markedly ankylosed with neurocranium), 181 (articulation, either direct or indirect, between autopalatine/dermopalatine and maxilla), 236 (presence of ossified urohyal/parurohyal), 244 (coronoid bones absent as independent ossifications) and 245 (prearticulars absent as independent ossifications) have been proposed as potential Teleostei synapomorphies by authors such as Schaefer \& Rosen (1961), Lauder (1980), Lauder \& Liem (1983), Jollie (1986), De Pinna (1996), Arratia \& Schultze (1990) and Arratia (1997, 1999). However, the results of the present work pointed out four potential Teleostei synapomorphies that, at least according to our knowledge, have not been previously proposed: those concerning characters 22 (arrector dorsalis subdivided into two well-developed sections), 23 (arrector dorsalis attaching on both the first and second pectoral rays), 132 (absence of distinct adductor mandibulae A3') and 167 (primordial ligament attaching posteriorly on posterolateral surface of mandible). In addition to the unambiguous synapomorphies listed above uniting the teleostean taxa examined in the present work, there are other features that may represent potential Teleostei synapomorphies. For example, the loss of the muscle branchiomandibularis $(14: 0 \rightarrow 1)$ : according to the results of the cladistic analysis, this feature may have occurred in Lepisosteus + Amia + the teleosts examined and then reverted in Amia or may have occurred independently in Lepisosteus and in teleosts. Although the two hypotheses appear as theoretically equally parsimonious, the independent acquisition, in Amia, of a muscle that is strikingly similar to the characteristic muscle branchiomandibularis of other actinopterygians seems rather unsound (see e.g. Lauder, 1980; Wilga et al., 2000). The loss of muscle protractor pectoralis $(24: 0 \rightarrow 1)$ is also a feature that may have occurred in Lepisosteus + Amia + the teleosts examined and then reverted in Amia or that may have occurred independently in Lepisosteus and in teleosts. Other features are e.g. the presence of distinct, strong ligaments connecting the anterior surface/anterior cartilage of autopalatines and/or dermopalatines and maxilla and/or premaxillae $(160: 0 \rightarrow 1)$ and the presence of an ossified interhyal (223: $0 \rightarrow 1$ ). According to the results of the cladistic analysis, these two latter features might represent synapomorphies of the Clupeocephala (see Fig. 1) and of the Elopomorpha, or, instead, might be synapomorphies of the clade including all the teleostean taxa examined, that were subsequently lost in the Osteoglossomorpha (as well as in other, more derived taxa: see below). These two features could, thus, possibly be interpreted as synapomorphies of the Elopomorpha + Clupeocephala, if the Osteoglossomorpha were accepted as the most basal extant teleostean clade examined (see e.g. Fig. 1). However, as can be seen in Figure 2, all (100\%) the parsimonious trees obtained in the cladistic analysis of the present work support the Elopomorpha, and not the Osteoglossomorpha, as the most basal teleostean group examined (see 'Clade C7' below).

\section{Clade C2: [247:0 $\rightarrow 1],[268: 0 \rightarrow 1]$}

As explained in the Introduction, the monophyly of an Elopomorpha clade including elopiforms, albuliforms, notacanthiforms, anguilliforms, and the peculiar saccopharyngiforms has been recently questioned by authors such as Filleul and Filleul \& Lavoué. As stressed these authors, no published morphological cladistic analysis has included representatives of all these taxa and supported their grouping in a monophyletic clade. Some recent molecular cladistic analyses supported the inclusion of these taxa in a monophyletic clade (e.g. Wang et al., 2003; Inoue et al., 2004), but others have contradicted this view (e.g. Obermiller \& Pfeiler, 2003). The elopiform, albuliform, notacanthiform, saccopharyngiform and anguilliform fishes included in the present cladistic analysis do appear in a monophyletic clade in all the 48 most parsimonious trees obtained (Fig. 2). In this respect, this is thus the first published cladistic morphological analysis supporting the monophyly of these fishes. It should however be stressed that the bootstrap value obtained for this clade $\mathrm{C} 2$ is not $\geq$ $50 \%$ (Fig. 2), i.e. this clade is not strongly supported by a bootstrap analysis. Interestingly, the monophyly of the Elopiformes is not supported by the tree of Figure 2, although it is also not contradicted by this tree: Elops, Megalops and the remaining elopomorphs are placed in an unresolved trichotomy. A close relationship between Elops and Megalops has been defended in recent molecular studies (e.g. Obermiller \& Pfeiler; Wang et al.; Inoue et al., 2004). It has been also defended in the past in studies such as Greenwood et al. (1966), Nelson (1973) and Forey et al. However, in some other studies Megalops was placed as the sister-group of Elops plus the remaining elopomorphs (e.g. Forey, 1973b) or was placed together with Elops and the other elopomorphs in a trichotomy such as that shown in Figure 2 (e.g. Patterson \& Rosen, 1977). 
Table I. Data matrix of the 271 characters included in the cladistic analysis. Order of characters follows that of Appendix 2. 'Inapplicable' and 'missing' character states for a certain taxon are indicated with '-' and with '?' respectively (for more details, see text). (Characters 001 to 271$)$.

0000000000000000000000000000000000000000000000000000000000000000000000000000000000000000000000000001111111111111111111111111111111111111 0000000001111111111222222222233333333334444444444555555555566666666667777777777888888888899999999990000000000111111111122222222223333333 1234567890123456789012345678901234567890123456789012345678901234567890123456789012345678901234567890123456789012345678901234567890123456 IERSOSteUS $\quad 000---0 ? 0000010000000001---0000---1-0000000010 ? 0000000000000100000000000001000000000000101001100000000000-00000-0001000-0---000000001-00$ AMA $\quad 1000--0 ? 0000000000000000---0010---0-000000000000 ? 00000000000000010010000000000000000000011001000000000000-0000110000100-0---000000000000$ H.PS $\quad 110000000000010110010111000000010000000100000000000000000000000011010000000000000000000000000000000001001000010-0000000-0--10000001-0000$ MEGALOPS $\quad 1100000000000101100101110000000000000001000000000000 ? 000000000001100000000000000 ? ? 00000000000000000010001000010-0000000-0--1000000010000$ ALBUA $\quad 000---00000001011001011100000001010000010000000010000000000000001101000000000000000000000000000000000000100101100010000-0--1000000010000$ NOTACANTHUS $12000000000001011001011100000001010000010101100000000000000010011101000000000000 ? 00010--000-00-000000101----01110010000-0---000100011-00$

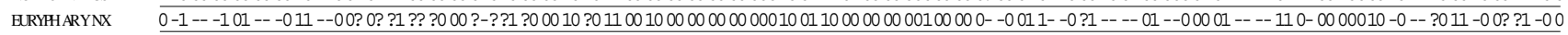

ANGUIJA $\frac{020-000000100101100101110000001-010000010001000000000000000010011101000000100000000010--000-00-000000001----110-0000000-0---100000001-00}{020-000000100101100101110000001-0 ? 00000100010000000000000010011101000000100000000010--000-00-000000001----110-0000000-0---100000000000}$ $\begin{array}{llll}\text { CONGER } & 020-000000100101100101110000001-0 ? 0000010001000000000000000010011101000000100000000010--000-00-000000001----110-0000000-0---100000000000 \\ \text { HCDON } & 110000000000010110010111000000000000000 ? 0100000000000 ? 000000000011000000001000000000000000000 ? 01000010001000110-0000000-0--10000001-0000\end{array}$ XENOMYSTIS 1 ?? 0? ?0?0000010010011111001000000100000100000000000000000000000011010000001000000000000000000001000010001100110-0000000-0--00000001-000 PANTCDON $\quad 1200000 ? 00000101100111110000000000000001000010 ? 0 ? 0000000000000000100000000 ? 000000000000000000010001011001111111000 ? 0000-0-00000001-1-00$ MORMYRUS $\quad 1000--0 ? 010001011001011100000001010000010100100010000000000010000101000000100000000000000000000100101000100 ? 11100010001-0--00000001-1-00$ ARCENINA $\quad 120000000000010011010111000000000100000100000010000000000000000111000000001000000000001000000000000000001100110-0000000-0--01000001-0000$ BATHYLAGLS $\quad 12000000000001011101011110000000011000010000001100000000000100011100000000100000--0000100000000000001101----11100000000-0--00000001-1-00$ ALEPOCFPHALS $\quad 1200000 ? 000001001101000100000000111000010100001000000000000100011100000000100000--0000100000000000001100110011100000000-0--00000001-0000$ SEARSA $\quad 1200000 ? 000001001101000100000000111000010000001000000000000100010101000000100000--000010 ? ? 000000000010000-0011100000000-0--00000001-0000$ XENOEERMICHTHYS SALMO $\quad 120000000000010111010111000000001010000100000000000000000001000111000000000000000000001000000000000010001100110-0000000-0--10000001-0000$ COREGONUS $\quad 12000000000001011101011100001000 ? 01000010100000000000000000 ? 000111000000000000000000001000000000000010001100110-0000000-0--10000001-0000$ THYMALLS $12000000000001011101011100000000101000010001000000000000000 ? 000111000000000000000000001000000000000010001100110-0000000-0--10000001-0000$ AULOPUS $\quad 12000000000001011111021000000000010000010000000000000000000000011101000001100000--0100100000000000000001----11100100000-0--10000001-0100$ CHOROPHIHALMUS $12000000000001011111021000000000010000010001 ? 00 ? 00000000000000011101000001000000--0100100000000000000001----11100100000-0--10000001-0100$ ASTRONESTHES $\quad 120000000000010111010$ ? 110000 ? 0010? 00001000100000000000000 ?? 00011101000000100000 ? ?01001?000001000 00010 $00110011100010000-0--10000001-0000$ STIOMAS $\quad 120000000000010111010 ? 110000 ? 00010100001000100000000000000$ ?? $\quad 10011101000000000000000100100000011000001001----11100010000-0--10000001-0000$ EOX $\quad 120000000000010111010111000010000 ? 1000010001000000000000000 ? 00011101000001-00000000000100000000000000001----110-0000000-0---000000010000$ UMBRA $\quad 120000000000010111010111000010001$ ?1 $\quad 1200010001100 ? 000000000001$ ?0 $011100000001100000000000100000000000000001----110-0000000-0---000000010000$ GALAXIAS $\quad 12000000000001011101011 ? 0000010000100001010110010000000000000001110000000010000000000010000000100000$ ?0 01 -- -- $1110-0000000-0$-- ?000000? ?0000 REIRCPNNA $\quad 1200000000000101110101110000000---1-00010001100100000000000000011100000001-00000000000100000101000001001----110-0000000-0--10000001-0000$ STOKELLIA OSMERLS DENTICES ETHMALOSA IISHA ENGRALLIS

THRIS SA

CHANOS CONORYNCHUS $1200000000000100110101110000000---1-00010001100100000000000000011100000001-00000000000100000101000001001----110-0000000-0--10000001-0000$ 1200000 ?0 $000010111010111000011000010000 ? 0001100100000000000100011100000000100000 ? 000001000000000000010001100110-0000000-0--10000001-0000$ 1200000 ?0 0000101110101110000 ?? $00001000010101100 ? 000000000000000111000000001000000000001000000000000010001100110-0000000-0$-- $10000001-1-00$

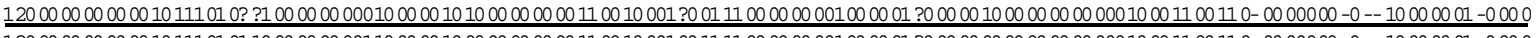
$120000000000010111010110000000001100000100000000000110010001001111000000001000001 ? 00000000000000000010001100110-0000000-0--10000001-0000$ $120000000000010111010111000000000100000101000000000110010001000111010000001010001100000000000000000010001100110-0000000-0--10000001-0000$ 120000000000010111010111000000010100000100000000000110010001 ? 0 $011100000000101000110000000000000000001000110011100000000-0--00000001-0000$ ?2000 $000000001011101011100000001010000010 ? 000000000110010001000111010000001010001$ ?0 $000010000000000001000110011100000000-0--? 0000001-0000$ $120000000000010111010110000000000000000101011000000010001001000111010000000010001100000000 ? 0 ? ? 0000000000110011101000000000000000001-0000$ $120001000000010111010110000000000000000101011000010010000001000111010000001010001-00001000 ? 0 ? ? 1000000000110011111000000000001000001-1-00$

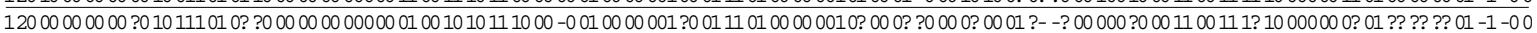

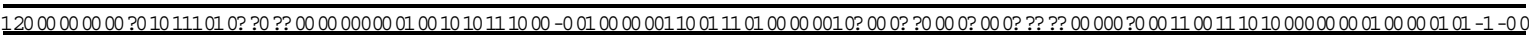
1200000000010100110101100000000000001001010110000000100000011001110100000010 ? 000 ? 00000000 ? 0 ? ? $000001000110111101000000000100000001-1-00$ 1200000000010100110101100000000000001001010110000000100000011001110100000010 ? 00 0? -000 0? 00 0? 0? ?1 $000001000110111101000000000100000001-1-00$ ?? ?? ?? ?? ?? ?? ?? ??? ?? ?? ?? ?? ? 000010 ? 000001 ? 1001000100 ?? ?? 0? ?01 ?? ? 11101 ?0 ?? ?? ? 0? 00 ?? ?? ?0 00 ? 00 0? ?? ?? ?0 0?0 000 0? ?? ?? ?? ?? ?? ??? ?? ?? ?? ?? ?? ?? ?? ?? ?? ?

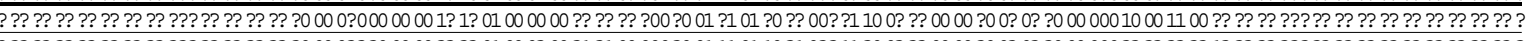

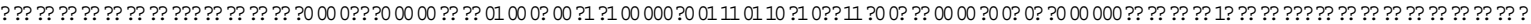

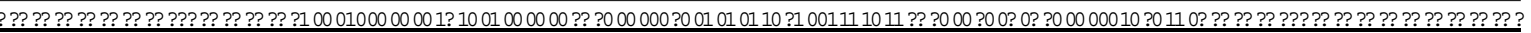
? ?? ?? ?? ?? ?? ?? ?? ??? ?? ?? ?? ?? ?0 00010 ?0 ?0 00 1? 1101000000 ?? ?0 0? ?00 ?0 01110110 ? 100011101 ? ?? 0000000 ? 0 ? ?0 0000011001100 ?1 ?? ?? ??? ?? ?? ?? ?? ?? ?? ?? ?? ?? ? 12000001000001011101000100010000000000010100100 ?10001000000001011101201200121200111000010000101000001000110011101000000000000000001-1-00 $12000001000001011101000 ? 0001001-0100000101001001100010000000110111012012001212001-1000010000001000000000110011101000000000000000001-1-11$ $12000001000001011101000000010000000000010100100010001000000001011101201200121200111000010000001000000000110011101000000000000000001-0000$ 12000001000001011101000 ? 00010000000000010100100 ?10001000000001011101201200121210111000010000001000001000110011101000000000000000001-0000 $12000001000001011101000 ? 00010000000000010100100010001000000001011101201200121210111000010000001000001000110011101000000000000000001-0000$ $120000000000010011010110000000011000000101001000000011100000000111012112101212001110000000001000000010001100111010000000000-000000010000$ 02- -00000000010011010110000000011000000101001000000011100000000111012112101212001110000000001000000010001100111010000000000-000100011-00

CIIHARINLS

BRYCON $\frac{120000000000010011010110000000011000000101001000100011100000000111112112101212001110000000001000000010001100110-10000000000-000000010001}{120000000000010011010110000000011000000101101000000011100000000111012112101212001110000100001000000010001100110-10000000000-000100010000}$

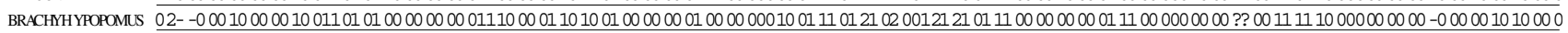

\section{STERNOPYGUS} GYMOTUS DHLOMYSIES

NEMATOGENYS TRICHOMYCTERLS CALCHTHYS CEIOPSIS

SIURLS

CHRYSIC HIHYS BAGRLS $\frac{120000010000110111010100000000011100001101001000000010000000100111012102001212101110000000001110000000000-00111110000000000-000001010000}{12000001000011001101010000000001110000110100100000001000000010011101210200121210111000000000101000000000 ? ? 00111010000000000-000001010000}$ $12000001000001001101000000000001110000010000100110001000001-10011101211201-2121011100101000111-0001100101100110-10000000000-000000010001$ $12000001000001011101000000000001110000010100100110001000001-10011101210201-212101-100101000111-0001100001100110-10000000000-100100001-01$ $12000001000001011101000000000001110000010100100110001000011-10011101010201-212101-100101000111-0001100101100110-10000000000-100100001-01$ $12000001000101011101000000000001110000010100100110001000011-10011101010201-212101-1001010011---0001120101100110-10000000000-100100001-01$ $12001001000001011101000010000001110000010000100110101000001-10011101210201-212101-100101000111-0000100101100110-10000000010-100000000001$ $12001001000001011101000011000001110001010000100010001000001-10011101211201-2121011100101000111-0001100101100110-10000000000-000000000001$ $12001001000001001101000011000001110000010000100110001000001-10011101211201-2121011100101000111-0001120101100110-10000000000-000000000001$ 


\begin{tabular}{|c|c|}
\hline & $\begin{array}{l}3334444444444555555555566666666667777777777888888888899999999990000000000111111111122222222223333333333444444444455555555555666666666677 \\
789012345678901234567890123456789012345678901234567890123456789012345678901234567890123456789012345678901234567890123456789012345678901 \\
\end{array}$ \\
\hline IEHSOSTEUS & $0-0000000000-0--01000100000000 ? 000000000000000000000000000000000000000000000000000----00000-0000--0000001000000000010000000000000000000$ \\
\hline AMIA & $-0000000001000 ? 00000010000000000000000000000000000000000000000001110000000000000000000000000001--00000000000000000000001-0000000000000$ \\
\hline HCOS & 0-0000000001000000000011001000100000000000001000000000000000000001000100000000?00000001000000001000100000001101-00000000100000000001000 \\
\hline MEGALOPS & $0-0000000001000000000011001000100000000000001000000000000000000001000000000000 ? 000000010000000010001000000011$ ? 1- 00000000100000000001000 \\
\hline ALBLA & $0-00000000010000001000110010011 ? 000000000000100000000100001000000100000000000000000000100001000000010000 ? 001101-00000000100000000001000$ \\
\hline NOTACANTHUS & 0-001000000100000010011?001000-000000000000? ? ? ? ?? ?01001000000001000000000000100000001000000000000100001001101-00000000100000000001000 \\
\hline BURYPHARYNX & 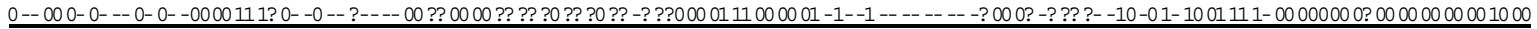 \\
\hline ANGULA & 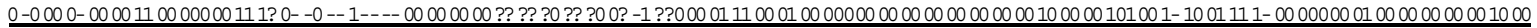 \\
\hline CONGER & 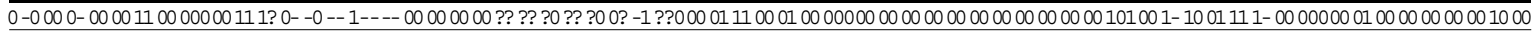 \\
\hline HODON & $0-01001000010000000001100010001000000000000110 ? 000000000000000000100010000000000000000000000000000010000100110 ? ? 00000000100010000000000$ \\
\hline XENOMYSTLS & $0-00000000010000000001100010011000000000001110 ? 0000000000000000001000001000000000000000000010000000100001001110 ? 00000000100010000000000$ \\
\hline PANTODON & $0-00000000010000000001100100-010-000000000$ ? $110 ? 0000000000000000011-00001-000000000$ ? ? ? ? $000000000000100001001110 ? 0000000010001000000$ \\
\hline MORMYRUS & $0-00001000010000001001100110-0 ? 0-00000000101 ?-? 000-0010-1000000011-00000-00000000000000000000000100100001001111-000000001 ? 0010000000000$ \\
\hline ARCENINA & 0-0101000001000010100111001001010000010000001000000101001000000001000000000000000000001001010000000100001101110100000000101000010000000 \\
\hline BATHYLAGLS & 0-0101? $00001000-10100111001001$ ?10000010000001000000101? $01000000 ? 01000000000000100000001001010000000100001001110100000000100000010000000$ \\
\hline ALEPOCPHALS & $0-0001000001000-10 ? 0001100100000000000000000100000010000 ? 000000001000000000000100000001000010000000100001001110100000000100000010000000$ \\
\hline SEARSA & $0-0000000001000-10000011001000 ? 00100000001001000000100000000000001000000000000100000001000010000000100001001110100000000100100010000000$ \\
\hline XENOLERMICHTHYS & $0-0000000001000-10000011001000 ? 00000000001001000000100001000000001000000000000100000011000010000000100001001110100000000100000010000000$ \\
\hline SALMO & $0-00000000010000000000111010001100000000000010001000000010000000010000000000000000000010000100000001000010011101000000001000000000$ \\
\hline COREGONUS & 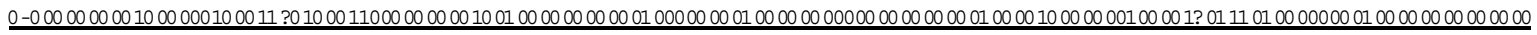 \\
\hline THYMALLS & 0-000000000100000000001110100011000000000000100010000000100000000100000000000000000000100001000000010000100111010 \\
\hline AULOPUS & $0-0000000001000-101000111010011100000000000010001000000000000000010001000000000000000010000100000 \mathrm{c}$ \\
\hline CHLOROPHIHALMUS & $0-0100100001000-10100011101001110000000000001000100000001000000001000000000000000000001000010000000100001001110100000000100001000000000$ \\
\hline ASTRONESTHES & 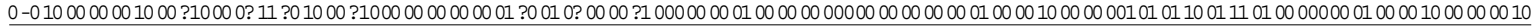 \\
\hline STOMIAS & 0-0100000001000010000? $11101001 ? 10000000000001000000000001000000001000000000000000000001100010000000101011001110100000000100001000000010$ \\
\hline EOX & $0-0000000001000000100011001000100000000000001000000001001001000001000 ? 00000000 ? 00000001000010000000100001001110100000000100000000000000$ \\
\hline UMBRA & $0-0100000001000000100111001000000000000000001000000000001001000001000000000000000000001000010000000100001001110100000000100000000000000$ \\
\hline GALAXAS & $0-00000110010000001001110010011000000000010010000000000-0--1000001000000000000 ? 00000001000010000000100001001110100000000100000000000000$ \\
\hline REIROPINA & $0-00000000010000000001110010011000000000001010 ? 0000000000000000001000000000000000000001000010000000100001001110100000000100000000000000$ \\
\hline STOKELIA & 0000 \\
\hline OSMERLS & $0-000000000100000000001110100$ \\
\hline HBCOGLOS SLS & 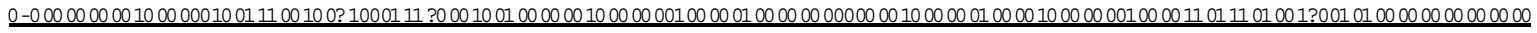 \\
\hline DENTICESS & $0-0100000101000000 ? 001100010001000000 ? 000000100000000000 ? 000000001000100000000001000001000010000000100001 ? 011101000000001000000000$ \\
\hline ETHMALOSA & $0-0001010001000000100011001001100000010000001000000000000000000001000100000000000000001000000000000100001101110100000000100000000000001$ \\
\hline IISHA & \\
\hline ENGRAULIS & $0-000101000100000000001100100110000000000000100000000000000000000100010010000000000000100000000000010000100111010000000010000 \mathrm{C}$ \\
\hline THRYSSA & \\
\hline CHANOS & 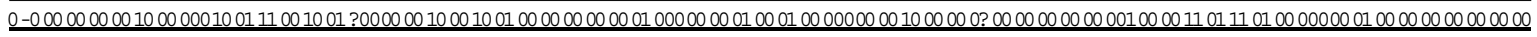 \\
\hline CONORYNCHUS & $0-1100000001000000100111001001 ? 0100001001100100100000000000010000100010000100001000000 ? 000 ? 00000000100001101110110000000100000000000100$ \\
\hline PHRACTC AEMLS & $0-000000000100000011011000100 ? ? 00000011101000010000000001100001011-0010000000000010010 ? 0 ? 01-1000000100001101110110100000100000100000000$ \\
\hline GRASSBCHTHYS & 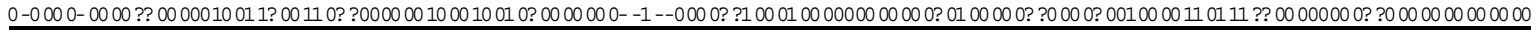 \\
\hline CROMERIA & $0-000010000100000010011 ? 001101 ? 000000100010010000000000-1--0000011-001000000000000 ? 0000000 ? ? 0000 ? 0010000110111 ? ? 00000000110000000000000$ \\
\hline PARAKNERIA & $0-00001000010000001001110011010000000100010010000000000010000100010001000000000000100010 ? 01-0000000100001101110101000000110000000000000$ \\
\hline KNERIA & $0-00000010010000001001110011010000000100010010000000000010000100010001000000000000100010001-0000000100001101110101000000110000000000000$ \\
\hline$\dagger$ †.APLENSSS & 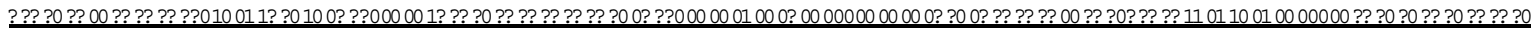 \\
\hline †C.MAROCCANLS & 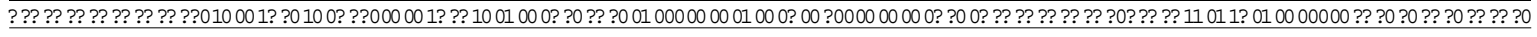 \\
\hline †S.DIASII & 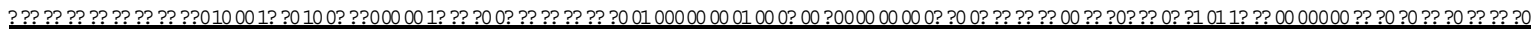 \\
\hline †C.MACROPOMA & 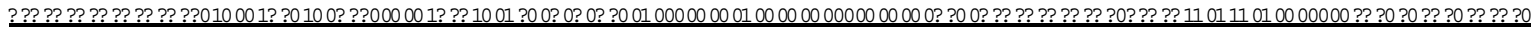 \\
\hline 汭 CHARACFORMS & 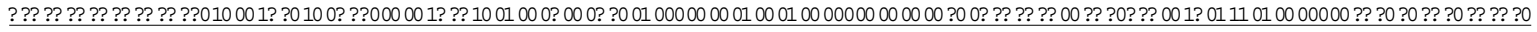 \\
\hline CATOSTOMLS & $0-0100101001010000100111001000000000010001001 ? 0001100000100000000100010000000001000000 ? 000000000000100001101110100000000100000000000000$ \\
\hline COBITS & 000000100001010000100111001000000000010001001000011000111000000001000100000000000000001000000000000100001101110100000000100000000000000 \\
\hline OPSARICHTHYS & $1-0101000001020000100111001000000000010001001100011000101000000001000100000000000000001000000000000100001101110100000000100000000000000$ \\
\hline DANO & $0-0000000001020000100111001000 ? 00000010001001100011000001000000001000100000000000000000000000000000100001101110100001000100000000000000$ \\
\hline BARBLS & $0-0000000001020000100111001000000000010001001100011000001000000001000100000000000000001000000000000100001101110100000000100000000000000$ \\
\hline XENOCHARAX & \\
\hline DSTLCHODUS & $0-0000101001000000100110001000 ? 0000000000100100000000010 ? 0000000010010000001000000000010000 ? 0000000100001011110100000000100000001000000$ \\
\hline CIIHARINUS & 000000101001000000100110001010100000000001001000000000101000000001001000000000010000001000000000000100001001110100000000100000001000000 \\
\hline BRYCON & $0-01001010010000000001100010101000000000010010000000001010000000010001000000000000000010000 ? 0000000100001001110100000000100000001000000$ \\
\hline BRACHYHYPOPOMUS & 0-0100100001000000100110001000010000010001011?0000?0010-1??0000001000000000000010000001010000000000100001101110000000000100000000000000 \\
\hline SIERNOPYGUS & $0-0100100001001000100110001000010000000001011$ ?0000? $0010-0$ ??:0000001000000000001010000001010000000000100001001110100000100100000000000000 \\
\hline GMMOTUS & $0-0100100001001000100110001000010000000001011 ? 0000 ? 0010-1$ ??0000001000000000001010000001010000000000100001001110000000000100000000000000 \\
\hline DHLOMYSES & $110000-000010000000001100010000000000000010010100000010-1$ ??0000? $11000001-0-001000000001010000000000100001001111-00000001100000000100000$ \\
\hline NEMATOGENYS & $010100-000011000001001100010000000000000010010100000010-1 ? ? 0000 ? 11000011-0-00101000100 ? 010000110000100001001111-00010001100000000110000$ \\
\hline TRICHOMYCTERUS & \\
\hline CALCHTHYS & $020000-000010000001001100010000100000100010010100000000-1$ ??0000? $11000001-0-001000000001010000000000100001001111-000000000-0000000100000$ \\
\hline CEIOPSIS & $020010-100010000001001100010000 ? 00000000010010100000010-1 ? ? 0000 ? 11000001-0-000000000001010000000000100001001111-00000001100000000110000$ \\
\hline SIURLS & $020000-000010000001001100010000100000000010010100000010-12 ? 0000 ? 11000001-0-001000000001010000000000100001001.111-00000000100000000110000$ \\
\hline CHRYSICHIHYS & 02000 0- $000010000001001100010000100000000010010100000010-0$ ??000 0? $110 ? 0001-0-001000000001010000000000100001001111-00000001100000000110000$ \\
\hline BAGRLS & 02000 0-000010000001001100010000100000000010010100000110-1??000 0? $11000001-0-001000000001010000000000100001001111-00000001100000000110000$ \\
\hline HMELODUS & $020000-000010001001001100010000100000000010010100000110-1$ ?? 0000 ? $11001001-0-001000000001010000000000100001001111-00000001100000000110000$ \\
\hline
\end{tabular}

The first synapomorphy listed above concerns the absence of the retroarticular as an independent ossification (char. 247). Within the fishes included in the cladistic analysis, this is a rather rare feature, being only found in elopomorphs, in catfishes and in Mormyrus (Hiodon was coded as '?': see char. 247), although it should be noted that 


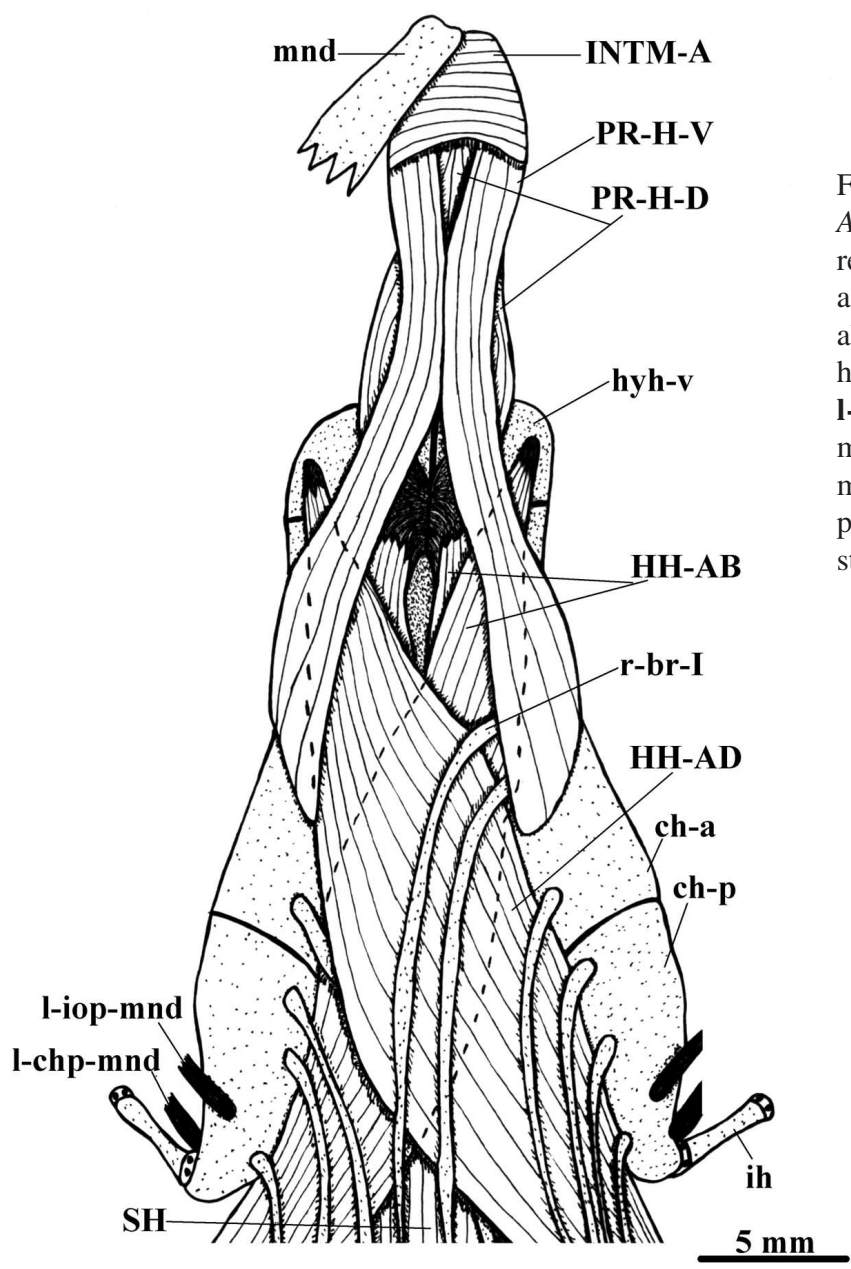

Fig. 5. Ventral view of the ventral cephalic musculature of Alepocephalus rostratus. On the right side, the mandible was removed; on the left side, the mandible was cut. ch-a, ch-p, anterior and posterior ceratohyals; HH-AB, hyohyoideus abductor; HH-AD, hyohyoidei adductores; hyh-v, ventral hypohyal; ih, interhyal; INTM-A, anterior intermandibularis; l-chp-mnd, ligament between posterior ceratohyal and mandible; l-iop-mnd, ligament between interopercle and mandible; mnd, mandible; PR-H-D, PR-H-V, sections of protractor hyoidei; r-br-I, branchiostegal ray I; SH, sternohyoideus.

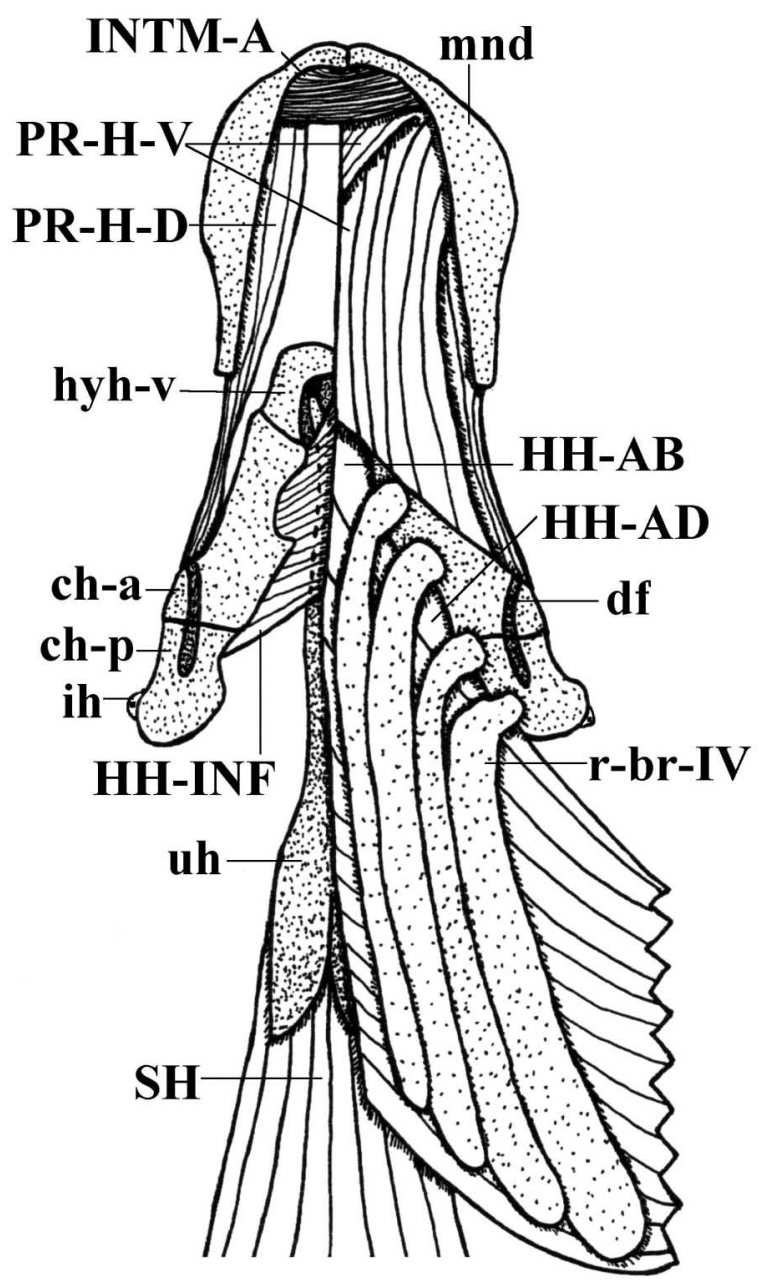

Fig. 6. Ventral view of the ventral cephalic musculature of Chanos chanos. On the right side all the hyoid muscles are exposed; on the left side the dorsal section of the protractor hyoidei, the hyohyoideus abductor and the hyohyoidei adductores were removed. ch-a, ch$\mathbf{p}$, anterior and posterior ceratohyals; $\mathbf{d f}$, deep fossa of anterior and posterior ceratohyals; HH-AB, hyohyoideus abductor; HH-AD, hyohyoidei adductores; HH-INF, hyohyoideus inferior; hyh-v, ventral hypohyal; ih, interhyal; INTM-A, anterior intermandibularis; mnd, mandible; PR-H-D, PR-H-V, sections of protractor hyoidei; r-br-IV, branchiostegal ray IV; SH, sternohyoideus; uh, urohyal. 
it is also found in some teleostean fishes that were not included in the analysis (see e.g. Nelson, 1973). The second synapomorphy, which is homoplasy free within the fishes examined, concerns the presence of a 'leptocephalus larva' (see char. 268). Apart these two unambiguous synapomorphies, there are some features that exhibit an ambiguous distribution in the tree but that may possibly also represent synapomorphies for this clade $\mathrm{C} 2$. One of these features concerns the 'anteroventral margin of prevomer situating well posteriorly to anteroventral margin of mesethmoid' (32: $0 \rightarrow 1)$. It is found in the specimens examined of the genera Elops, Albula and Notacanthus, and cannot be discerned in the anguilliform (due to a complete fusion between the prevomer and the mesethmoid) and saccopharyngiform (such a fusion might also occur, but this is not clear) fishes analyzed. Thus, this feature might be interpreted either as acquired independently in Elops and in the clade $\mathrm{C} 3$ or as acquired in the elopomorph clade and then reverted in Megalops (other hypothesis would be to interpret the acquisition of the feature in the clade uniting the non-Megalops elopomorph fishes examined, if Megalops were to be placed in the most basal position within clade C2). It should however be noted that this feature is rather homoplasious, being found in some other teleostean groups examined (see below). Two other features with ambiguous distributions that may possibly also represent elopomorph synapomorphies are the presence of distinct, strong ligaments connecting the anterior surface/anterior cartilage of the autopalatines and/or dermopalatines and the maxillae and/ or premaxillae $(160: 0 \rightarrow 1)$ and the presence of an ossified interhyal $(223: 0 \rightarrow 1)$ (see 'Clade $\mathrm{C} 1$ ' above).

Elops: $[102: 0 \rightarrow 1],[131: 0 \rightarrow 1],[206: 0 \rightarrow 1]$; Megalops: [101:0 $\rightarrow 1]$

\section{Clade C3: [34:0 $\rightarrow 1]$}

As expected (see Fig. 1) the albuliform, notacanthiform, anguilliform and saccopharyngiform fishes examined are grouped together. Apart the synapomorphy listed above, there are various other features with an ambiguous distribution that may possible represent synapomorphies of this clade, such as those concerning character $32(0 \rightarrow 1)$ (if a 'slow' optimization is chosen) and concerning characters $1(1 \rightarrow 0), 111(0 \rightarrow 1), 115(0 \rightarrow 1), 155$ $(0 \rightarrow 1), 190(0 \rightarrow 1)$ and $232(1 \rightarrow 0)$ (if a 'fast' optimization is chosen).

Albula: $[2: 1 \rightarrow 0],[49: 0 \rightarrow 1],[166: 0 \rightarrow 1],[\mathbf{1 9 5 : 0} \rightarrow \mathbf{1}]$, [228:0 $\rightarrow 1]$

Clade C4: $[2: 1 \rightarrow 2],[44: 0 \rightarrow 1],[61: 0 \rightarrow 1],[64: 0 \rightarrow 1]$, $[\mathbf{8 5 : 0} \rightarrow \mathbf{1}],[104: 0 \rightarrow 1],[133: 0 \rightarrow 1],[158: 0 \rightarrow 1],[193: 0 \rightarrow 1]$
The grouping of notacanthiform, anguilliform and saccopharyngiform fishes is expected (see Fig. 1). The posterior intermandibularis forming the protractor hyoidei and not being deeply mixed with the anterior intermandibularis (char. 2) and the absence of adductor mandibulae Aw (char. 133) have not been previously proposed in the literature as synapomorphies of this group.

Notacanthus: [42:0 $\rightarrow 1],[102: 0 \rightarrow 1],[128: 0 \rightarrow 1]$, [141:0 $\rightarrow 1],[215: 0 \rightarrow 1]$

Clade C5: [75:0 $\rightarrow 1],[109: 0 \rightarrow 1],[157: 0 \rightarrow 1],[200: 0 \rightarrow 1]$, [201:0 $\rightarrow 1]$, [239:0 $\rightarrow 1$ ],$[246: 0 \rightarrow 1]$

The grouping of anguilliform and saccopharyngiform fishes is expected (see Fig. 1) and is well-corroborated, being supported by a bootstrap value of $95 \%$.

Eurypharynx: $[3: 0 \rightarrow 1],[7: 0 \rightarrow 1],[9: 0 \rightarrow 1],[15: 0 \rightarrow 1]$, $[35: 0 \rightarrow 1],[48: 0 \rightarrow 1],[66: 1 \rightarrow 0],[68: 1 \rightarrow 0],[86: 0 \rightarrow 1]$, [91:0 $\rightarrow 1],[\mathbf{9 7 : 0 \rightarrow 1 ]},[\mathbf{1 1 8 : 0 \rightarrow 1}],[\mathbf{1 2 6 : 0 \rightarrow 1 ]},[\mathbf{1 2 7}: \mathbf{0} \rightarrow \mathbf{1}]$, $[148: 1 \rightarrow 0],[208: 0 \rightarrow 1], \quad[\mathbf{2 1 0}: \mathbf{0} \rightarrow \mathbf{1}], \quad[\mathbf{2 1 3 : 0} \rightarrow \mathbf{1}]$, [235:0 $\rightarrow 1],[236: 1 \rightarrow 0]$

\section{Clade C6: [125:0 $\rightarrow 1$ ], [206:0 $\rightarrow 1]$}

The order Anguilliformes is usually considered a monophyletic group, and the well-supported grouping of the anguilliform genera Conger and Anguilla (with a bootstrap value of 91\%) is thus expected (see e.g. Greenwood et al., 1966; Forey, 1973b; Nelson, 1973; Patterson \& Rosen; Obermiller \& Pfeiler). But authors such as Forey et al., Belouze, Wang et al. and Inoue et al. (2004) have defended that some anguilliforms (e.g. congroids or, alternatively, anguilloids) are more closely related to saccopharyngiforms than to other anguilliforms, a view that is not supported by the present work. It is however obvious that only a study including numerous anguilliform and saccopharyngiform taxa, and, it is important to stress this, also numerous other elopomorph and non-elopomorph fishes, can help to address this question in a more conclusive way.

Anguilla: $[228: 0 \rightarrow 1]$; Conger: $[133: 1 \rightarrow 0]$

Clade C7: [75:0 $\rightarrow 1],[102: 0 \rightarrow 1],[109: 0 \rightarrow 1],[131: 0 \rightarrow 1]$, [158:0 $\rightarrow 1],[241: 0 \rightarrow 1]$

As referred above (see 'Clade C1') all (100\%) the most parsimonious trees obtained place the Elopomorpha, and not Osteoglossomorpha, as the most basal teleostean group examined (Fig. 2). However, it is important to stress that this clade $\mathrm{C} 7$, including the osteoglossomorph and the remaining non-elopomorph teleosts examined, is not 


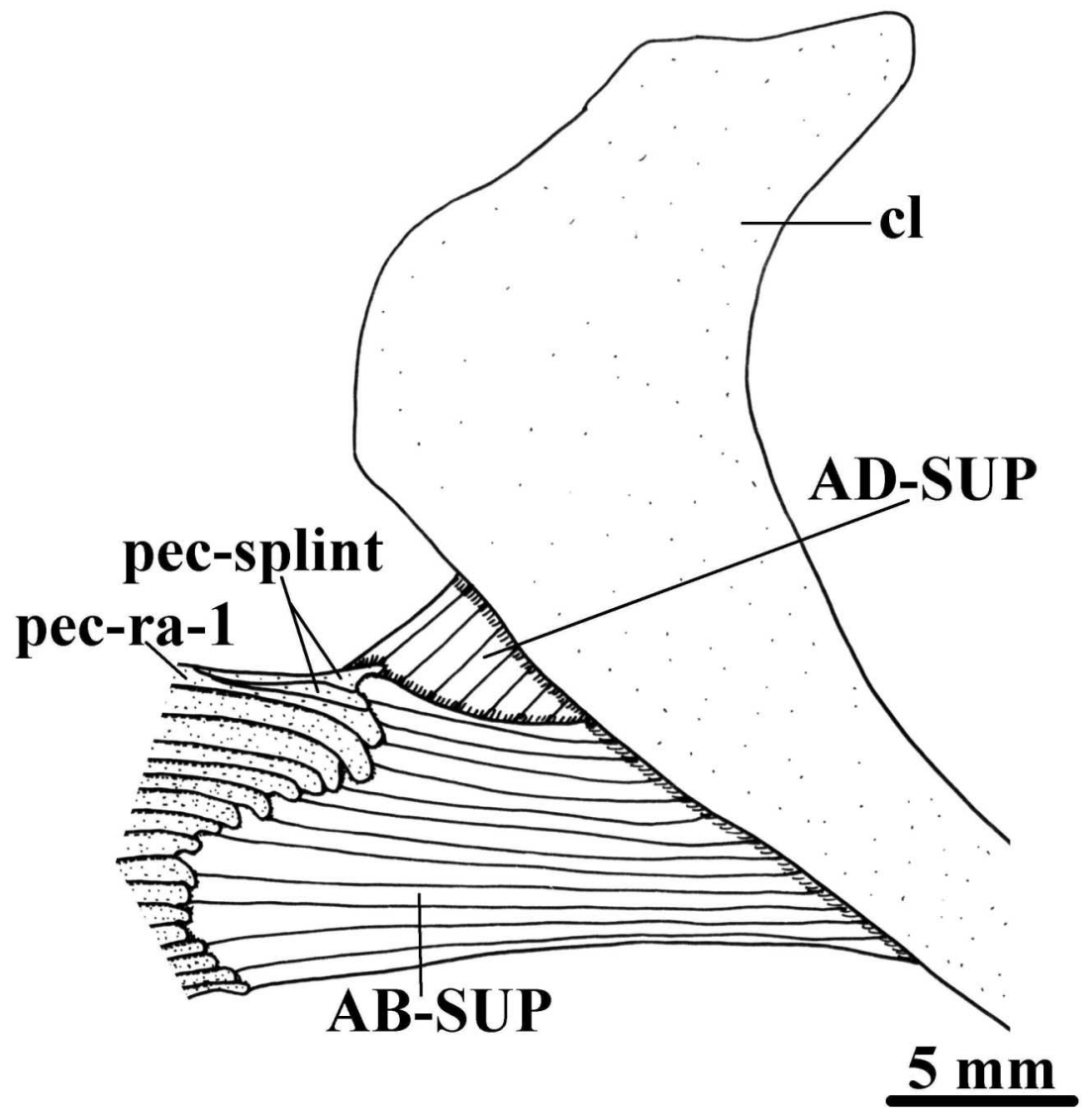

Fig. 7. Lateral view of the pectoral girdle musculature of Amia calva, all the musculature is exposed. ABSUP, abductor superficialis; ADSUP, adductor superficialis; cl, cleithrum; pec-ra-1, pectoral ray 1 ; pec-splint, pectoral splint.

supported by a bootstrap value $\geq 50 \%$ (Fig. 2). Six unambiguous synapomorphies support this clade in the analysis: fusion of at least some parapophyses of the two first free vertebrae to the respective centra $(75: 0 \rightarrow 1$, subsequently reverted in some taxa of this clade and independently occurring in the elopomorph anguilliforms + saccopharyngiforms); mesial limb of coracoids (or scapulocoracoids) broad and anteroposteriorly elongated $(101: 0 \rightarrow 1$, subsequently reverted in some taxa of this clade and independently occurring in the elopomorph Megalops); absence of pectoral splints $(109: 0 \rightarrow 1$, not reverted in any taxa of this clade and independently occurring in the elopomorph anguilliforms + saccopharyngiforms); absence of well-differentiated, separated section A3' of adductor mandibulae $(131: 0 \rightarrow 1$, subsequently reverted in some taxa of this clade and independently occurring in the elopomorph Elops; the condition in Eurypharynx is not clear); supramaxillae absent as independent ossifications $(158: 0 \rightarrow$ 1 , subsequently reverted in some taxa of this clade and independently occurring in the elopomorph notacanthiforms + anguilliforms + saccopharyngiforms); absence of ossified gular plate $(241: 0 \rightarrow 1$, not reverted in the taxa examined belonging to this clade but independently occurring in the elopomorph notacanthiforms + anguilliforms + saccopharyngiforms; the condition in Albula is not clear). It should however be noted that some of these features characterizing the clade including the osteoglossomorph and the remaining non-elopomorph teleosts examined might actually not diagnose a clade including all non-elopomorph teleosts known. For example, supramaxillae and gular plates have been described in some fossil osteoglossomorphs (e.g. Taverne, 1972, 1977b, 1978; pers. comm.). If these structures were in fact plesiomorphically present in osteoglossomorphs, their absence would thus not constitute a valid feature to diagnose a clade including all osteoglossomorph + remaining non-elopomorph teleosts.

As referred in the Introduction, it is usually accepted that osteoglossomorphs occupy a more basal position within Teleostei than elopomorphs (e.g. Patterson, 1977; Patterson \& Rosen; Lauder \& Liem; Ishiguro et al; Obermiller \& Pleifer; Inoue et al., 2003, 2004; Wang et al.) (see Fig. 1). However, a more basal position of elopomorphs, such as that suggested in the present work, has also been suggested by various authors, e.g. Greenwood et al., Li (1996), Shen (1996), Arratia (1997, 1999). 


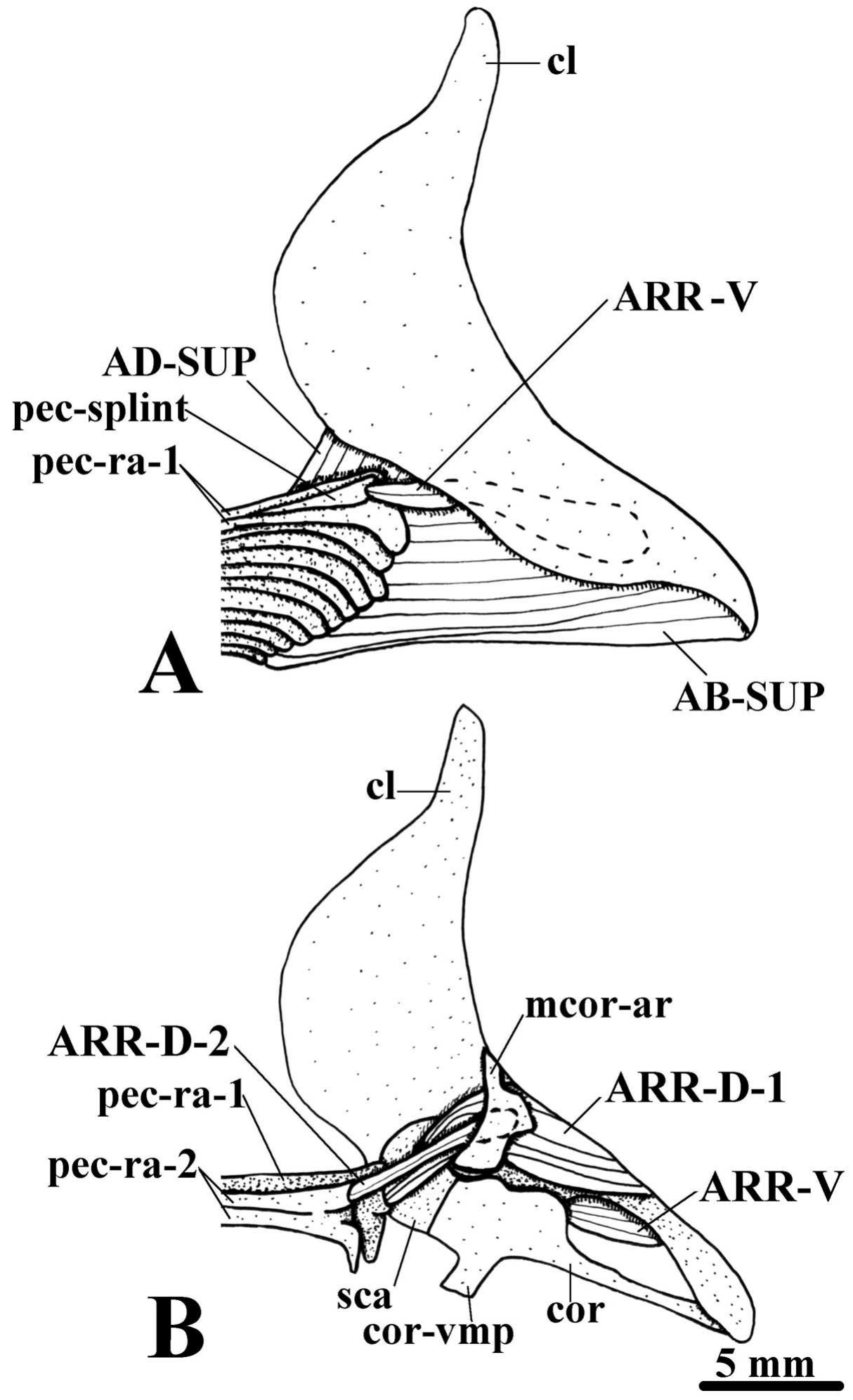

Fig. 8. Lateral (A) and mesial (B) view of the pectoral girdle musculature of Elops saurus; in the mesial view the adductor superficialis and abductor superficialis are not shown. AB-SUP, abductor superficialis, ADSUP, adductor superficialis; ARR-D-1, 2, arrector dorsalis 1 and 2; ARR-V, arrector ventralis; cl, cleithrum; cor, coracoid; cor-vmp, ventromesial process of coracoid; mcor-ar, mesocoracoid arch; pec-ra-1, 2, pectoral rays 1 and 2; pec-slint, pectoral splint; sca, scapula. 


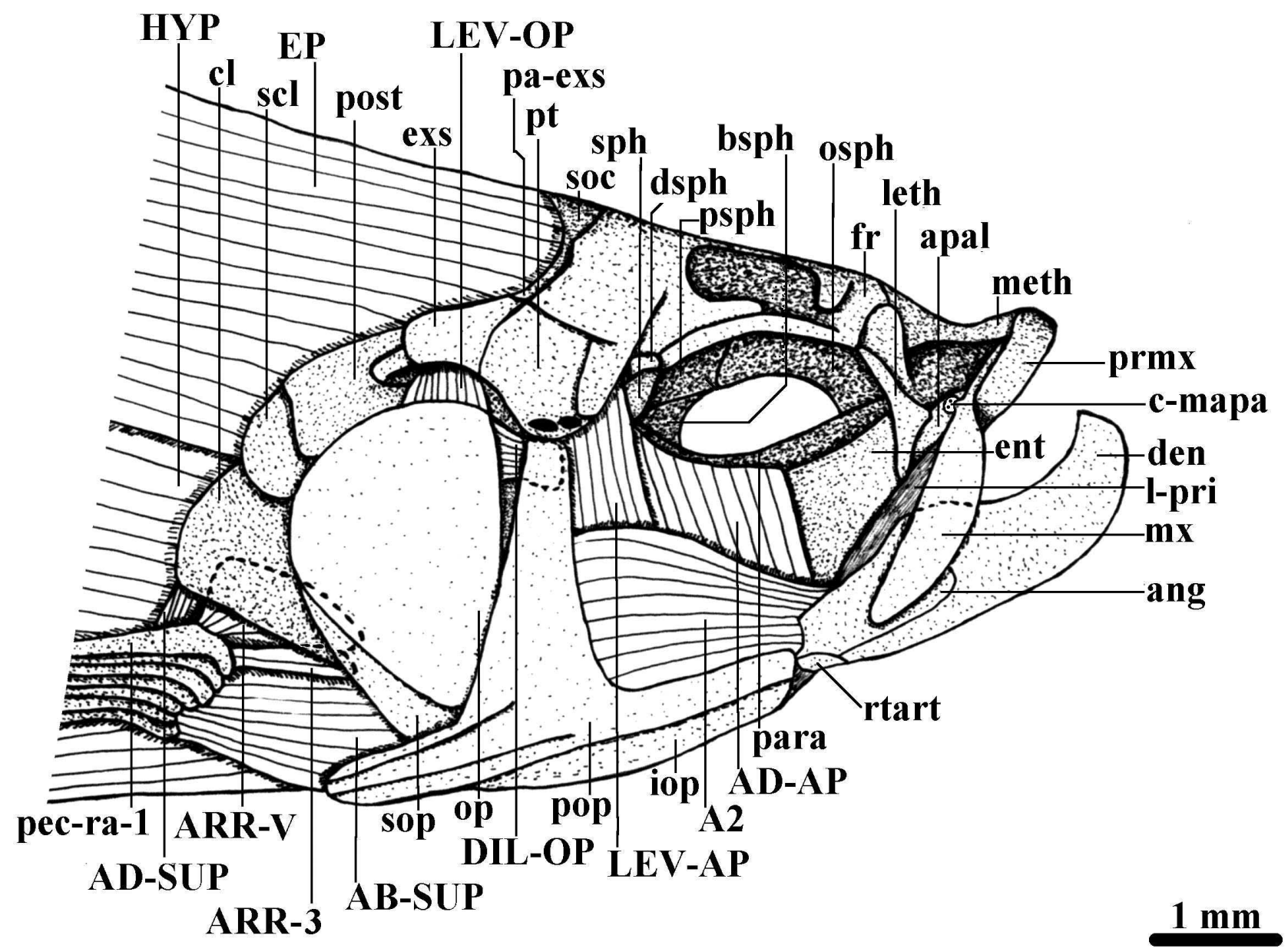

Fig. 9. Lateral view of the cephalic musculature of Denticeps clupeoides. All muscles are exposed; the teeth of the jaws, as well as the onodontes, nasals, infraorbitals and postcleithra, were removed. A2, section of adductor mandibulae; AB-SUP, abductor superficialis; AD-AP, adductor arcus palatini; AD-SUP, adductor superficialis 1; ang, angular; apal, autopalatine; ARR-3, arrector 3; ARR-V, arrector ventralis; bsph, basisphenoid; c-mapa, small cartilage between maxilla and autopalatine; cl, cleithrum; den, dentary bone; DIL-OP, dilatator operculi; dsph, dermosphenotic; ent, entopterygoid; EP, epaxialis; exs, extrascapular; fr, frontal; HYP, hypoaxialis; iop, interopercle; l-pri, primordial ligament; leth, lateral-ethmoid; LEV-AP, levator arcus palatini; LEV-OP, levator operculi; meth, mesethmoid; mx, maxilla; op, opercle; osph, orbitosphenoid; pa-exs, parieto-extrascapular; para, parasphenoid; pec-ra-1, pectoral ray 1; pop, preopercle; post, posttemporal; prmx, premaxilla; psph, pterosphenoid; pt, pterotic; rtart, retroarticular; scl, supracleithrum; soc, supraoccipital; sop, subopercle; sph, sphenotic.

\section{Clade C8: $[96: 0 \rightarrow 1],[180: 0 \rightarrow 1],[261: 0 \rightarrow 1]$}

As stated in the recent paper of Lavoué \& Sullivan (2004), although the Osteoglossomorpha is widely accepted as a monophyletic unit, the only cladistic analyses that have tested the monophyly of this group by including representatives of its four families sensu Hilton and an appropriate sample of other teleostean taxa are essentially molecular ones. In the present cladistic analysis, the representatives of these four osteoglossomorph families (Hiodon: Hiodontidae; Pantodon: Osteoglossidae; Xenomystus: Notopteridae; Mormyrus: Mormyridae) do appear grouped in a monophyletic clade (C8), which is supported by the three unambiguous synapomorphies listed above but is not supported by a bootstrap value $\geq 50 \%$ (Fig. 2 ). The first synapomorphy concerns the peculiar anteroventrolateral bifurcation of the posttemporal in a shorter, lateral arm carrying a sensorial canal and a longer, mesial arm corresponding to the ossified 'ligament between the posttemporal and the posterior margin of the neurocranium' of the present work $(96: 0 \rightarrow 1)$. This feature is exclusively found in the osteoglossomorphs examined except Pantodon, in which the latter ligament is not ossified. The second synapomorphy concerns the poorly ossified, or 


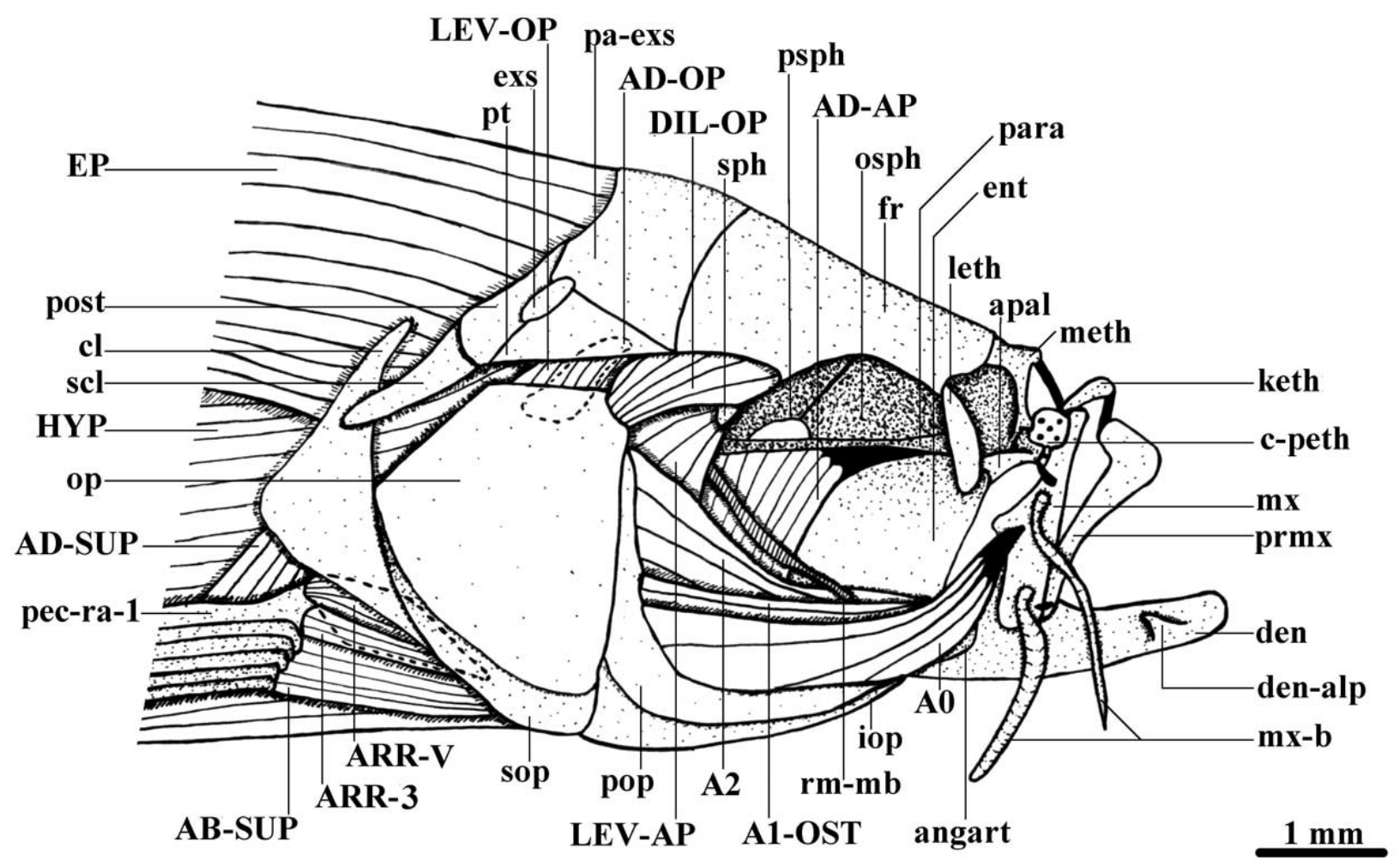

Fig. 10. - Lateral view of the cephalic musculature of Danio rerio. All muscles are exposed, the maxillary barbels and the mesial branch of the ramus mandibularis are also illustrated; the nasals, infraorbitals and postcleithra were removed. A0, A1-OST, A2, sections of adductor mandibulae; AB-SUP, abductor superficialis; AD-AP, adductor arcus palatini; AD-OP, adductor operculi; AD-SUP, adductor superficialis; angart, angulo-articular; apal, autopalatine; ARR-3, arrector 3; ARR-V, arrector ventralis; c-peth, pre-ethmoid cartilage; cl, cleithrum; den, dentary bone; den-alp, anterolateral process of dentary bone; DIL-OP, dilatator operculi; ent, entopterygoid; EP, epaxialis; exs, extrascapular; fr, frontal; HYP, hypoaxialis; iop, interopercle; keth, kinethmoid; leth, lateral-ethmoid; LEV-AP, levator arcus palatini; LEV-OP, levator operculi; meth, mesethmoid; mx, maxilla; mx-b, maxillary barbel; op, opercle; osph, orbitosphenoid; pa-exs, parieto-extrascapular; para, parasphenoid; pec-ra-1, pectoral ray 1; pop, preopercle; post, posttemporal; prmx, premaxilla; psph, pterosphenoid; pt, pterotic; rm-mb, mesial branch of ramus mandibularis; scl, supracleithrum; sop, subopercle; sph, sphenotic.

completely unossified, autopalatine $(180: 0 \rightarrow 1)$, a feature that is only also found in a few fishes examined in the present work, such as gymnotiforms. The third synapomorphy concerns the presence of a 'tongue-bite mechanism' with dorsal teeth on parasphenoid, a feature that is homoplasy free within the fishes examined $(261: 0 \rightarrow 1)$. Contrary to the first feature, the latter two have been listed as potential osteoglossomorph synapomorphies in previous works such as Lauder \& Liem, Li \& Wilson (1996), Arratia (1997, 1999) and Hilton. As mentioned above, there are two features with ambiguous distributions that might possibly constitute synapomorphies of the osteoglossomorphs examined: the absence of distinct, strong ligaments connecting the anterior surface/anterior cartilage of the autopalatines and/or dermopalatines to the maxillae and/or premaxillae (160: $1 \rightarrow 0)$ and the absence of an ossified interhyal $(223: 1 \rightarrow 0)$ (see 'Clade $\mathrm{C} 1$ ').
Hiodon: $[42: 0 \rightarrow 1],[140: 0 \rightarrow 1],[143: 0 \rightarrow 1],[206: 0 \rightarrow 1]$

Clade C9: No unambiguous synapomorphies

Although a detailed discussion of the relationships between the four osteoglossomorph families (see above) is beyond the main scope of the present work, it is worthy to note that in the majority (66\%) of the most parsimonious trees obtained Hiodon appears as the sister-group of the clade including the other osteoglossomorphs examined (Fig. 2), as expected (see Fig. 1). However, no features can be unambiguously interpreted as synapomorphies of this latter clade in the 'majority fools' tree shown in Fig. 2, and this clade is not supported by a bootstrap value $\geq 50 \%$. In the majority of the most parsimonious trees in which the clade appears, it is however diagnosed by an unambiguous synapomorphy (124: $1 \rightarrow 0$ ), and can be possibly diagnosed 
by other features if a 'fast optimization' is chosen (e.g. 21: $0 \rightarrow 1$; 34: $0 \rightarrow 1$; 68: $0 \rightarrow 1 ; 208: 1 \rightarrow 0$ ) or, alternatively, if a 'slow optimization' is chosen (e.g. 246: $0 \rightarrow 1$ ). In the most parsimonious trees in which the clade does not appear, Hiodon is grouped with Xenomystus, with a single feature supporting this grouping (96: $0 \rightarrow 1$ ), and this only if a 'slow optimization' is chosen. Some authors have suggested that some notopterids (the group in which Xenomystus is nowadays included) might be more related to Hiodon than to some other extant osteoglossomorphs (e.g. Greenwood et al.; Nelson, 1968; Greenwood, 1973; Lauder \& Liem). It can thus be said that this latter view is not completely contradicted by the results of the present work, although it is important to remind that, in the overall, the majority of the most parsimonious threes obtained in this work do support the grouping of the non-hiodontid osteoglossomorph fishes examined (Fig. 2).

Xenomystus: $[16: 1 \rightarrow 0],[27: 0 \rightarrow 1],[166: 0 \rightarrow 1],[179: 0 \rightarrow 1]$, [228:0 $\rightarrow 1]$

Clade C10: $[45: 0 \rightarrow 1],[65: 1 \rightarrow 0],[99: 0 \rightarrow 1],[111: 0 \rightarrow 1]$, [133:0 $\rightarrow 1],[\mathbf{1 6 2 : 0} \rightarrow \mathbf{1}],[201: 0 \rightarrow 1]$

Pantodon: $[2: 1 \rightarrow 2],[95: 0 \rightarrow 1],[96: 1 \rightarrow 0],[\mathbf{1 0 7 : 0} \rightarrow \mathbf{1}]$, $[163: 1 \rightarrow 0],[223: 0 \rightarrow 1] ;$ Mormyrus: $[2: 1 \rightarrow 0],[\mathbf{1 0 : 0} \rightarrow \mathbf{1}]$, $[32: 0 \rightarrow 1],[42: 0 \rightarrow 1],[61: 0 \rightarrow 1],[\mathbf{1 1 9}: \mathbf{0} \rightarrow \mathbf{1}],[143: 0 \rightarrow 1]$, $[155: 0 \rightarrow 1],[178: 0 \rightarrow 1],[190: 0 \rightarrow 1],[193: 0 \rightarrow 1],[\mathbf{2 3 3 : 0 \rightarrow 1}]$, [247:0 $\rightarrow 1]$

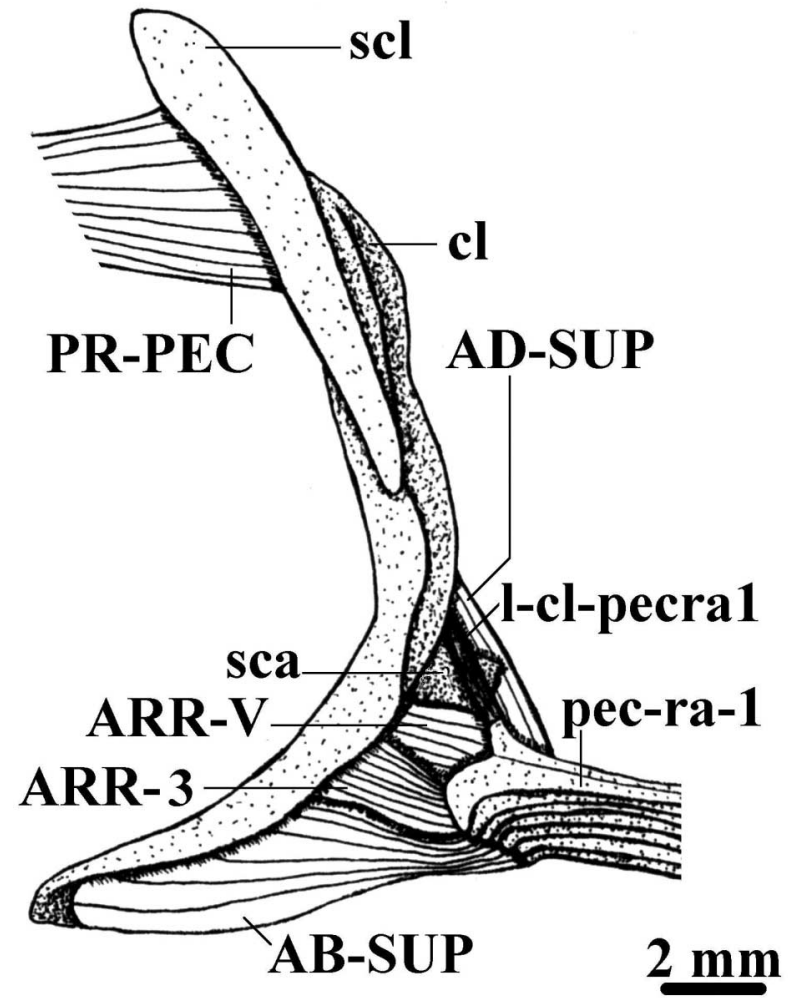

Clade C11: $[2: 1 \rightarrow 2],[18: 0 \rightarrow 1],[60: 0 \rightarrow 1],[64: 0 \rightarrow 1]$

The assembly of the non-elopomorph and nonosteoglossomorph teleosts examined in clade $\mathrm{C} 11$ is expected (see Fig. 1: Clupeocephala). Although this clade is not supported by a bootstrap value $\geq 50 \%$ (Fig. 2), it is supported by four unambiguous synapomorphies, one of them being actually homoplasy free within the fishes examined: posterior intermandibularis included in protractor hyoidei and not deeply mixed with anterior intermandibularis $(2: 1 \rightarrow 2$, not reverted in fishes of this clade $\mathrm{C} 11$ but independently occurring in Pantodon and in Nothacanthiformes + Saccopharyngiformes + Anguilliformes); presence of distinct muscle 'arrector 3' (18: $0 \rightarrow 1$, homoplasy free within the fishes examined); main bodies of parietals (or of parietoextrascapulars) widely separated from each other in dorsal view (60: $0 \rightarrow 1$, not independently acquired within the taxa examined of other clades, but subsequently reverted in some more terminal groups of this clade C11: see below); absence of parasphenoid teeth (64: $0 \rightarrow 1$, not subsequently reverted within the fishes examined of this clade C11, and only occurring independently, within the taxa analyzed, in Nothacanthiformes + Saccopharyngiformes + Anguilliformes). Contrary to the two latter features, the two former ones have not been previously proposed as clupeocephalan synapomorphies. Some other features with an ambiguous distribution may be interpreted as synapomorphies of this clade if a 'fast optimization' is chosen $(155: 0 \rightarrow 1 ; 193: 0 \rightarrow 1)$ or, alternatively, if a 'slow optimization' is chosen $(160: 0 \rightarrow 1 ; 223: 0 \rightarrow 1 ; 246: 0 \rightarrow 1$; 248:0 $\rightarrow 1$ ) (see e.g. 'Clade C1' above).

Clade C12: [35:0 $\rightarrow 1],[87: 0 \rightarrow 1],[228: 0 \rightarrow 1]$

The grouping of the euteleostean fishes analyzed in clade $\mathrm{C} 12$ is expected (see Fig. 1). It is not supported by a bootstrap value $\geq 50 \%$, but is supported by three unambiguous synapomorphies in the cladistic analysis: 'ethmoid endoskeleton' ossification markedly reduced (35: $0 \rightarrow 1$, only occurring independently in a few taxa outside this clade $\mathrm{C} 12$ and only being reverted in a few taxa examined of this clade as e.g. aulopiforms); main body of posttemporal (or posttemporo-supracleithrum) lying far from neurocranium, with almost no contact between these two structures (87: $0 \rightarrow 1$, not reverted within the fishes examined of this clade $\mathrm{C} 12$, and only occurring independently in a

Fig. 11. Lateral view of the pectoral girdle musculature of Chanos chanos. AB-SUP, abductor superficialis; AD-SUP, adductor superficialis; ARR-3, arrector 3; ARR-V, arrector ventralis; cl, cleithrum; l-cl-pecra1, ligament between cleithrum and pectoral ray 1; pec-ra-1, pectoral ray 1; PR-PEC, protractor pectoralis; sca, scapula; scl, supracleithrum. 
few taxa outside the clade, e.g. Gonorynchus); mandibulohyoid and mandibulo-interopercular ligaments not wellseparated from each other $(87: 0 \rightarrow 1$, not reverted within fishes examined of this clade $\mathrm{C} 12$, and only occurring independently in a few taxa outside the clade as e.g. Anguilla, Albula, Denticeps and Xenomystus). Contrary to the first feature, the latter two have not been previously proposed as synapomorphies of the Euteleostei. There is one feature with an ambiguous distribution that may be interpreted as synapomorphy of this clade, if a 'slow optimization' is chosen $(193: 0 \rightarrow 1)$.

Clade C13: $[34: 0 \rightarrow 1],[47: 0 \rightarrow 1],[153: 0 \rightarrow 1],[167: 1 \rightarrow 0]$, $[188: 0 \rightarrow 1],[264: 0 \rightarrow 1]$

The grouping of the argentinoid and alepocephaloid fishes examined is strongly supported by six unambiguous synapomorphies (two of them being homoplasy-free within the fishes examined), and by a bootstrap value of $74 \%$ (Fig.
2): posterodorsal portion of mesethmoid (or of supraethmoid) being markedly compressed transversally when seen in dorsal view (34: $0 \rightarrow 1$, not reverted within taxa examined of this clade $\mathrm{C} 13$, but occurring independently in some groups outside the clade, e.g. characiforms, gymnotiforms and siluriforms); both autopterotic and dermopterotic bones present as independent, distinct ossifications (47: $0 \rightarrow 1$, homoplasy free within the teleostean taxa examined); fibers of hypaxialis and/or epaxialis peculiarly covering great part of neurocranial floor $(153: 0 \rightarrow 1$, not reverted inside this clade C13 and only occurring independently in the aulopiforms + stomiiforms examined); primordial ligament attaching posteriorly on dorsal surface of coronoid process $(167: 0 \rightarrow 1$, occurring in some groups outside this clade $\mathrm{C} 13$ but not reverted inside it; Bathylagus, Xenodermichthys and Searsia were coded as 'Inapplicable' for this character as they seemingly do not have a distinct primordial ligament); peculiar dorsoventral enlargement of posterior portion of autopalatine (188: $0 \rightarrow 1$, not reverted inside this clade $\mathrm{C} 13$ and only occurring outside of it in the osmeroid specimens examined); presence of peculiar 'accessory cartilage of the fifth ceratobranchial' (264: $0 \rightarrow 1$, homoplasy free within the taxa examined). Contrary to the other features listed above, the first and forth features have not been previously proposed as synapomorphies of the Argentiniformes. Various features with an ambiguous distribution may be interpreted as synapomorphies of this clade if a 'fast optimization' is chosen $(16: 1 \rightarrow 0 ; 102: 0 \rightarrow 1$; $111: 0 \rightarrow 1 ; 124: 1 \rightarrow 0 ; 142: 0 \rightarrow 1 ; 215: 0 \rightarrow 1)$.

It should be noted that, contrary to what is usually accepted (e.g. Greenwood \& Rosen, 1971; Rosen, 1973, 1974, 1985; Fink \& Weitzman, 1982; Lauder \& Liem; Fink, 1984; Begle, 1991, 1992; Nelson, 2004; Johnson \& Patterson, 1996; Sanford, 2000; Stiassny et $a l$.), some recent molecular cladistic analyses (e.g. Ishiguro et al.; Lavoué et al., 2005) have contradicted the monophyly of Argentiniformes (sensu this work: see Figs. $1,2)$. According to these molecular analyses, the Alepocephaloidea is the sister-groups of either the Clupeomorpha or the Ostariophysi, but not of the Argentinoidea. This particular

Fig. 12. Lateral (A) and mesial (B) views of the anterior portion of the first pectoral ray and the insertions of the section 1 of the arrector dorsalis, of the arrector 3 and of the arrector ventralis in Chanos chanos. ARR-3, arrector 3; ARR-D-1, section 1 of arrector dorsalis; ARR-V, arrector ventralis. 


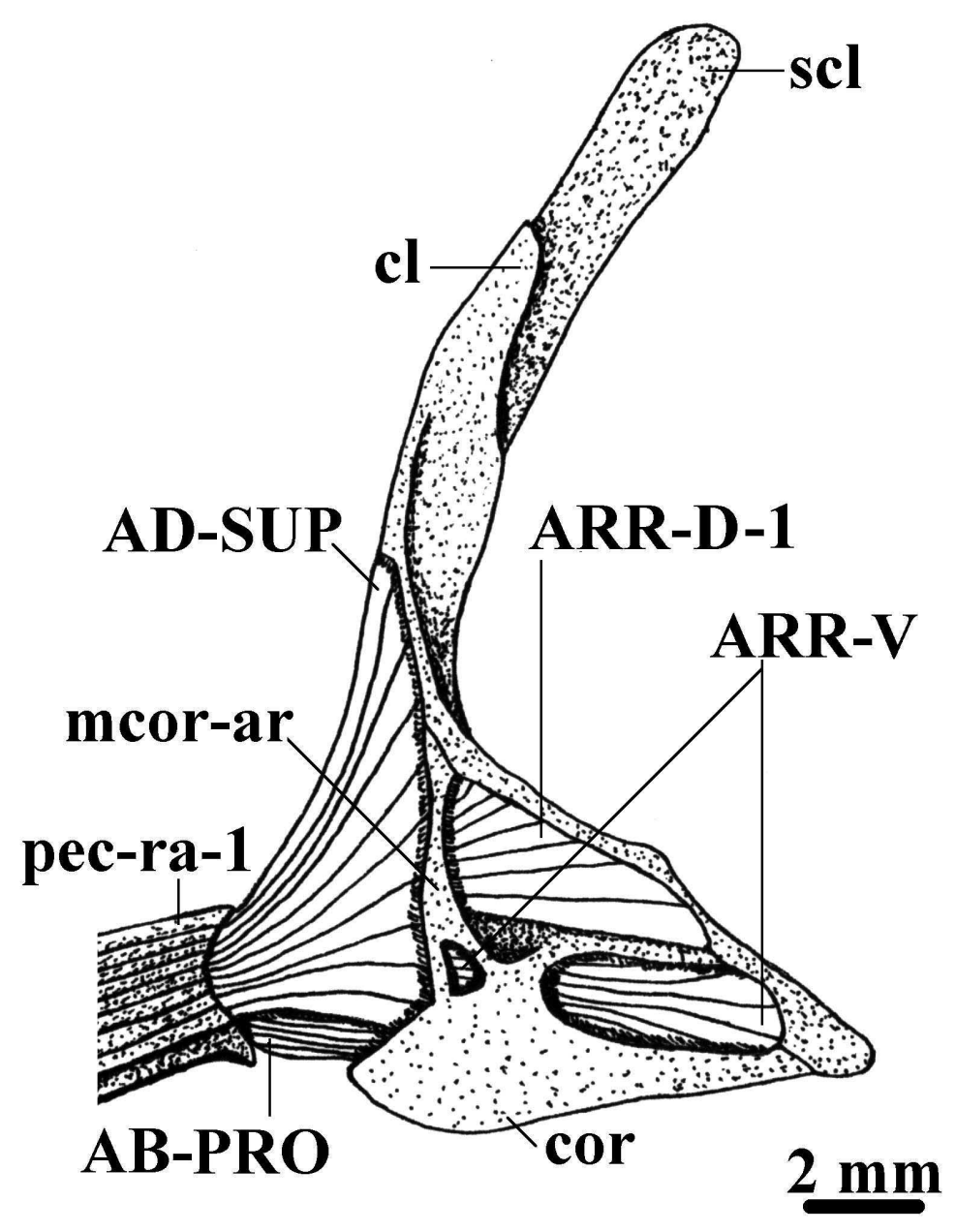

Fig. 13. -Mesial view of the pectoral girdle musculature of Chanos chanos, the lateral muscle abductor profundus is also shown. AB-PRO, abductor profundus; AD-SUP, adductor superficialis; ARR-D-1, arrector dorsalis 1; ARR-V, arrector ventralis; cl, cleithrum; cor, coracoid; mcor-ar, mesocoracoid arch; pec-ra-1, pectoral ray 1; scl, supracleithrum.

Argentina: $[35: 1 \rightarrow 0],[60: 1 \rightarrow 0],[101: 1 \rightarrow 0]$, $[125: 0 \rightarrow 1], \quad[242: 0 \rightarrow 1] ; \quad[\mathbf{2 5 9 : 0} \rightarrow \mathbf{1}]$ Bathylagus: $[25: 0 \rightarrow 1],[48: 0 \rightarrow 1],[104: 0 \rightarrow 1]$, [133:0 $\rightarrow 1]$

Clade C15: $[22: 1 \rightarrow 0],[23: 1 \rightarrow 0],[33: 0 \rightarrow 1]$, [158:1 $\rightarrow 0$ ]

The grouping of the alepocephaloid fishes examined is expected (see Fig. 1) and is supported by a bootstrap value of $88 \%$.

Alepocephalus: No unambiguous features

Clade C16: $[68: 0 \rightarrow 1],[105: 1 \rightarrow 0],[178: 0 \rightarrow 1]$

Xenodermichthys: $[101: 1 \rightarrow 0],[\mathbf{2 2 2 : 0} \rightarrow \mathbf{1}]$; Searsia: $[65: 1 \rightarrow 0],[170: 0 \rightarrow 1],[193: 1 \rightarrow 0]$, [260:0 $\rightarrow 1]$

Clade C17: No unambiguous synapomorphies

The grouping of the non-argentiniform euteleosteans examined in a same clade is supported in two thirds of the 48 most parsimonious trees obtained in the cladistic analysis, but is not supported by a bootstrap value $\geq 50 \%$ (Fig. 2). In half of the most parsimonious trees in which this clade appears, the clade is diagnosed by an unambiguous synapomorphy: the attachment of a mainly undivided A2 on the mesial surface of the mandible being accomplished by means of two welldistinguished, thick tendons $(124: 0 \rightarrow 1)$. Two other features may be interpreted as synapomorphies of this clade if a 'fast optimization' is chosen: rostrodermethmoids ossified and not fused with median supraethmoid $(29: 0 \rightarrow 1)$ and orbitosphenoid not present as independent ossification (44: $0 \rightarrow 1$ ). In the most parsimonious trees in which this clade does not appear, the argentiniforms appear as the sister-group of a clade including the salmoniform + neoteleostean fishes examined. In those trees no unambiguous synapomorphies support such a sister-group relationship: only the choosing of a 'fast optimization' $(33: 0 \rightarrow 1 ; 158: 1 \rightarrow 0 ; 168: 0 \rightarrow 1)$ or of a 'slow optimization' (193: $0 \rightarrow 1$ ) can reveal, in these trees, potential synapomorphies to support such a relationship. It can thus be said that this latter view is not completely contradicted by the results of the present work, although it 


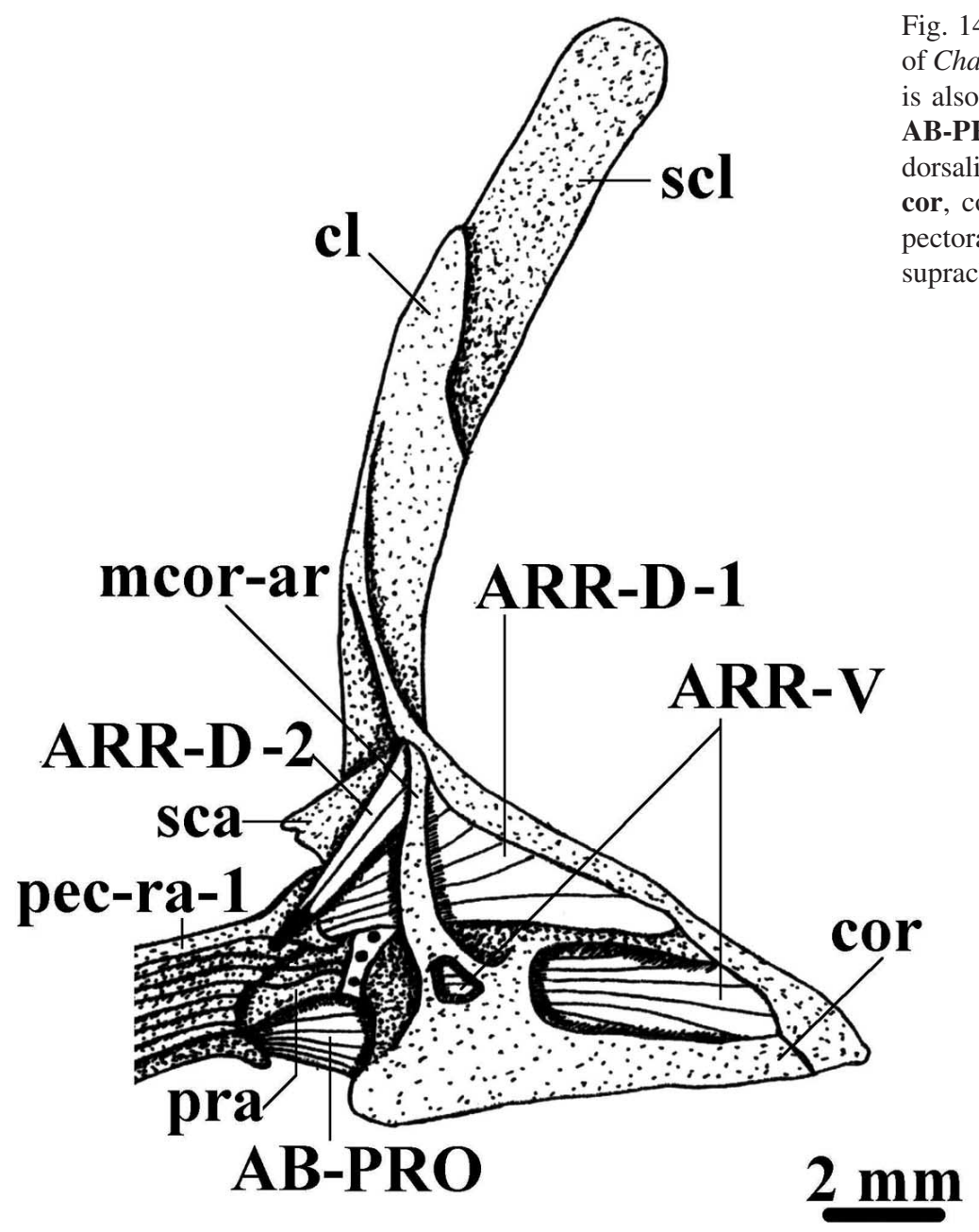

Fig. 14. Mesial view of the pectoral girdle musculature of Chanos chanos, the lateral muscle abductor profundus is also shown; the adductor superficialis was removed. RO, abductor superficialis, ARR-D-1, 2, arrector and 2; ARR-V, arrector ventralis; cl, cleithrum; or, coracoid; mcor-ar, mesocoracoid arch; pec-ra-1, ectoral ray 1; pra, proximal radials; sca, scapula; scl, upracleithrum.

argentiniforms. A brief, up-to-dated summary of these and other hypotheses concerning basal euteleostean relationships has been provided by Ishiguro et al.. In short, it can be said that, together with the phylogenetic hypothesis shown in Fig. 2 of the present work, almost all possible combinations between the major basal euteleostean groups have already been proposed in the literature. The present work provides strong support for the monophyly of the Alepocephaloidea, of the Argentinoidea and of the Alepocephaloidea + Argentinoidea (see above), and some support for the monophyly of the Galaxioidea + Osmeroidea and of the Esociformes (see below), but does not provide strong evidence to resolve the relationships between the Argentiniformes, the Salmoniformes, the Neoteleostei, the Esociformes and the Osmeriformes (see below). is important to remind that, in the overall, the majority of the most parsimonious threes obtained in this work do support the grouping of the non-argentiniform euteleosteans examined (Fig. 2). However, the evidence supporting this clade $\mathrm{C} 17$ is rather week.

The relationships between basal euteleosteans have been widely discussed, and, as seen above, remain problematic (e.g. Greenwood et al.; Gosline, 1969; Rosen, 1973, 1974, 1985; Fink \& Weitzman; Lauder \& Liem; Fink, 1984; Begle, 1991, 1992; Johnson \& Patterson; Sanford, 2000). For instance, authors such as Ishiguro et al. consider that the osmeriforms are closely related to the Argentinoidea, and that the esociforms are closely related to the salmoniforms. Authors such as Fink \& Weitzman, Lauder \& Liem and Begle $(1991,1992)$ consider that the osmeriforms are closely related to the argentiniforms, and that the esociforms are not closely related to the salmoniforms. Authors such as Johnson \& Patterson, in turn, defend a close relationship between osmeriforms and salmoniforms, and between the clade formed by these two latter groups and the
Clade C18: $[33: 0 \rightarrow 1],[75: 1 \rightarrow 0],[158: 1 \rightarrow 0],[161: 0 \rightarrow 1]$, $[168: 1 \rightarrow 0],[185: 0 \rightarrow 1]$

The assembly of the salmoniform and neoteleostean fishes examined is this clade is supported by six unambiguous synapomorphies, but is not supported by a bootstrap value $\geq$ $50 \%$. These synapomorphies are: presence of anterolateral processes of mesethmoid supporting and/or articulating with premaxillae $(33: 0 \rightarrow 1$, occurring independently outside this clade $\mathrm{C} 18$ in a few groups, and reverted, inside of this clade, in the aulopiforms; the members of the genus Coregonus might display either CS0 or CS1 of this character); parapophyses of two first free vertebrae not fused to centra (75: $0 \rightarrow 1$, occurring in a few groups outside of this clade C18, and reverted, inside this clade, in Aulopus and Astronesthes); supramaxillae present as independent ossifications (158: $1 \rightarrow 0$, occurring in various groups outside of this clade $\mathrm{C} 18$, but not reverted inside of it, although it should be noted that Astronesthes and Stomias were coded 


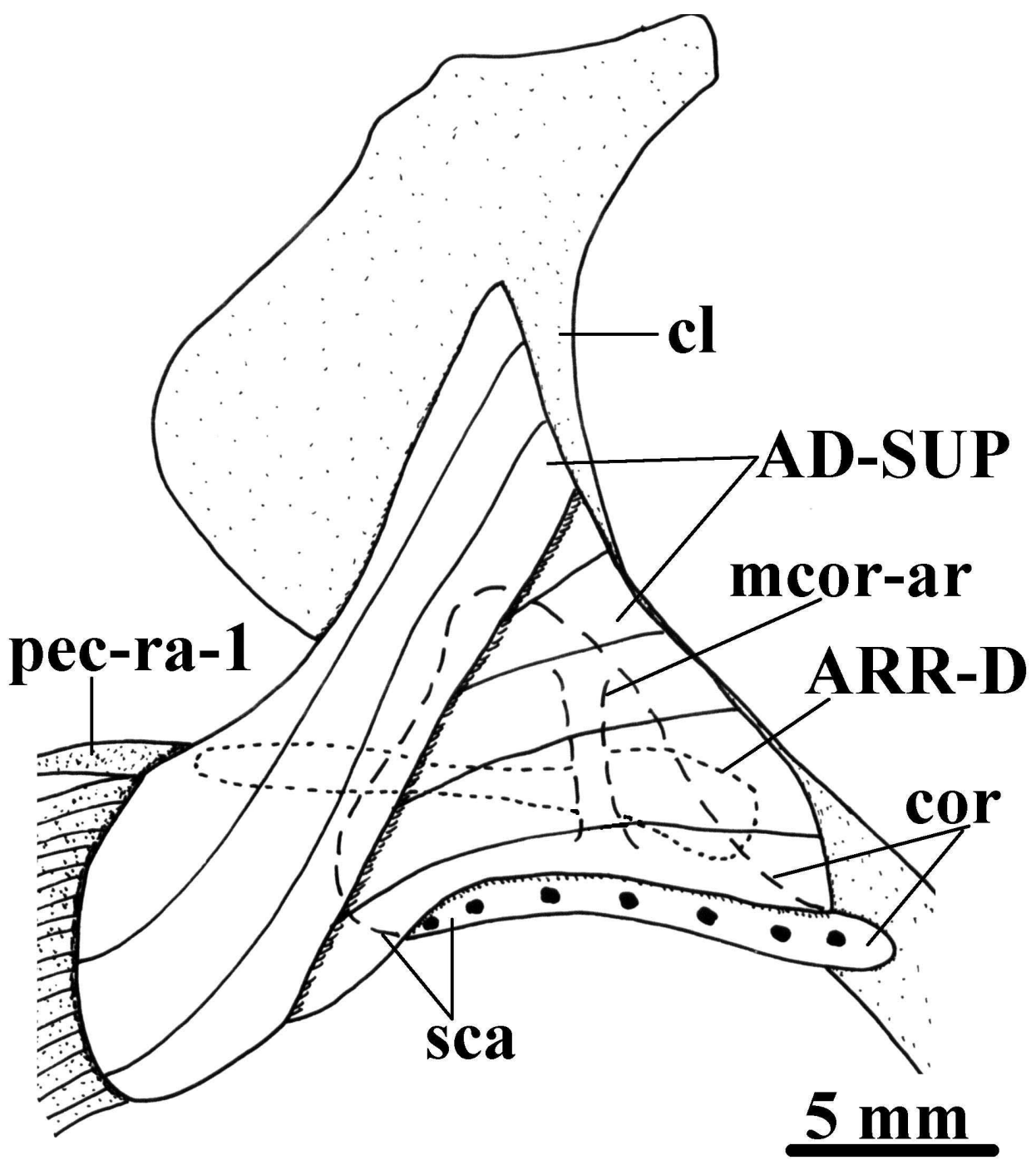

Fig. 15. Mesial view of the pectoral girdle musculature of Amia calva. AD-SUP, adductor superficialis; ARR-D, arrector dorsalis; cl, cleithrum; cor, coracoid; mcor-ar, mesocoracoid arch; pec-ra-1, pectoral ray 1 ; sca, scapula.

as '?' for this character); presence of well-developed 'rostral' cartilaginous or cartilaginous-like structures associated with the posterior surface of well-developed premaxillary dorsomedial processes attached to/articulating with the ethmoid region $(161: 0 \rightarrow 1$, within the fishes examined by us, found exclusively in this clade $\mathrm{C} 18$, with the single exception of Osmerus); presence of strong, well-defined ligament between premaxilla and proximal surface of maxilla (168: $0 \rightarrow 1$, occurring in some groups outside of this clade C18, but not reverted inside of it); anterior portion and/or anterior cartilage of autopalatine forming peculiar 'broad hook' covering a great portion of proximal portion of maxilla in lateral view (185: $0 \rightarrow 1$, found exclusively in the taxa of this clade $\mathrm{C} 18$, and only reverted, within the fishes examined, in Coregonus and Stomias). There is a feature with an ambiguous distribution that may be interpreted as a synapomorphy of this clade, if a 'fast optimization' is chosen $(155: 1 \rightarrow 0)$. It should be noted that, although nowadays many authors consider the Esociformes as the probable sister-group of the Neoteleostei (see Fig. 1), some studies have defended, in the past, that salmoniforms are closely related to neoteleosteans (e.g. Lauder \& Liem; Fink, 1984).

Salmo: No unambiguous features; Coregonus: [29:0 $\rightarrow 1$, $[42: 0 \rightarrow 1],[178: 0 \rightarrow 1],[185: 1 \rightarrow 0]$; Thymallus: No unambiguous features

Clade C19: [68:0 $\rightarrow 1]$, [84:0 $\rightarrow 1$ ] $,[111: 0 \rightarrow 1],[153: 0 \rightarrow 1]$, $[262: 0 \rightarrow 1]$

The grouping of the neoteleostean fishes studied in this clade is expected (see Fig. 1). It is supported by a 
Fig. 16. Mesial view of the pectoral girdle musculature of Lepisosteus osseus, the lateral muscle abductor superficialis is also shown. AB-SUP, abductor superficialis; AD-SUP, adductor superficialis; ARR-D, arrector dorsalis; cl, cleithrum; cor, coracoid; mcor-ar, mesocoracoid arch; pec-ra-1, pectoral ray 1 ; sca, scapula.

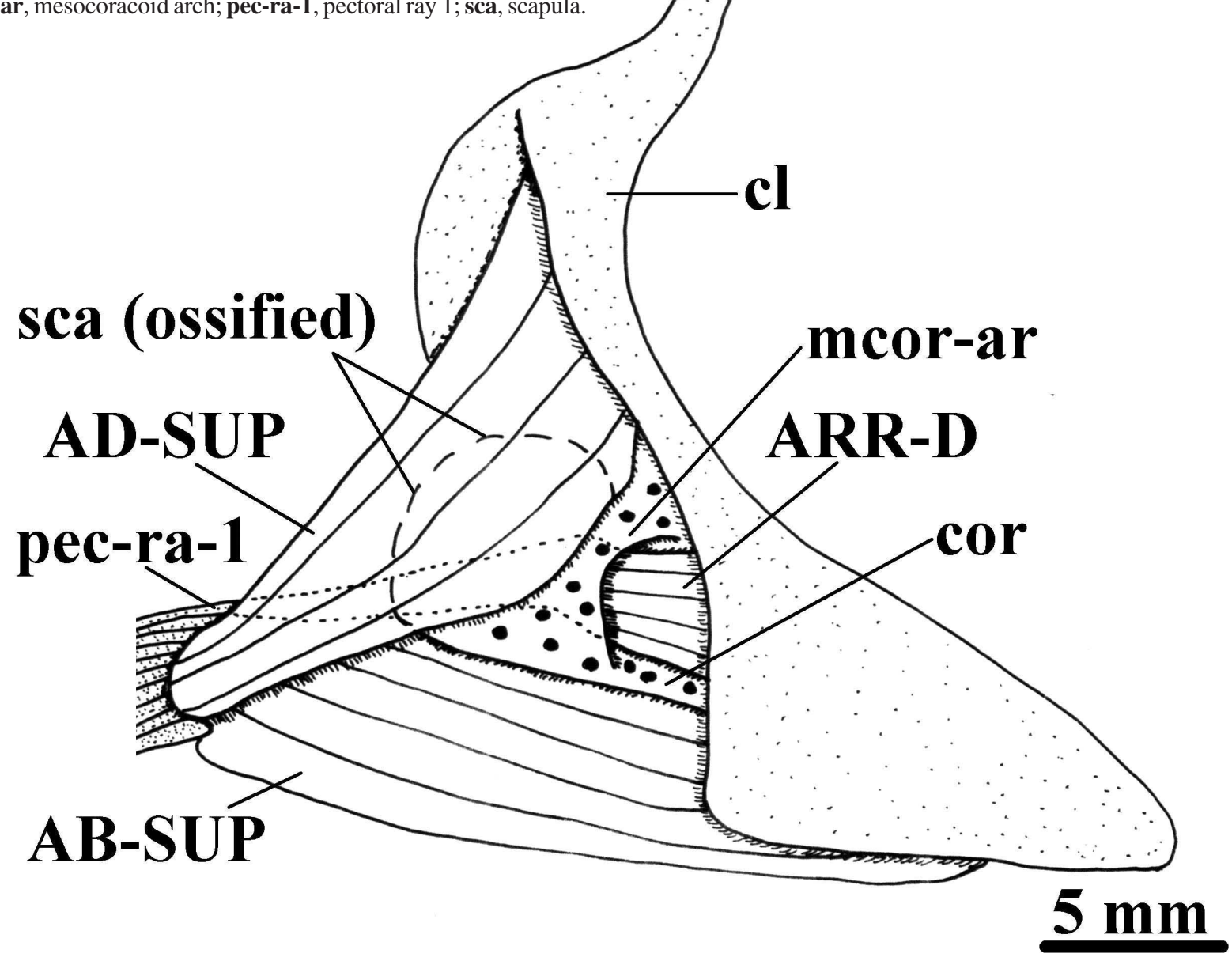

bootstrap value of $62 \%$ (Fig. 2) and by five synapomorphies: anteroposterior elongation of anterior neural arches $(68$ : $0 \rightarrow 1$, not reverted in the fishes we have examined from this clade C19, but occurring in some taxa outside of it); peculiarly large, distinct 'precervical gap' filled mainly with connective tissue between first free vertebra and neurocranium $(84: 0 \rightarrow 1$, homoplasy free within the fishes examined); adductor mandibulae attaching not only on mandible and/or primordial ligament, near its mandibular insertion, but also on other structures $(111: 0 \rightarrow 1$, not reverted inside this clade $\mathrm{C} 19$, but occurring in some taxa outside of it); fibers of hypaxialis and/or epaxialis peculiarly covering great part of neurocranial floor $(153: 0 \rightarrow 1$, not reverted inside this clade $\mathrm{C} 19$ but also occurring in the argentiniform fishes analyzed); presence of peculiar muscle retractor dorsalis (262: $0 \rightarrow 1$, homoplasy free within the fishes examined). There are some features with an ambiguous distribution that may be interpreted as synapomorphies of this clade C19 if a 'fast optimization' is chosen $(22: 1 \rightarrow 2 ; 60: 1 \rightarrow 0 ; 104: 0 \rightarrow 1$; $140: 0 \rightarrow 1 ; 166: 0 \rightarrow 1)$. It should be noted that, although some features listed above might effectively reveal to be potential synapomorphies of the Neoteleostei, this can evidently only be examined appropriately in a study including numerous other representative neoteleostean taxa.

Clade C20: $[19: 0 \rightarrow 1],[24: 1 \rightarrow 0],[33: 1 \rightarrow 0],[34: 0 \rightarrow 1]$, $[35: 1 \rightarrow 0],[74: 0 \rightarrow 1],[101: 1 \rightarrow 0],[\mathbf{1 1 4 : 0 \rightarrow 1}],[134: 0 \rightarrow 1]$

The grouping of the aulopiform fishes examined in this clade is expected (see Fig. 1). It is supported by the nine features listed above and by a bootstrap value of 99\% (Fig. 2). A detailed discussion of the synapomorphies of the Eurypterygii (Aulopiformes + Ctenosquamata), is clearly beyond the main scope of this work, as it includes a single eurypterygian group (see Fig. 1). In fact, it should be stressed that some of the nine features listed above may well be 


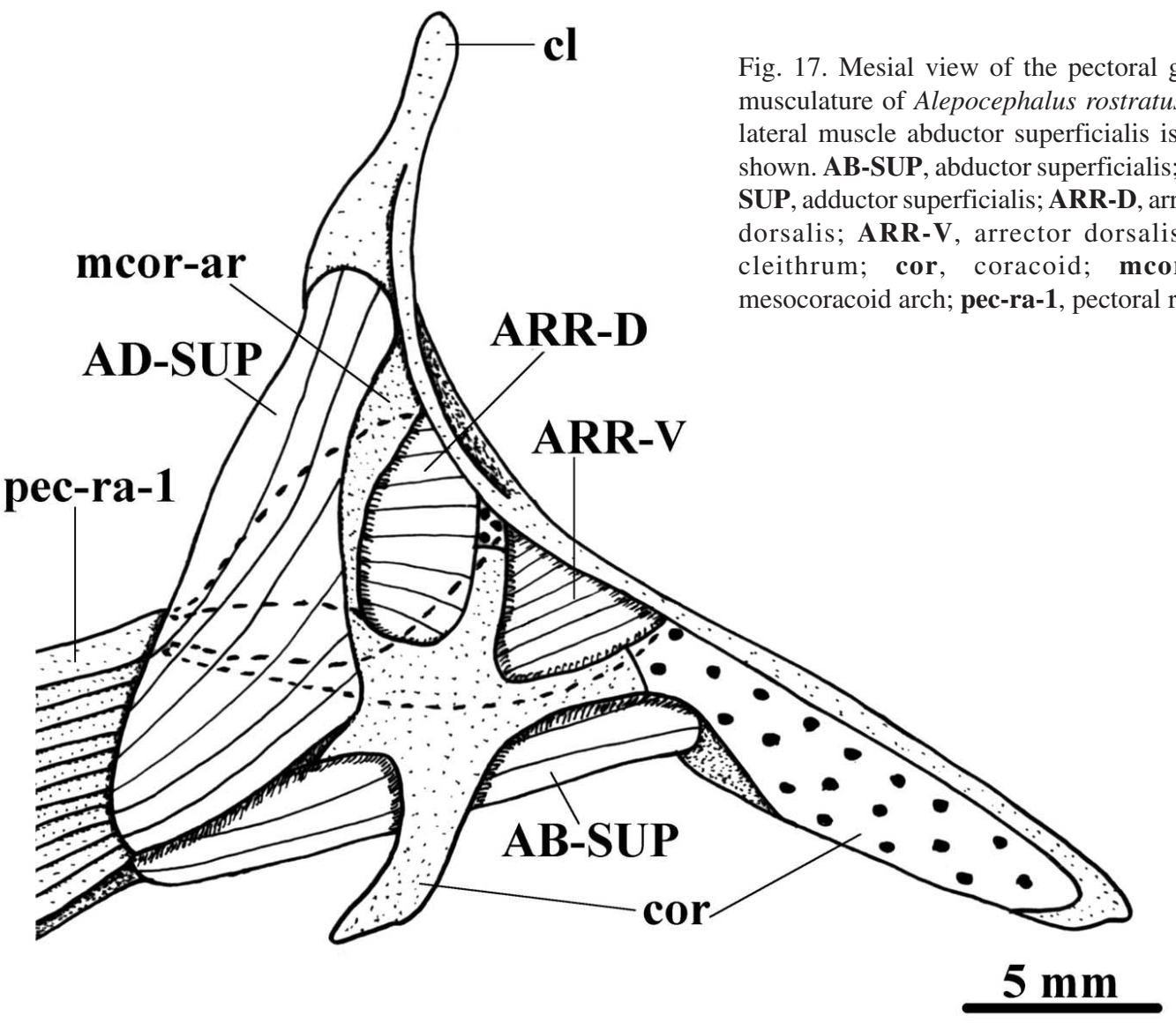

Fig. 17. Mesial view of the pectoral girdle ( dorsalis; ARR-V, arrector dorsalis; cl, cleithrum; cor, coracoid; mcor-ar, mesocoracoid arch; pec-ra-1, pectoral ray 1.

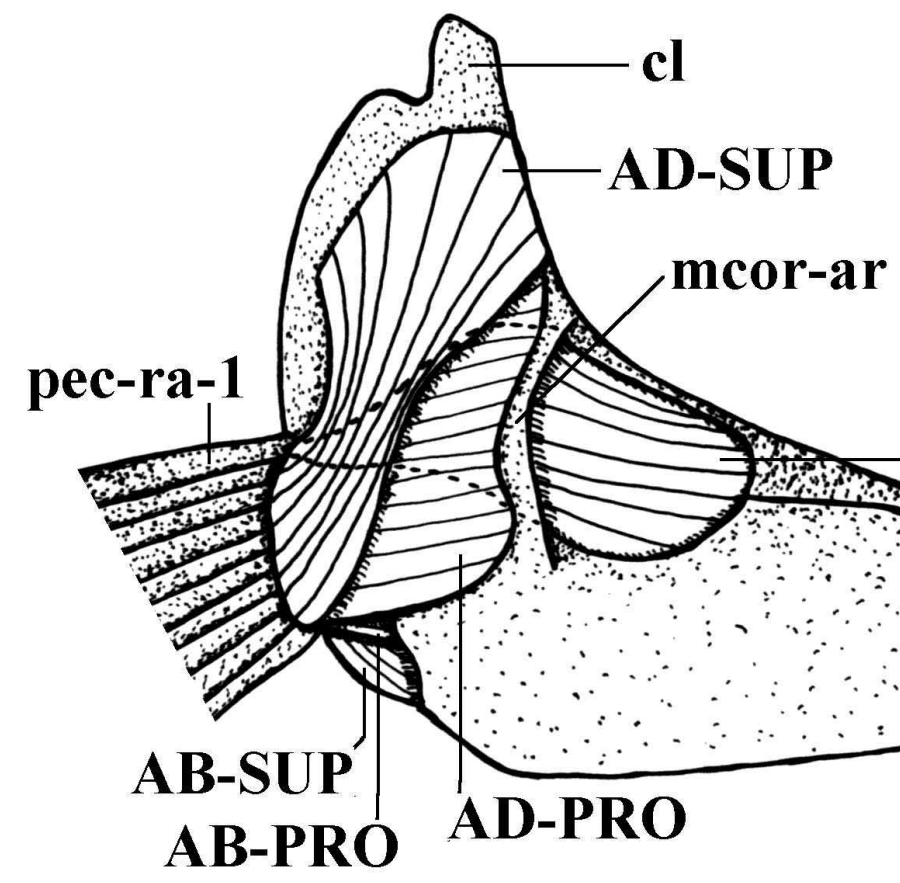

Fig. 18. Mesial view of the pectoral girdle musculature of Denticeps clupeoides, the lateral muscles abductor superficialis and abductor profundus are also shown. AB-PRO, abductor profundus; AB-SUP, abductor superficialis; AD-PRO, adductor profundus; AD-SUP, adductor superficialis; ARR-D, arrector dorsalis; cl, cleithrum; cor, coracoid; mcor-ar, mesocoracoid arch; pec-ra-1, pectoral ray 1 .

\section{ARR-D}

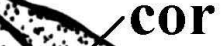

$\times$ 

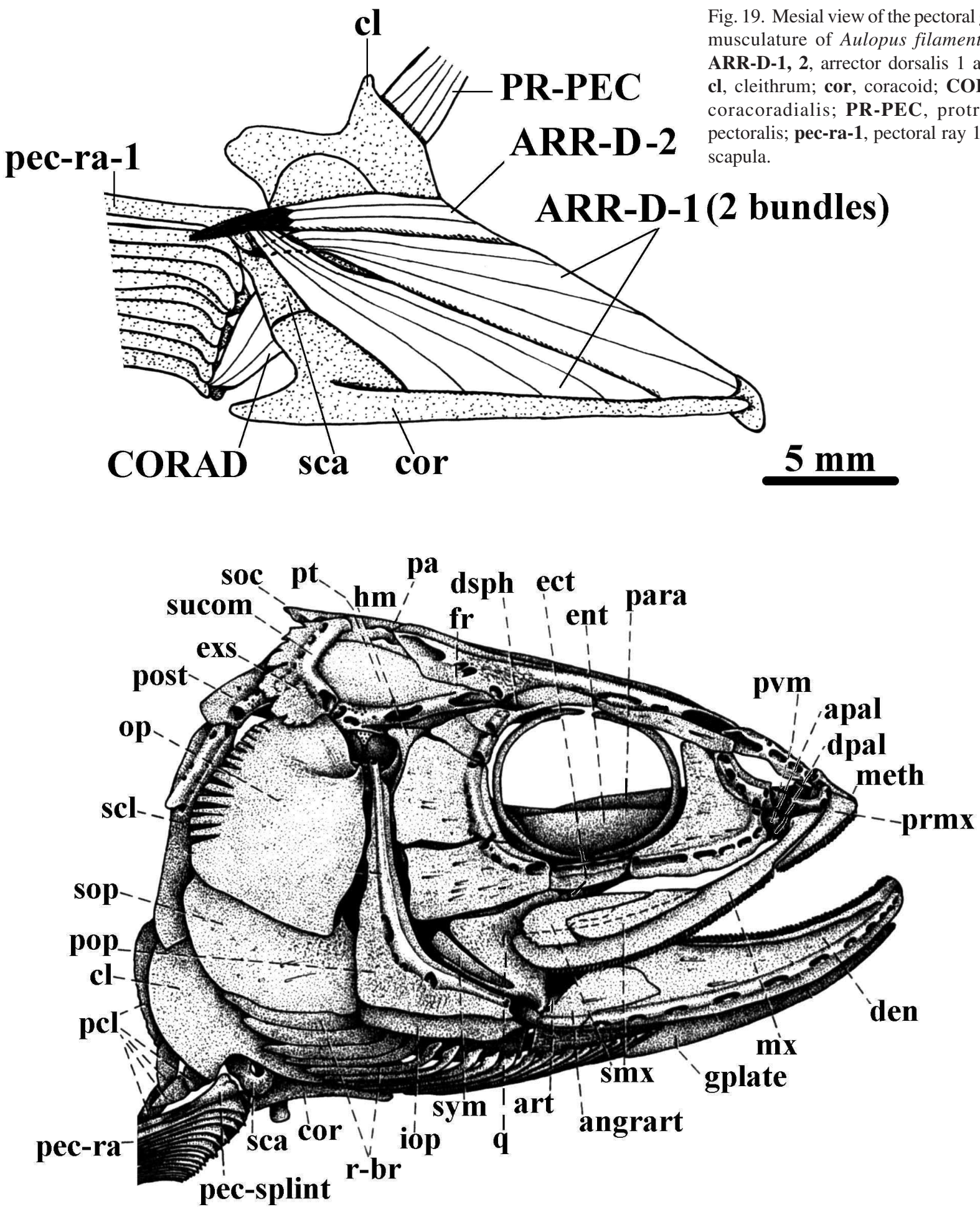

Fig. 20. Lateral view of the cranium and pectoral girdle of Elops lacerta (modified from Taverne, 1974). angrart, anguloretroarticular; apal, autopalatine; art, articular; cl, cleithrum; cor, coracoid; den, dentary bone; dpal, dermopalatine; dsph, dermosphenotic; ect, ectopterygoid; ent, entopterygoid; exs, extrascapular; fr, frontal; gplate, gular plate; hm, hyomandibula; iop, interopercle; meth, mesethmoid; mx, maxilla; op, opercle; osph, orbitosphenoid; pa, parietal; para, parasphenoid; pcl, posterocleithum; pec-ra, pectoral ray; pec-splint, pectoral splint; pop, preopercle; post, posttemporal; prmx, premaxilla; pt, pterotic; pvm, prevomer; q, quadrate; r-br, branchiostegal ray; sca, scapula; scl, supracleithrum; smx, supramaxillae; soc, supraoccipital; sop, subopercle; sucom, supratemporal comissure; sym, symplectic. 
synapomorphies of the Eurypterygii as a whole, and not of the Aulopiformes. For instance, the consistent presence of the coracoradialis $(19: 0 \rightarrow 1)$, of the protractor pectoralis $(24$ : $1 \rightarrow 0)$ and of the adductor mandibulae A1 (114: $0 \rightarrow 1)$ have been proposed by some authors as synapomorphies of eurypterygian fishes (e.g. Winterbottom, 1974; Greenwood \& Lauder, 1981; Lauder \& Liem; Gosline, 1986; Wu \& Shen, 2004). Another example concerns the attachment of the Aw on the suspensorium and/or opercular series $(134: 0 \rightarrow 1)$. As explained in the description of character 134, this feature is found in many non-aulopiform eurypterygian fishes and may well constitute a potential eurypterygian synapomorphy. The taxonomic distribution of these features can only be appropriately examined in a study including numerous other representative eurypterygian taxa.

Aulopus: $\quad[75: 0 \rightarrow 1], \quad[193: 1 \rightarrow 0], \quad[206: 0 \rightarrow 1]$; Chlorophthalmus: [143:0 $\rightarrow 1]$

Clade C21: $[94: 0 \rightarrow 1],[115: 0 \rightarrow 1],[238: 0 \rightarrow 1],[240: 0 \rightarrow 1]$, [270:1 $\rightarrow 0$ ]

The grouping of the stomiiform fishes examined is expected (see Fig. 1). It is supported by the five features listed above and by a bootstrap value of $94 \%$ (Fig. 2).

Astronesthes: $[75: 0 \rightarrow 1]$; Stomias: $[85: 0 \rightarrow 1],[185: 1 \rightarrow 0]$, [224:0 $\rightarrow 1]$

Clade C22: $[104: 0 \rightarrow 1],[196: 0 \rightarrow 1]$

The assembly of the esociform and osmeriform fishes examined by us in this clade $\mathrm{C} 22$ is supported by two synapomorphies and is not supported by a bootstrap value $\geq$ $50 \%$ (Fig. 2). These synapomorphies are: mesocoracoid arch absent (104: $0 \rightarrow 1$, occurring in some groups outside of this clade C22 and reverted inside of it in Osmerus + Plecoglossus); presence of peculiar, prominent hyomandibular lateral spur at or below the level of the opercular process (196: $0 \rightarrow 1$, within the fishes examined, occurring exclusively in the taxa of this clade C22 and only reverted in Stokellia + Retropinna). Some features with ambiguous distributions may be interpreted as synapomorphies of this clade if a 'fast optimization' is chosen $(45: 0 \rightarrow 1)$ or, alternatively, if a 'slow optimization' is adopted (44: $0 \rightarrow 1 ; 155: 0 \rightarrow 1)$. It is important to note that although many authors (e.g. Rosen, 1973, 1974; Johnson \& Patterson; Springer \& Johnson) consider the Salmoniformes as the probable sister-group of the Osmeriformes (see Fig. 1), some studies have partially supported a closer relationship between esociforms and osmeriforms than between these latter fishes and the salmoniforms (see e.g. Waters et al., 2000: Figs. 4, 5).
Clade C23: $[29: 0 \rightarrow 1],[74: 0 \rightarrow 1],[101: 1 \rightarrow 0],[131: 1 \rightarrow 0]$

The grouping of the esociform fishes examined is expected (see Fig. 1). It is supported by the four synapomorphies listed above and by a bootstrap value of $68 \%$ (Fig. 2).

Esox: $[68: 0 \rightarrow 1],[158: 1 \rightarrow 0],[190: 0 \rightarrow 1] ;$ Umbra: $[33: 0 \rightarrow 1]$, $[140: 0 \rightarrow 1],[167: 1 \rightarrow 0]$

Clade C24: [48:0 $\rightarrow 1],[60: 1 \rightarrow 0],[166: 0 \rightarrow 1],[193: 1 \rightarrow 0]$

This clade is expected (see Fig. 1). It is supported by the four synapomorphies listed above, and by a bootstrap value of $51 \%$ (Fig. 2). Interestingly, the results of the cladistic analysis do not support, but also do not contradict, the monophyly of the Galaxioidea: the galaxiid Galaxias appears in a trichotomy that also includes the galaxioid retropinnids Retropinna + Stokellia and the osmeroids Osmerus + Plecoglossus. This is very likely the result of not having included more osmeriform representatives in the present study (see e.g. the strong evidence presented by Johnson \& Patterson, to support the monophyly of the Galaxioidea). However, it should also be noted that in the recent molecular analysis of López et al. (2004) some galaxioid fishes do also appear more closely related to certain osmeroids than to other galaxioids (see e.g. their Fig. 2).

Galaxias: $[42: 0 \rightarrow 1],[144: 0 \rightarrow 1],[145: 0 \rightarrow 1],[178: 0 \rightarrow 1]$

Clade C25: [74:0 $\rightarrow 1],[93: 0 \rightarrow 1],[179: 0 \rightarrow 1],[196: 1 \rightarrow 0]$

The grouping of the retropinnid galaxioids examined is expected (see e.g. Patterson \& Johnson, 1996: Fig. 19). It is supported by the four synapomorphies listed above and by a bootstrap value of $94 \%$.

Retropinna: [155:1 $\rightarrow 0$ ]; Stokellia: $[16: 1 \rightarrow 0]$

Clade C26: $[104: 1 \rightarrow 0],[188: 0 \rightarrow 1],[216: 0 \rightarrow 1]$

The grouping of the osmeroid fishes examined is expected (see Fig. 1).

Osmerus: $[60: 0 \rightarrow 1],[155: 1 \rightarrow 0],[158: 1 \rightarrow 0],[161: 0 \rightarrow 1]$; Plecoglossus: [42:0 $\rightarrow 1],[133: 0 \rightarrow 1],[171: 0 \rightarrow 1]$, $[172: 0 \rightarrow 1],[173: 0 \rightarrow 1],[178: 0 \rightarrow 1],[242: 0 \rightarrow 1],[251: 0 \rightarrow 1]$

Clade C27: [53:0 $\rightarrow 1$ ], [81:0 $\rightarrow 1$ ] $,[82: 0 \rightarrow 1],[206: 0 \rightarrow 1]$

The clade including the clupeomorph and ostariophysan fishes examined is supported by a bootstrap value of $50 \%$ and by four unambiguous synapomorphies, 


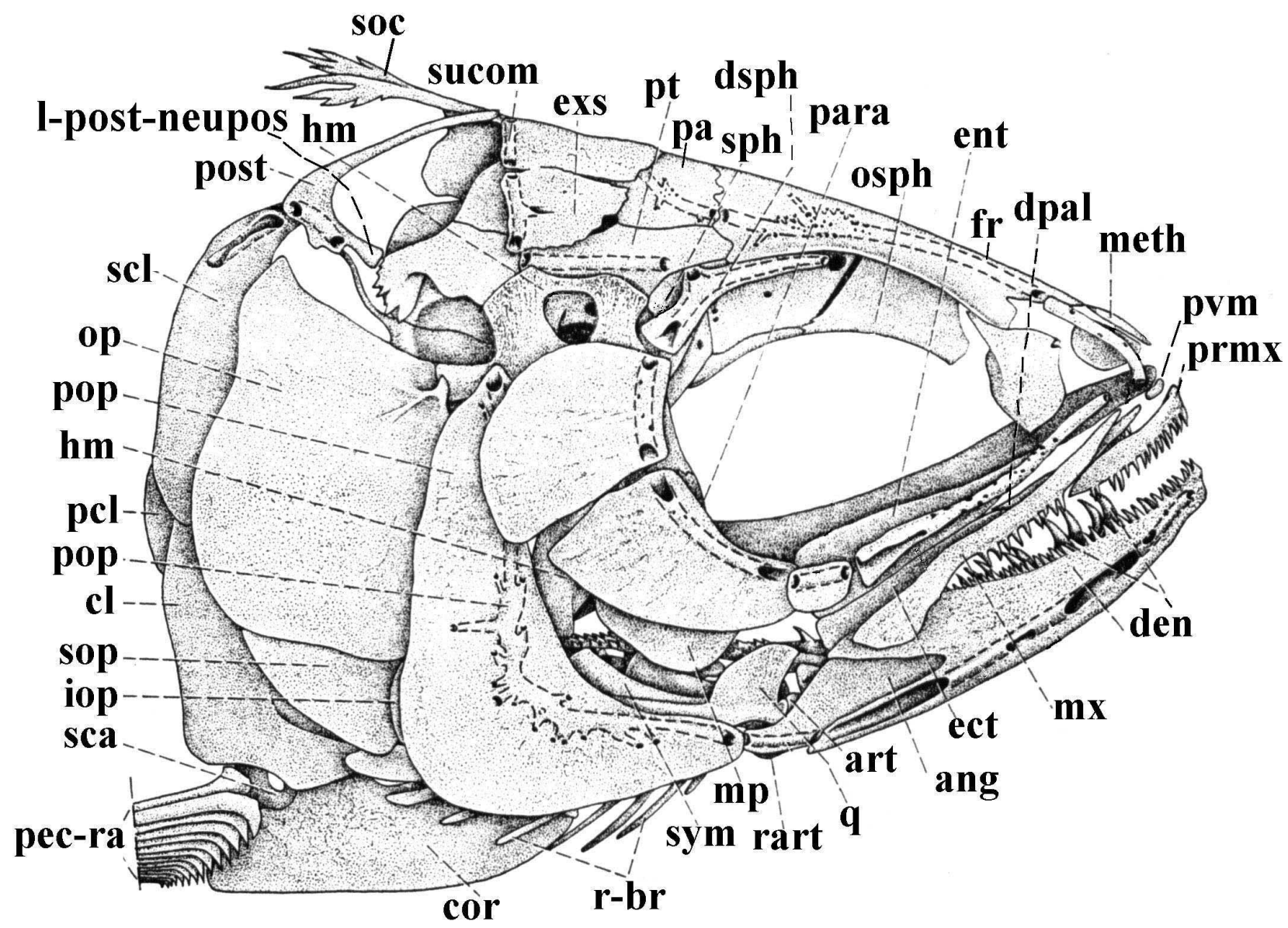

Fig. 21. Lateral view of the cranium and pectoral girdle of Hiodon tergisus (modified from Taverne, 1977b). ang, angular; apal, autopalatine; art, articular; cl, cleithrum; cor, coracoid; den, dentary bone; dpal, dermopalatine; dsph, dermosphenotic; ect, ectopterygoid; ent, entopterygoid; exs, extrascapular; fr, frontal; hm, hyomandibula; iop, interopercle; l-post-neupos, ossified ligament between posttemporal and posterior region of neurocranium; meth, mesethmoid; mp, metapterygoid; mx, maxilla; op, opercle; osph, orbitosphenoid; pa, parietal; para, parasphenoid; pcl, posterocleithum; pec-ra, pectoral ray; pop, preopercle; post, posttemporal; prmx, premaxilla; pt, pterotic; pvm, prevomer; q, quadrate; r-br, branchiostegal ray; rart, retroarticular; sca, scapula; scl, supracleithrum; sph, sphenotic; soc, supraoccipital; sop, subopercle; sucom, supratemporal comissure; sym, symplectic.

of which 3 are seemingly homoplasy free within the fishes examined : position of sacculi and lagenae more posterior and principally nearer to midline $(53: 0 \rightarrow 1$, homoplasy free within the fishes examined in which this character could be discerned); swimbladder with a silvery peritoneal tunic covering at least part of its anterior portion $(81: 0 \rightarrow 1$, homoplasy free within the fishes examined in which this character could be discerned); swimbladder markedly divided into peculiar anterior and posterior chambers (82: $0 \rightarrow 1$, homoplasy free within the fishes examined in which this character could be discerned); hyomandibula exhibiting two articulatory heads for neurocranium (206: $0 \rightarrow 1$, independently occurring in some fishes outside this clade C27 and reverted in some taxa of this clade: see below). The three first features were considered by authors such as
Rosen \& Greenwood (1970) to be potential synapomorphies of the Ostariophysi. However, Grande \& De Pinna (2004) have recently defended that these features are also found in many clupeomorphs and that they may well constitute, in fact, otocephalan synapomorphies. This latter view is supported by the present work. There are three features with an ambiguous distribution that may be interpreted as potential synapomorphies of this clade $\mathrm{C} 28$ if a 'fast optimization' is chosen $(42: 0 \rightarrow 1 ; 174: 0 \rightarrow 1 ; 242$ : $0 \rightarrow 1)$.

Although the otocephalan clade is nowadays accepted by most researchers (e.g. Lecointre, 1995; Johnson \& Patterson; Arratia, 1997, 1999; Filleul \& Lavoué; Inoue et al.; Elmerot et al., 2002; Wang et al.; Zaragüeta-Bagils 


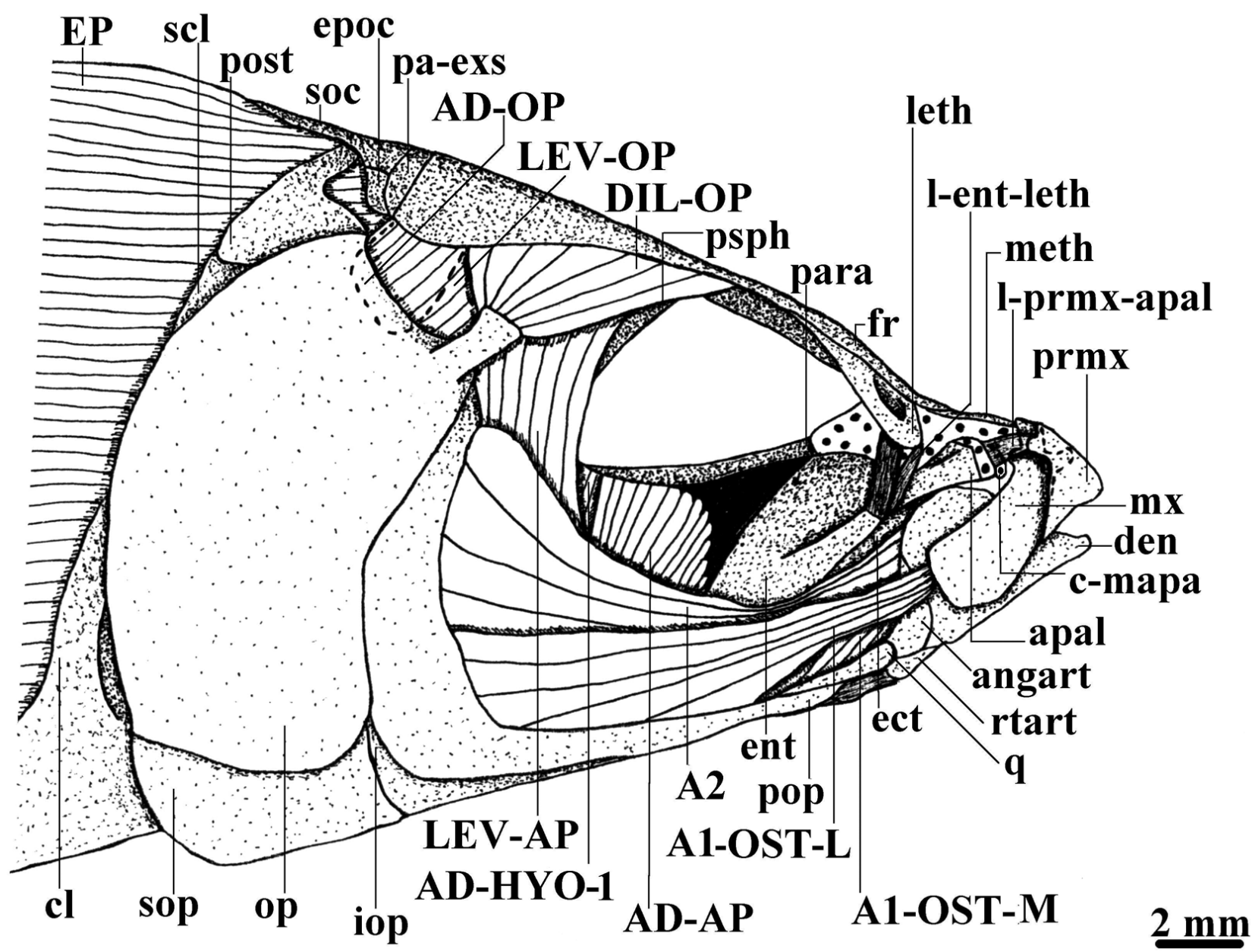

Fig. 22. Lateral view of the cephalic musculature of Chanos chanos. The pectoral girdle muscles are not illustrated; the nasals and infraorbitals were removed. A1-OST-L, A1-OST-M, A2, sections of adductor mandibulae; AD-AP, adductor arcus palatini; AD-OP, adductor operculi; AD-HYO-1, adductor hyomandibulae 1; angart, angulo-articular; apal, autopalatine; c-mapa, small cartilage between maxilla and autopalatine; cl, cleithrum; den, dentary bone; DIL-OP, dilatator operculi; ect, ectopterygoid; ent, entopterygoid; EP, epaxialis; epoc, epioccipital; fr, frontal; iop, interopercle; l-ent-leth, ligament between entopterygoid and lateral-ethmoid; l-prmx-apal, ligament between premaxilla and autopalatine; leth, lateral-ethmoid; LEV-AP, levator arcus palatini; LEV-OP, levator operculi; meth, mesethmoid; mx, maxilla; op, opercle; pa-exs, parieto-extrascapular; para, parasphenoid; pop, preopercle; post, posttemporal; prmx, premaxilla; psph, pterosphenoid; q, quadrate; rtart, retroarticular; scl, supracleithrum; soc, supraoccipital; sop, subopercle.

et al., 2002; Stiassny et al., 2004) (see Fig. 1), some authors, based on molecular cladistic analyses, have argued that the Otocephala should be enlarged in order to also include the Alepocephaloidea (Ishiguro et al.; e.g. Lavoué et al., 2005). This subject was already discussed above (see 'Clade C13'). These latter authors argue that the results of their analyses do not directly contradict the results of most morphological cladistic analyses, as these morphological analyses almost never included, in a same matrix, representatives of the Clupeomorpha, of the Ostariophysi, of the Alepocephaloidea, and of other teleostean taxa to which these three groups should be compared. We fully agree with this point. However, it should be noted that, with the present work, there are already two extensive morphological cladistic analyses that did include these three groups and many other teleost taxa in a same matrix and that did contradict the inclusion of the Alepocephaloidea in the otocephalan clade (Patterson \& Johnson; this work).

Clade C28: $[34: 0 \rightarrow 1],[52: 0 \rightarrow 1],[56: 0 \rightarrow 1],[271: 0 \rightarrow 1]$

The grouping of the clupeomorph fishes examined is expected (see Fig. 1). It is supported by a bootstrap value of $67 \%$ and by the four synapomorphies listed above, three of which are homoplasy free within the fishes examined.

Denticeps: $[88: 0 \rightarrow 1],[140: 0 \rightarrow 1],[146: 0 \rightarrow 1],[160: 1 \rightarrow 0]$, [217:0 $\rightarrow 1],[228: 0 \rightarrow 1]$ 


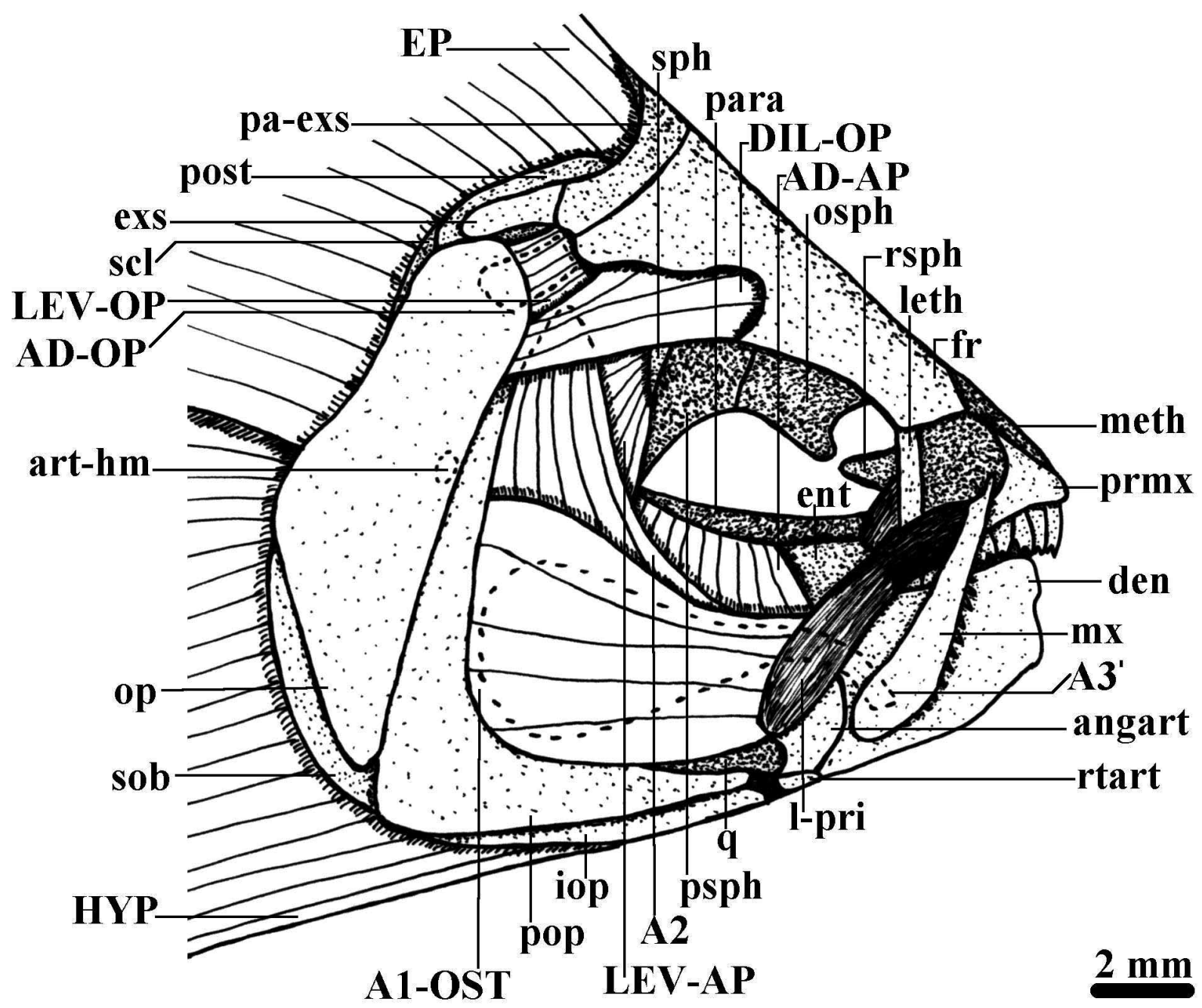

Fig. 23. Lateral view of the cephalic musculature of Brycon guatemalensis. The pectoral girdle muscles are not illustrated; the postcleithra and the most ventral elements of the pectoral girdle, as well as the nasals and infraorbitals, were removed. A1-OST, A2, A3', sections of adductor mandibulae; AD-AP, adductor arcus palatini; AD-OP, adductor operculi; angart, angulo-articular; den, dentary bone; DIL-OP, dilatator operculi; ent, entopterygoid; EP, epaxialis; exs, extrascapular; fr, frontal; HYP, hypoaxialis; iop, interopercle; l-pri, primordial ligament; leth, lateral-ethmoid; LEV-AP, levator arcus palatini; LEV-OP, levator operculi; meth, mesethmoid; mx, maxilla; op, opercle; osph, orbitosphenoid; pa-exs, parieto-extrascapular; para, parasphenoid; pop, preopercle; post, posttemporal; prmx, premaxilla; psph, pterosphenoid; q, quadrate; rsph, rhinosphenoid; rtart, retroarticular; scl, supracleithrum; sop, subopercle; sph, sphenotic.

\section{Clade C29: [142:0 $\rightarrow 1],[158: 1 \rightarrow 0],[166: 0 \rightarrow 1]$}

As expected, Denticeps appears as the sister-group of the remaining clupeiforms examined (see Fig. 1).

Ethmalosa: $[24: 1 \rightarrow 0],[33: 0 \rightarrow 1],[\mathbf{6 3 : 0} \rightarrow \mathbf{1}],[144: 0 \rightarrow 1]$

\section{Clade C30: [77:0 $\rightarrow 1]$}

As seen in Figure 1, many authors consider the relationships between the Clupeoidea, the Engrauloidea and the Pristigasteroidea as still unresolved. This subject was recently revised by Di Dario (2002), who defended a sistergroup relationship between the Clupeoidea and the Engrauloidea. The present work does not support this view, since the engrauloid and pristigasteroid fishes examined are grouped together in this clade $\mathrm{C} 30$. Apart the synapomorphy listed above (70: $0 \rightarrow 1$ ), the sister-group relationship between these fishes may be supported by other four synapomorphies, if a 'fast optimization' is chosen $(68: 0 \rightarrow 1 ; 155: 1 \rightarrow 0 ; 174$ : $1 \rightarrow 0 ; 242: 1 \rightarrow 0)$. However, it should be stressed that this clade is not supported by a bootstrap value $\geq 50 \%$ (Fig. 2). 


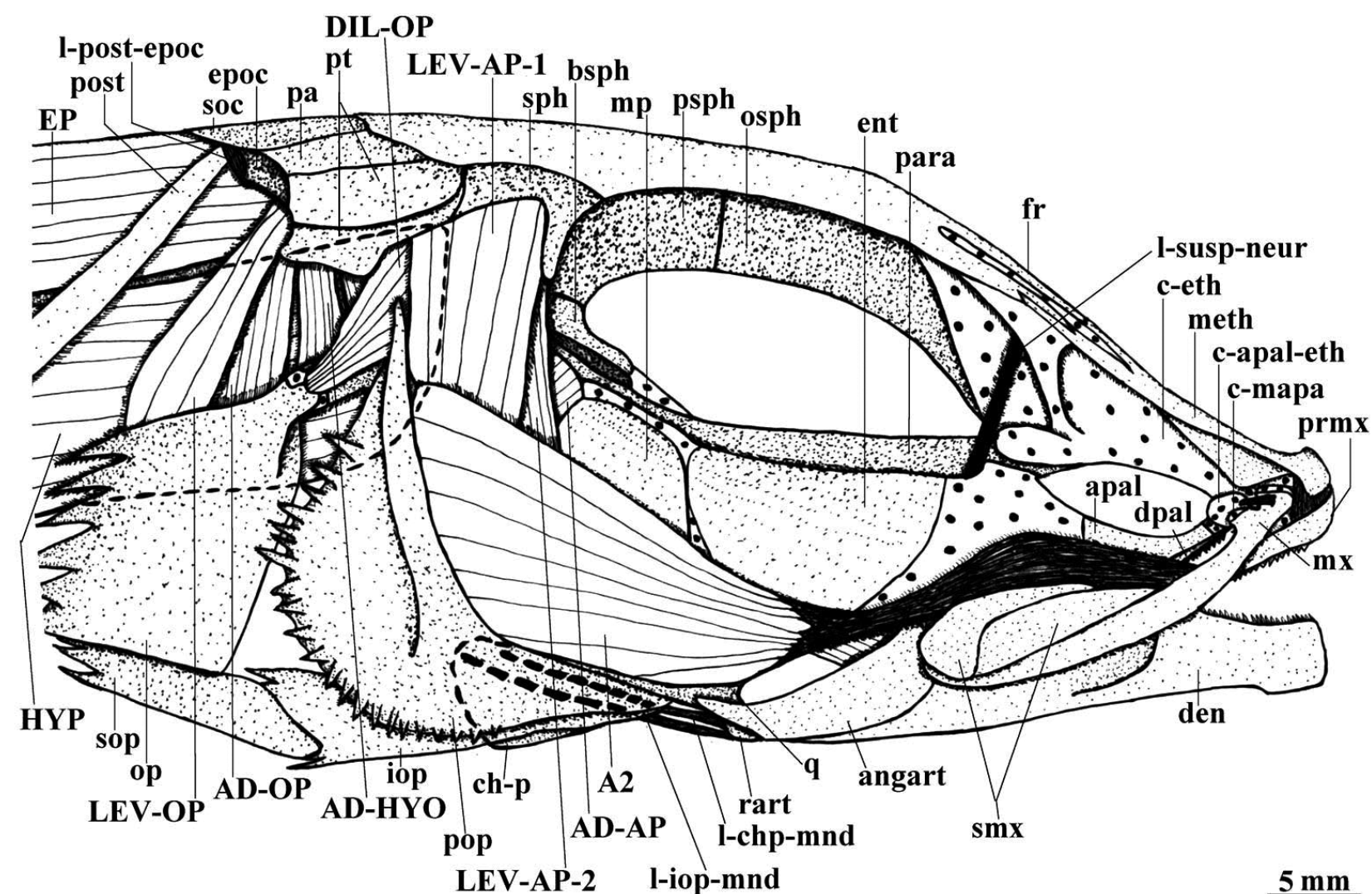

Fig. 24. Lateral view of the cephalic musculature of Alepocephalus rostratus. The pectoral girdle muscles are not illustrated; most elements of the pectoral girdle, as well as the nasals and infraorbitals, were removed. A2, adductor mandibulae A2; AD-AP, adductor arcus palatini; AD-HYO, adductor hyomandibulae; AD-OP, adductor operculi; angart, angulo-articular; apal, autopalatine; bsph, basisphenoid; c-apal-eth, cartilage between autopalatine and ethmoid region; c-eth, ethmoid cartilage; c-mapa, small cartilage between maxilla and autopalatine; ch-p, posterior ceratohyal; den, dentary bone; dpal, dermopalatine; DIL-OP, dilatator operculi; ent, entopterygoid; EP, epaxialis; epoc, epioccipital; fr, frontal; HYP, hypoaxialis; iop, interopercle; l-chp-mnd, ligament between posterior ceratohyal and mandible; l-iop-mnd, ligament between interopercle and mandible; l-pri, primordial ligament; l-post-epoc, ligament between posttemporal and epioccipital; l-susp-neur, ligament between suspensorium and neurocranium; leth, lateral-ethmoid; LEV-AP-1, 2, sections of levator arcus palatini; LEV-OP, levator operculi; meth, mesethmoid; mp, metapterygoid; mx, maxilla; op, opercle; osph, orbitosphenoid; pa, parietal; para, parasphenoid; pop, preopercle; post, posttemporal; prmx, premaxilla; psph, pterosphenoid; pt, pterotic; q, quadrate; rtart, retroarticular; smx, supramaxillae; soc, supraoccipital; sop, subopercle; sph, sphenotic.

Obviously, the relationships between the Clupeoidea, the Engrauloidea and the Pristigasteroidea can only be appropriately examined in a cladistic analysis including many other representatives of these three groups.

Ilisha: $[143: 0 \rightarrow 1],[160: 1 \rightarrow 0]$

Clade C31: [32:0 $\rightarrow 1],[111: 0 \rightarrow 1],[209: 0 \rightarrow 1]$

As expected (see Fig. 1), the two engrauloid taxa examined are grouped together. This clade is supported by a bootstrap value of $66 \%$ (Fig. 2).

Engraulis: $[144: 0 \rightarrow 1]$; Thryssa: $[88: 0 \rightarrow 1],[166: 1 \rightarrow 0]$
Clade C32: [24:1 $\rightarrow 0]$, [45:0 $\rightarrow 1],[77: 0 \rightarrow 1],[111: 0 \rightarrow 1]$, [113:0 $\rightarrow 1],[167: 1 \rightarrow 0],[178: 0 \rightarrow 1]$

The assembly of the ostariophysan fishes examined in this clade is expected (see Fig. 1). It is supported by a bootstrap value of $78 \%$ and by the following unambiguous synapomorphies (one of them, 113: $0 \rightarrow 1$, being homoplasy free within the fishes examined): presence of protractor pectoralis $(24: 0 \rightarrow 1)$; absence of basisphenoid (45: $0 \rightarrow 1)$; ribs/parapophyses of third free vertebra highly modified ( 77 : $0 \rightarrow 1$ ); adductor mandibulae attaching not only on mandible and/or primordial ligament, near its mandibular insertion, but also on other structures (111: $0 \rightarrow 1$ ); presence of adductor mandibulae A1-OST (113: $0 \rightarrow 1$ ); primordial ligament 


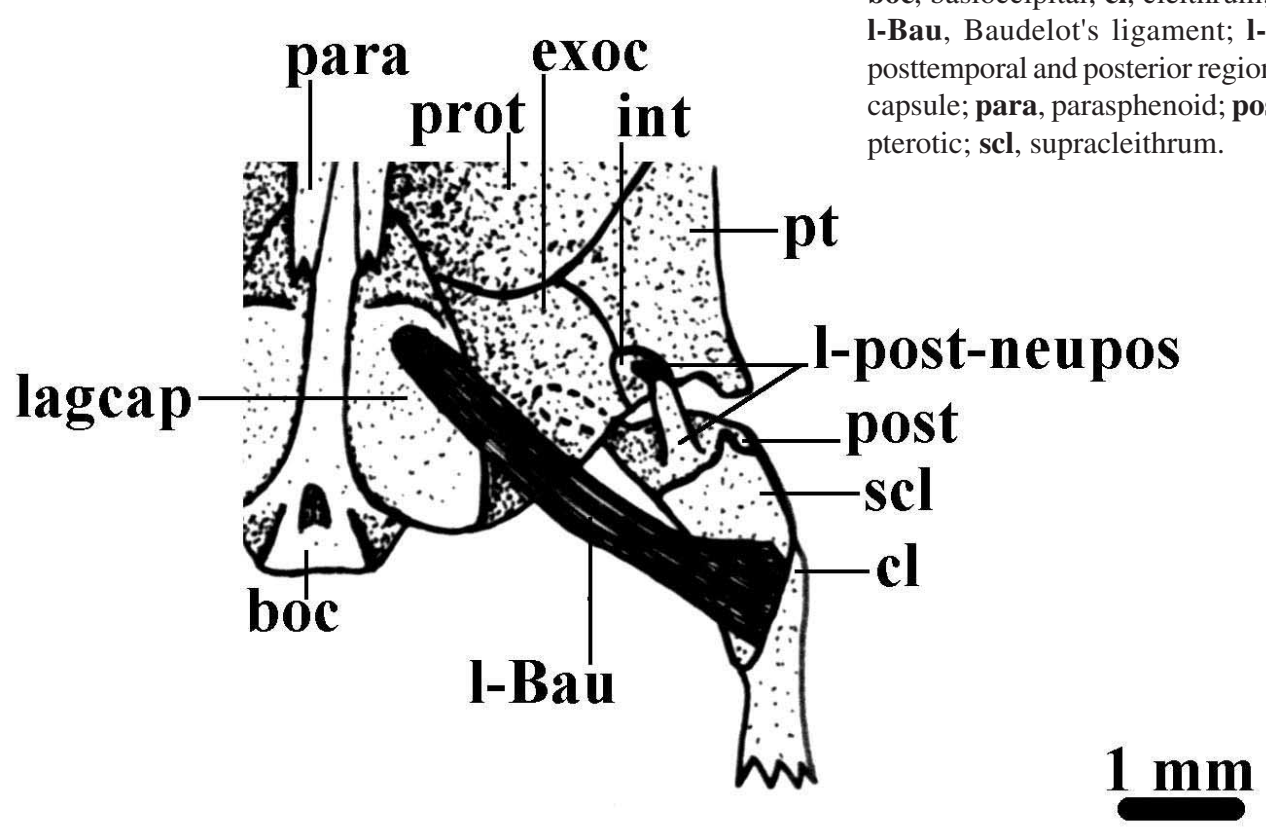

Fig. 25. Ventral view of the posterior region of the neurocranium and dorsal elements of the pectoral girdle of Brycon guatemalensis. boc, basioccipital; cl, cleithrum; exoc, exoccipital; int, intercalar; l-Bau, Baudelot's ligament; l-post-neupos, ligament between posttemporal and posterior region of neurocranium; lagcap, lagenar capsule; para, parasphenoid; post, posttemporal; prot, prootic; pt, pterotic; scl, supracleithrum.

attaching posteriorly on dorsal surface of coronoid process (167: 1à0); absence of toothed dermopalatine $(178: 0 \rightarrow 1)$. It is important to note that the scoring of the first feature as an ostariophysan synapomorphy might well be an artificial result associated with the using of the specific clupeomorph taxa included in the present cladistic analysis. This is because various clupeomorphs other than Ethmalosa (the only clupeomorph analyzed with CSO) actually have a protractor pectoralis (see e.g. Greenwood \& Lauder). Also, one should be cautious about the feature concerning the attachment of the primordial ligament on the dorsal surface of the coronoid process. This feature was considered by Fink \& Fink (1981, 1996) as a synapomorphy of gymnotiforms + siluriforms. However, the cypriniforms examined in the present work do also exhibit a primordial ligament attaching posteriorly on the dorsal surface of the coronoid process (except Danio, in which this feature could not be appropriately discerned). Since the condition present in the gonorynchiform and in the fossil taxa examined is also not clear, either because it was difficult to discern this feature or because a distinct primordial ligament is seemingly missing, such an attachment of this ligament on the dorsal surface of the coronoid process was scored in the cladogram as a potential ostariophysan synapomorphy. However, precisely because the condition in these taxa is not clear, one should be reticent regarding the acceptance of this feature as a synapomorphy of the Ostariophysi as a whole. The other feature listed above that was not listed by Fink \& Fink $(1981,1996)$ as an ostariophysan synapomorphy is the presence of an A1-OST. This feature is exclusively, and consistently, found in ostariophysans, and does seem to constitute a well-grounded synapomorphy of these fishes (e.g. Gosline, 1989; Diogo \& Chardon, 2000; Diogo; this work). The monophyly of ostariophysans is therefore well supported (Fig. 2), thus supporting some recent molecular studies (e.g. Lavoué et al.) and contradicting some others, in which some or all gonorynchiforms were placed as the sister-group of some or all clupeiforms included in those studies (e.g. Ishiguro et al.; Saitoh et al., 2003; Wang et al., 2003; Inoue et al., 2004).

Clade C33: $[44: 0 \rightarrow 1],[166: 0 \rightarrow 1]$

The grouping of the gonorynchiform fishes examined is expected (see Fig. 1). It is supported by a bootstrap value of $55 \%$ (Fig. 2) and by the two synapomorphies listed above. Interestingly, the genus Gonorynchus, the genus Chanos, and the Kneriidae sensu Grande \& Poyato-Ariza (1999), appear in an unresolved trichotomy (Fig. 2). In the most recent and extensive morphological cladistic analysis of the Gonorynchiformes (Grande \& Poyato-Ariza) the Gonorynchidae, in which Gonorynchus is included, is placed as the sister-group of the Kneriidae. However, in the most recent and extensive molecular cladistic analysis of this order (Lavoué et al.) Gonorynchus appears as the sister-group of the remaining extant gonorynchiform genera. As stressed about 20 years ago by Howes (1985), the phylogenetic position of Gonorynchus thus continues to be a particularly problematic issue. As stated by Howes (1985), at least some members of the genus Gonorynchus share some peculiar derived anatomical features with the Kneriidae (e.g. 133: 


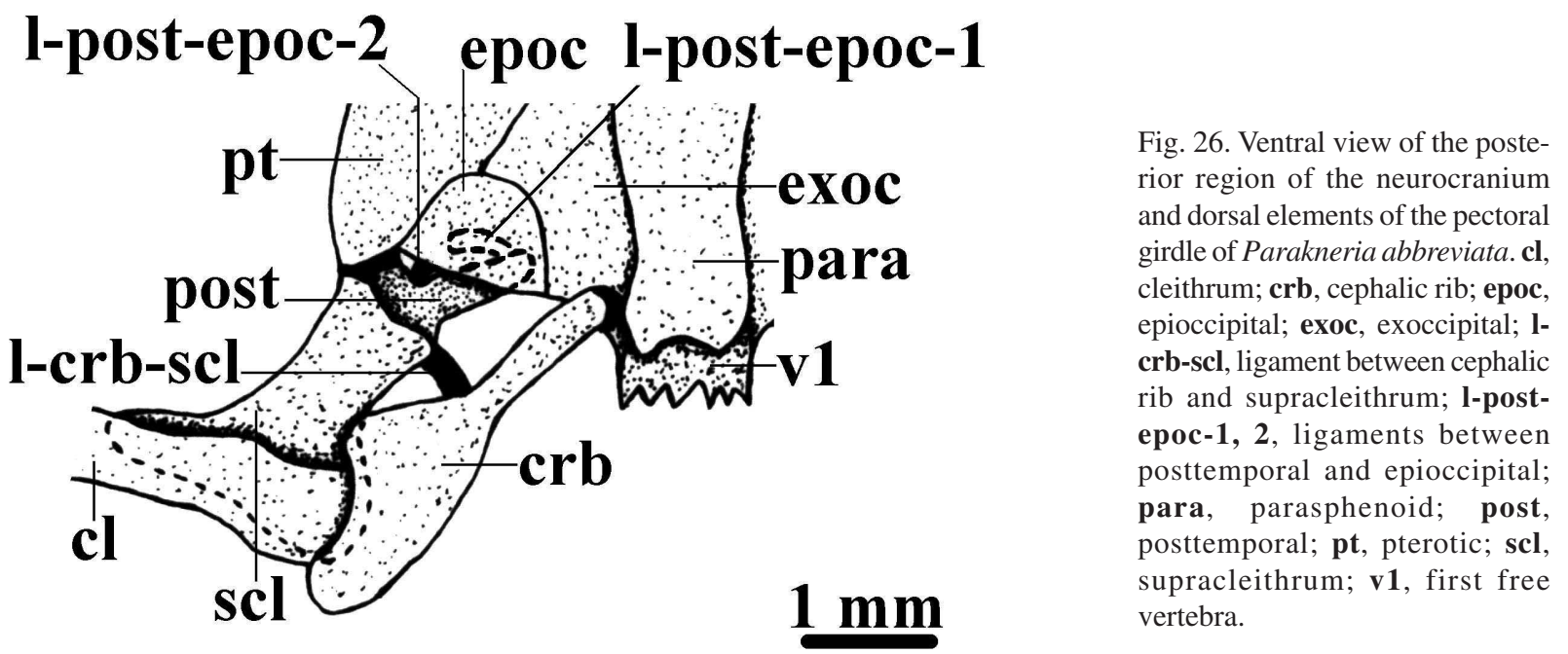

$0 \rightarrow 1$, absence of adductor mandibulae Aw), with the genus Phractolaemus (249: $0 \rightarrow 1$, mandible highly modified, the dentary bone being roughly perpendicular to the main body of the mandible), and with the genus Chanos $(216: 0 \rightarrow 1$, presence of prominent, thin, dorsally/anterodorsally oriented anterodorsal projection of opercle). It is hoped that work in progress, together with T. Grande and F. Poyato-Ariza, which focuses on the osteology of all the gonorynchiform fossil taxa as well as on both the myology and osteology of all the extant taxa of this order, could help to clarify this question.

Chanos: $[57: 0 \rightarrow 1],[75: 1 \rightarrow 0]$; Gonorynchus: $[6: 0 \rightarrow 1]$, $[50: 0 \rightarrow 1],[87: 0 \rightarrow 1],[95: 0 \rightarrow 1],[112: 0 \rightarrow 1],[125: 0 \rightarrow 1]$, $[139: 0 \rightarrow 1], \quad[140: 0 \rightarrow 1], \quad[\mathbf{1 6 9 : 0 \rightarrow 1}], \quad[\mathbf{1 7 7 : 0 \rightarrow 1}]$, $[\mathbf{1 8 4 : 0 \rightarrow 1}], \quad[193: 1 \rightarrow 0], \quad[\mathbf{1 9 7 : 0} \rightarrow \mathbf{1}], \quad[\mathbf{2 1 1 : 0 \rightarrow 1}]$, $[249: 0 \rightarrow 1],[269: 0 \rightarrow 1]$

Clade C34: $[37: 0 \rightarrow 1],[123: 0 \rightarrow 1],[227: 0 \rightarrow 1]$

The grouping of the kneriid taxa examined is expected (e.g. Grande \& Poyato-Ariza, 1999). It is supported by a bootstrap value of $66 \%$ and by the three synapomorphies listed above (Fig. 2).

Phractolaemus: $[4: 0 \rightarrow 1],[36: 0 \rightarrow 1],[41: 0 \rightarrow 1],[86: 0 \rightarrow 1]$, $[88: 0 \rightarrow 1],[98: 0 \rightarrow \mathbf{1}],[112: 0 \rightarrow 1],[\mathbf{1 2 0 : 0} \rightarrow \mathbf{1}],[\mathbf{1 2 1 : 0 \rightarrow 1 ] ,}$ $[156: 0 \rightarrow 1], \quad[160: 1 \rightarrow 0], \quad[175: 0 \rightarrow 1], \quad[176: 0 \rightarrow 1]$, $[181: 0 \rightarrow 1], \quad[183: 0 \rightarrow 1], \quad[\mathbf{1 9 4}: 0 \rightarrow \mathbf{1}], \quad[\mathbf{1 9 9 : 0} \rightarrow \mathbf{1}]$, $[\mathbf{2 1 8 : 0 \rightarrow 1 ] , ~ [ 2 2 1 : 0 \rightarrow 1 ] , ~ [ 2 2 9 : 0 \rightarrow 1 ] , ~ [ 2 4 9 : 0 \rightarrow 1 ] , ~}$ $[251: 0 \rightarrow 1],[263: 0 \rightarrow 1]$

Clade C35: $[61: 0 \rightarrow 1],[164: 0 \rightarrow 1],[258: 0 \rightarrow 1]$

The assembly of these four taxa examined is expected (e.g. Grande \& Poyato-Ariza, 1999). It is supported by a bootstrap value of $71 \%$ and by the three synapomorphies listed above (Fig. 2).

Clade C36: $[46: 0 \rightarrow 1],[223: 1 \rightarrow 0]$

The grouping of the two taxa examined belonging to the Cromeriini is expected (e.g. Grande \& Poyato-Ariza). It is supported by a bootstrap value of $78 \%$ and by the two synapomorphies listed above (Fig. 2).

Grasseichthys: [221:0 $\rightarrow$ 1]; Cromeria: No unambiguous features

Clade C37: $[108: 0 \rightarrow 1],[198: 0 \rightarrow 1],[250: 0 \rightarrow 1]$

The grouping of the two taxa examined belonging to the Kneriini is expected (e.g. Grande \& Poyato-Ariza). It is supported by a bootstrap value of $90 \%$ and by the three synapomorphies listed above (Fig. 2).

Parakneria: No unambiguous features; Kneria: [145:0 $\rightarrow 1]$

Clade C38: $[32: 0 \rightarrow 1]$

In Taverne's (1999) paper describing $\uparrow$ Sorbininardus apuliensis, that author considered probable (based on a handmade tree made by him) that this taxon is an ostariophysan, and namely the sister-group of Gonorynchiformes. The results of the present study support the first hypothesis, but do not provide support for the second: within ostariophysans, $\dagger$ Sorbininardus apuliensis appears more closely related to the non-gonorynchiform fishes examined than to gonorynchiforms (Fig. 2). However, it should be 


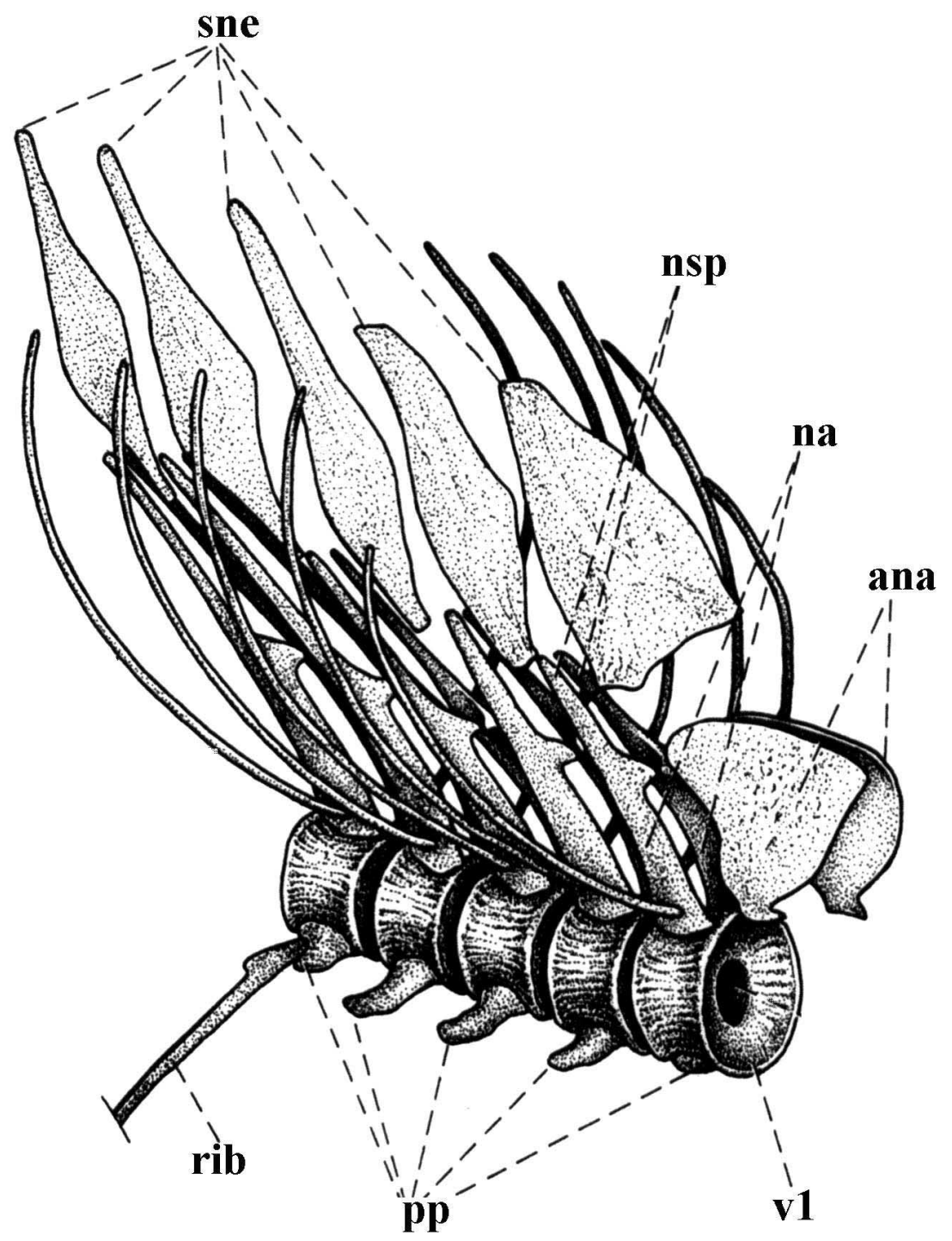

Fig. 27. Dorsolateral view of anterior vertebrae of Elops lacerta (modified from Taverne, 1974). ana, anterior neural arch; na, neural arch; nsp, neural spine; pp, parapophysis; rib, rib of fifth free vertebra; sne, supraneural; v1, first free vertebra.

stressed that this clade 38 is not supported by a bootstrap $\geq$ $50 \%$ (Fig. 2), and is supported by a single synapomorphy: anteroventral margin of prevomer situates well posteriorly to anteroventral margin of mesethmoid (32: $0 \rightarrow 1$, only occurring independently in a few taxa outside this clade C38 and only reverted, inside of it, in cypriniforms; the condition of $†$ Santanichthys diasii and of $†$ Clupavus maroccanus is not clear). Fink \& Fink (1981, 1996) considered a similar feature as a synapomorphy of the clade including siluriforms + gymnotiforms + characiforms. Because this feature, as defined in the present work, is seemingly also found in $†$ Sorbininardus apuliensis (e.g.
Taverne, 1999: Fig. 3), in †Chanoides macropoma (e.g. Patterson, 1984: fig. 6B) and in $\dagger$ Lusitanichthys characiformis (e.g. Gayet, 1985: fig. 19; p. 114) (the condition of the two other fossil taxa included in the analysis is not clear), it was scored in the tree of Figure 2 as a synapomorphy of this clade C38. One should however keep in mind that, as explained above, this is the only unambiguous synapomorphy supporting this clade C38 and, thus, that the evidence provided in the present work to support the clade is not strong, although it is stronger than that supporting a close relationship between $\dagger$ Sorbininardus apuliensis and gonorynchiforms (Fig. 2). 


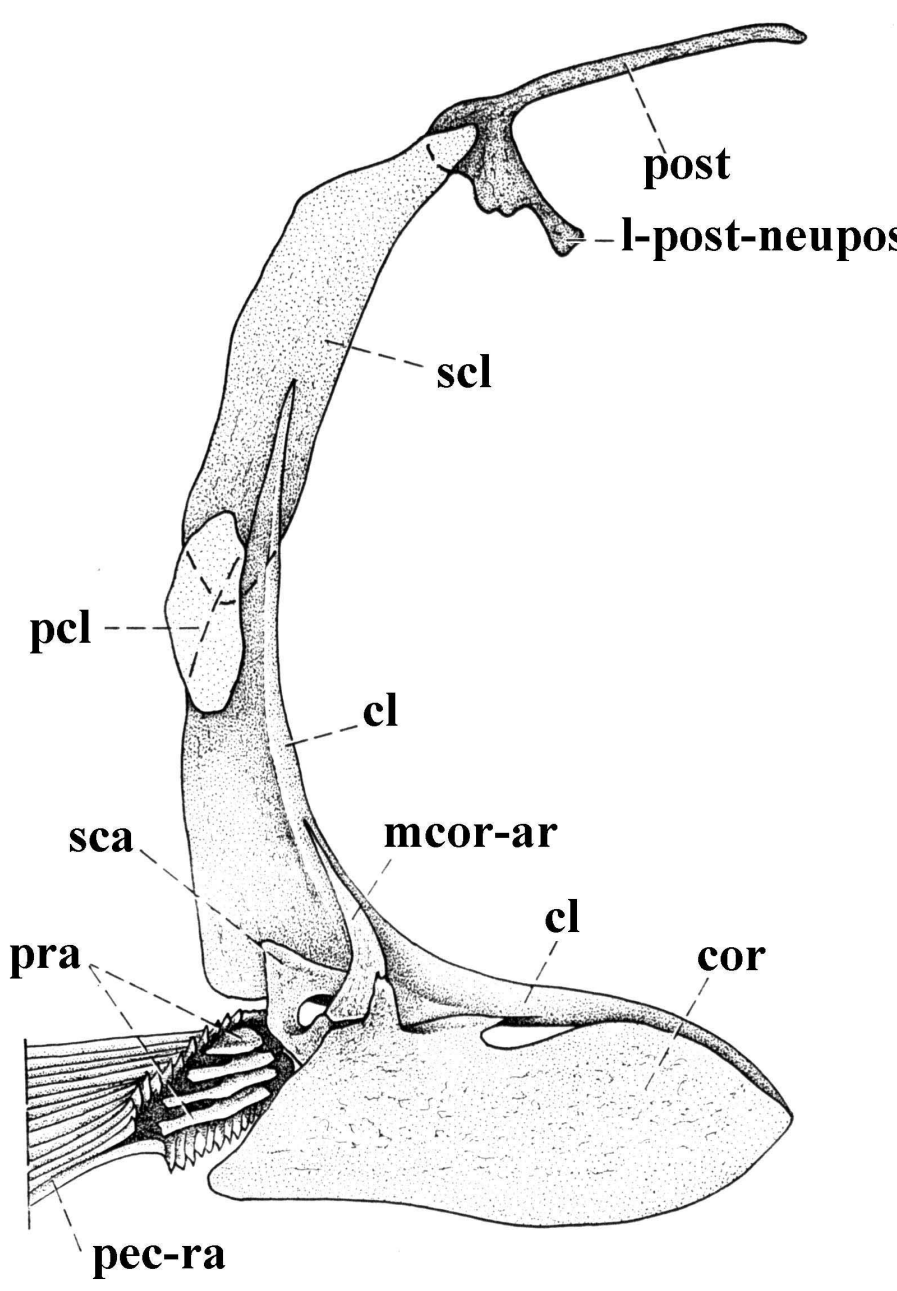

Fig. 28. Mesial view of the pectoral girdle of Hiodon tergisus (modified from Taverne, 1977b). cl, cleithrum; cor, coracoid; l-post-neupos, ossified ligament between posttemporal and posterior region of neurocranium; mcorar, mesocoracoid arch; pcl, postcleithrum; pec-ra, pectoral ray; post, posttemporal; pra, proximal radial; sca, scapula; scl, supracleithrum. of 'rudimentary tripus' (76: $0 \rightarrow 1$; the condition in $\dagger$ Clupavus maroccanus is not clear); presence of 'rudimentary os suspensorium' (78: $0 \rightarrow 1$; the condition in $\dagger$ Santanichthys diasii is not clear). Some features with ambiguous distributions may be interpreted as synapomorphies of this clade if a 'fast optimization' is chosen (e.g. 101: $0 \rightarrow 1$, mesial limb of coracoids or scapulo-coracoids broad and anteroposteriorly elongated) or, alternatively, if a 'slow optimization' is adopted (e.g. 69: $0 \rightarrow 1$, presence of 'rudimentary scaphium').

Clade C40: $[158: 1 \rightarrow 0]$

This clade is supported by a bootstrap value of $78 \%$ and by an unambiguous synapomorphy: the presence of supramaxillae (158: $1 \rightarrow 0$, among the ostariophysans examined, the four fossil taxa included in this clade are the only ones with supramaxillae; some characiforms do have supramaxillae, but this is seemingly a derived feature for the order: e.g. Fink \& Fink, 1981, 1996). Whether these and other 'fossil Otophysi' (sensu Grande \& De Pinna) are placed in a monophyletic group or not, their placement outside the clade including the four extant otophysan orders (Fig. 2) has important phylogenetic and evolutionary implications. For instance, this indicates that the characteristic Weberian apparatus of the members of these four extant otophysan orders was acquired only once, thus supporting the view of authors such as Fink \& Fink (1981, 1996), Fink et al., (1984) and Patterson (1975) and contradicting those of authors such as Gayet (1981, 1985, 1986). We plan to discuss this subject and the respective evolutionary implications of the phylogenetic results obtained in further detail in a future work. $\dagger$ Sorbininardus apuliensis: $[49: 0 \rightarrow 1],[101: 1 \rightarrow 0]$, [246:1 $\rightarrow 0]$

Clade C39: [60:1 $\rightarrow 0],[76: 0 \rightarrow 1],[78: 0 \rightarrow 1]$

This clade is supported by three unambiguous synapomorphies and by a bootstrap value of $76 \%$ (Fig. 2). In principle, it can be named Otophysi, although this places the Sorbininardiformes in a kind of limbo (because they are not Otophysi but, according to the scenario proposed in Fig. 2, they cannot be considered Anatophysi, as this will rend the Anatophysi paraphyletic). The three unambiguous synapomorphies supporting this clade $\mathrm{C} 39$ are: main bodies of parietals (or of parieto-extrascapulars) not widely separated from each other in dorsal view $(60: 1 \rightarrow 0)$; presence $\dagger$ Clupavus maroccanus: No unambiguous features; $\dagger$ Santanichthys diasii: $[55: 0 \rightarrow 1]$

Clade 41: $[80: 0 \rightarrow 1]$

Although there is only a single unambiguous synapomorphy uniting $\dagger$ Chanoides macropoma and $\dagger$ Lusitanichthys characiformis (centrum of third free vertebra markedly shorter than other surrounding centra), it is interesting to notice that this feature is homoplasy free within the numerous fishes included in the cladistic analysis of the present work, and also that this clade C41 is supported by a bootstrap value of $62 \%$.

$\dagger$ Chanoides macropoma: $[28: 0 \rightarrow 1],[65: 1 \rightarrow 0],[206: 1 \rightarrow 0]$; 


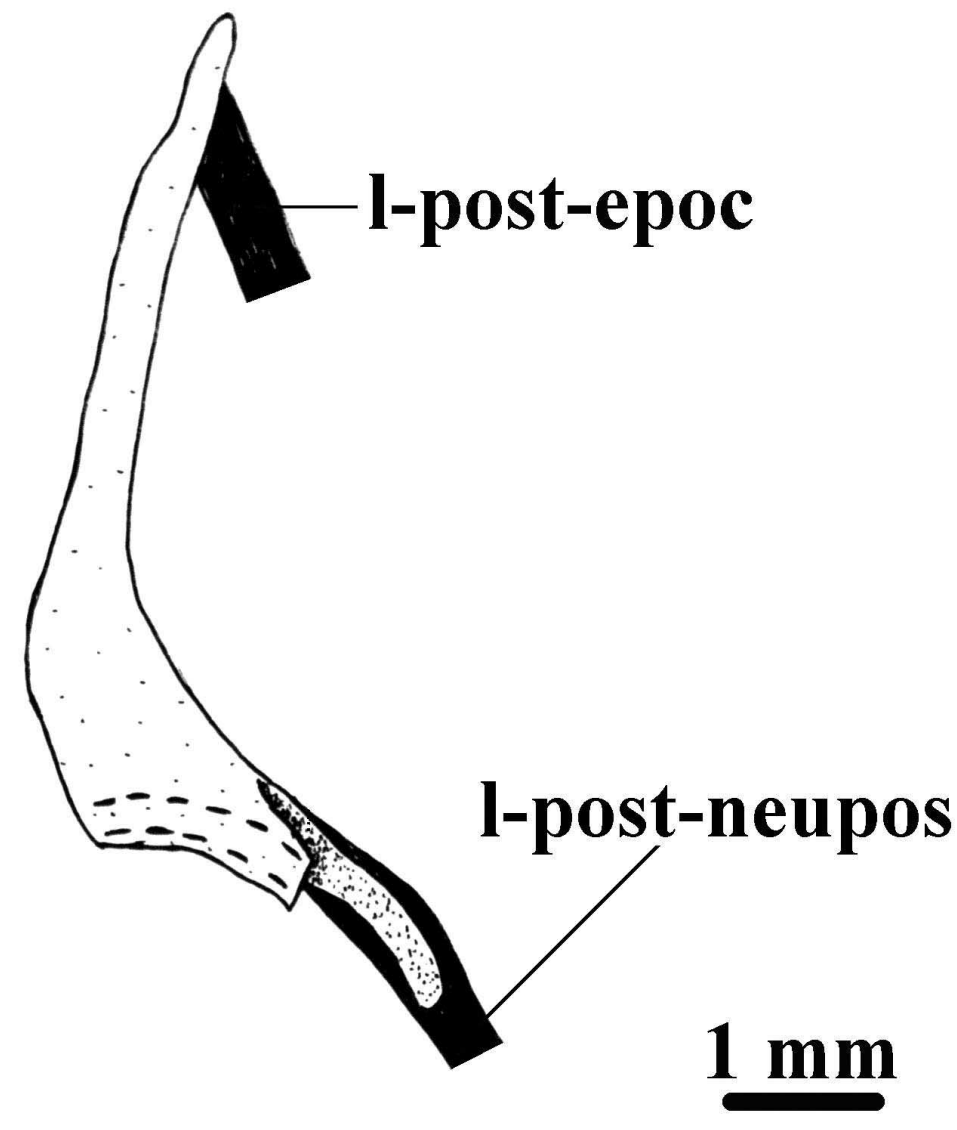

Fig. 29. - Lateral view of the posttemporal of Mormyrus tapirus. l-post-epoc, ligament between posttemporal and epioccipital; l-post-neupos, ligament between posttemporal and posterior region of neurocranium.
Clade 43: $[22: 1 \rightarrow 0],[28: 0 \rightarrow 1],[32: 1 \rightarrow 0]$ $[49: 0 \rightarrow 1],[\mathbf{6 2 : 0} \rightarrow \mathbf{1}],[88: 0 \rightarrow 1],[\mathbf{1 5 0 : 0} \rightarrow \mathbf{1}]$ $[186: 0 \rightarrow 1],[187: 0 \rightarrow 1]$

The grouping of the cypriniform fishes examined is expected (see Fig. 1) and supported by a bootstrap value of $91 \%$. Contrary to the other synapomorphies listed above, the arrector dorsalis not subdivided into different sections $(22: 1 \rightarrow 0)$ and the dorsomesial limb of posttemporal (or posttemporo-supracleithrum) not markedly thin and mesially extended $(88: 0 \rightarrow 1)$ were not proposed as potential cypriniform synapomorphies in previous works.

Clade 44: $[133: 0 \rightarrow 1]$

The assembly of the two taxa examined belonging to the Cobitoidea is expected (see e.g. Siebert, 1987; Liu et al., 2002; Liu, 2004).

Catostomus: $[93: 0 \rightarrow 1],[140: 0 \rightarrow 1],[145: 0 \rightarrow 1]$, [216:0 $\rightarrow 1]$; Cobitis: $[31: 0 \rightarrow 1],[34: 0 \rightarrow 1]$, $[61: 0 \rightarrow 1],[\mathbf{1 3 5 : 0 \rightarrow 1 ]},[136: 0 \rightarrow 1],[191: 0 \rightarrow 1]$, $[192: 0 \rightarrow 1]$

Clade 45: $[150: 1 \rightarrow 2],[182: 0 \rightarrow 1]$

The assembly of the three taxa examined belonging to the Cyprinoidea is expected (see e.g. Siebert, 1987; Liu et al., 2002; Liu, 2004). This clade 45 is supported by a bootstrap value of $56 \%$ (Fig. 2). $\dagger$ Lusitanichthys characiformis: $[43: 0 \rightarrow 1],[75: 1 \rightarrow 0]$, [102:0à1]

Clade 42: [69:1 $\rightarrow 2],[72: 1 \rightarrow 2],[76: 1 \rightarrow 2],[78: 1 \rightarrow 2]$

This clade is supported by a bootstrap value of $75 \%$ and by four unambiguous synapomorphies: presence of characteristic scaphium $(69: 1 \rightarrow 2)$, intercalarium $(72: 1 \rightarrow 2)$, tripus (76: $1 \rightarrow 2$ ) and os suspensorium $(78: 1 \rightarrow 2)$. Apart these features, two other features with ambiguous distributions may be interpreted as synapomorphies of this clade if a 'fast optimization' is chosen (95: $0 \rightarrow 1$, 'ligament between posttemporal and posterior margin of neurocranium' not ossified) or, alternatively, if a 'slow optimization' is chosen (83: $0 \rightarrow 1$, perilymph system of inner ear peculiarly extended posteriorly, constituting sinus impar; coded as '?' in the five fossil taxa included in the cladistic analysis). See comments above for 'Clade C40'.
Opsariichthys: $[137: 0 \rightarrow 1],[140: 0 \rightarrow 1],[142: 0 \rightarrow 1]$, [191:0 $\rightarrow 1]$

Clade 46: $[79: 0 \rightarrow 1]$

This clade 46 is supported by a bootstrap value of $77 \%$ (Fig. 2).

Danio: [223:1 $\rightarrow 0]$, [253:0 $\rightarrow$ 1]; Barbus: No unambiguous features

Clade 47: $[16: 1 \rightarrow 0],[33: 0 \rightarrow 1],[\mathbf{7 0 : 0} \rightarrow \mathbf{1}],[93: 0 \rightarrow 1]$, [131:1 $\rightarrow 0],[160: 1 \rightarrow 0],[174: 1 \rightarrow 0],[206: 1 \rightarrow 0],[242: 1 \rightarrow 0]$

The close relationship between the characiform, gymnotiform and siluriform fishes examined is expected (see Fig. 1) and is supported by a bootstrap value of $77 \%$ (Fig. 2 ). It should be noted that among the nine features 


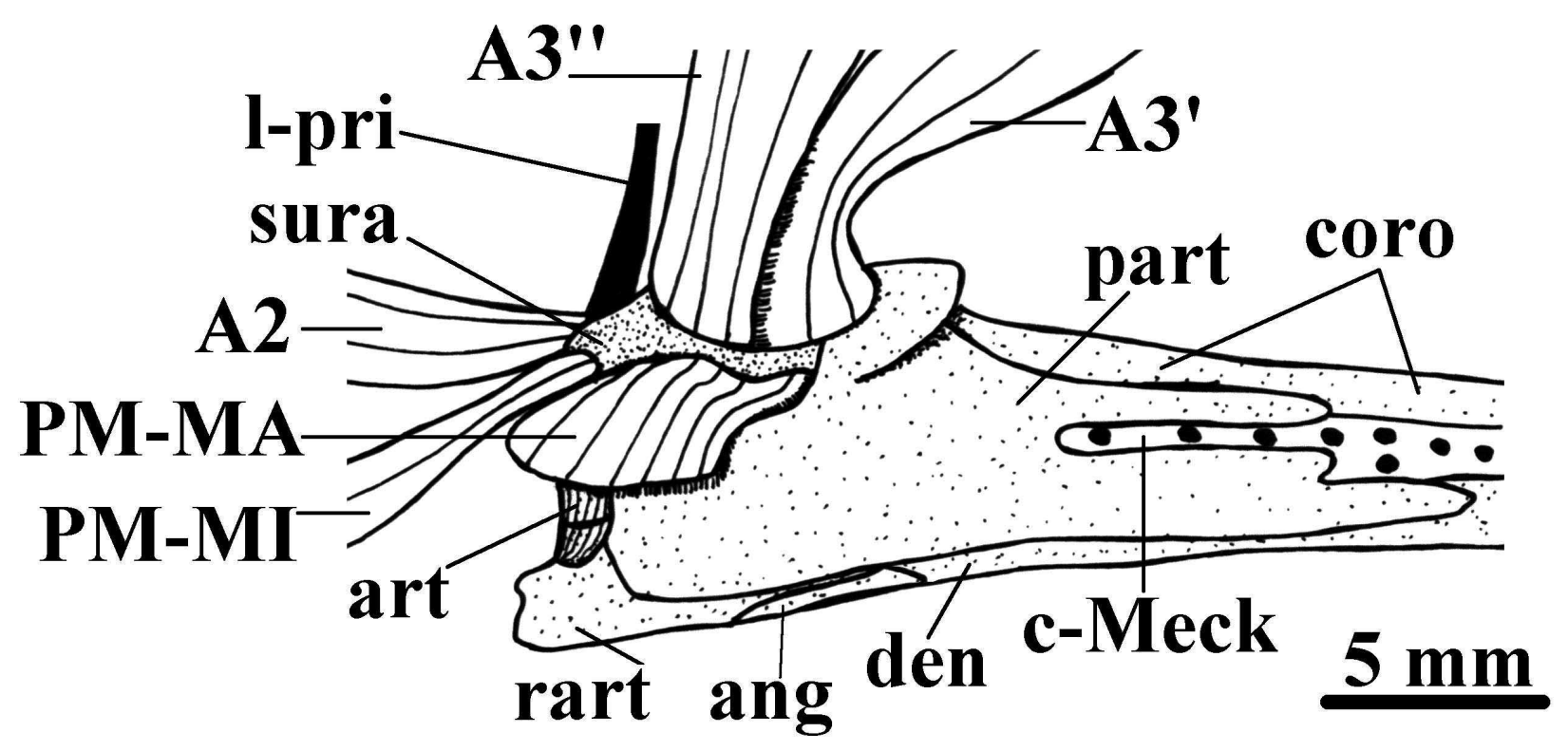

Fig. 30. Mesial view of the left mandible and adductor mandibulae of Lepisosteus osseus, the primordial ligament is also shown; mandibular teeth were removed. A2, A3', A3", sections of adductor mandibulae; ang, angular; art, articular; c-Meck, Meckel's cartilage; coro, coronoid; den, dentary bone; l-pri, primordial ligament; part, prearticular; PM-MA, PM-MI, palatomandibularis major and minor; rtart, retroarticular; sura, surangular.

characterizing this clade, six concern reversions to the plesiomorphic condition. Although this distribution appears to be the most parsimonious one by the strict application of the principle of parsimony, in such a discussion one should also analyze carefully each feature and discuss it in a critical way. That the first fishes of this clade C47 suffered a truly 'explosive morphological reversion', with two thirds of the characters diagnosing this clade being reversions, seems, at least at first sight, rather unsound. However, this does not mean necessarily that there is something wrong with this clade. In fact, the grouping of characiforms, gymnotiforms and siluriforms in a monophyletic unit has been strongly and repeatedly supported by numerous morphological (e.g. Fink, 1981, 1996; Lauder \& Liem; Arratia, 1992; this study) and molecular (e.g. Dimmick \& Larson, 1996; Saitoh et al.; Lavoué et al.) phylogenetic studies in the last years. What we think might be happening here is that by strictly applying the principle of parsimony, the absence of premaxillary (174, state 1) and mandibular (242, state 1) teeth in gonorynchiforms, cypriniforms and the fossil taxa examined is interpreted as the plesiomorphic condition for ostariophysans, later reverted in this clade 47. However, this could be an example of one of those cases in which evolution might not compulsorily work by following strict parsimony. That is, one can suppose, for instance, that these teeth were independently lost in gonorynchiforms, in cypriniforms, and in the fossil groups included in the cladistic analysis, instead of being completely lost in an evolutionary line of fishes of which part later completely reacquired them. The principle of parsimony may well be the common rule, and we do think that this is very likely the case (thence our commitment to phylogenetic analyses following the cladistic methodology), but there is no prove, so far, that exceptions to this rule are completely impossible in evolution. The example concerning the loss of teeth referred just above might be one of those exceptions.

Clade 48: $[\mathbf{5 4 : 0 \rightarrow 1}],[55: 0 \rightarrow 1],[\mathbf{7 3 : 0} \rightarrow \mathbf{1}],[95: 01 \rightarrow 0]$, $[145: 0 \rightarrow 1],[167: 0 \rightarrow 1],[191: 0 \rightarrow 1],[205: 0 \rightarrow 1],[265: 0 \rightarrow 1]$

The grouping of the characiform fishes examined is expected (see Fig. 1) and is supported by a bootstrap value of $99 \%$ (Fig. 2). The present cladistic analysis did not support, but did neither contradict, the grouping of the distichodontid genera Distichodus and Xenocharax, nor the close relationship between these distichodontid taxa and the citharinid Citarhinus, as would be expected according to the works of authors such as Vari (1979), Orti \& Meyer (1997) and Buckup (1998). 


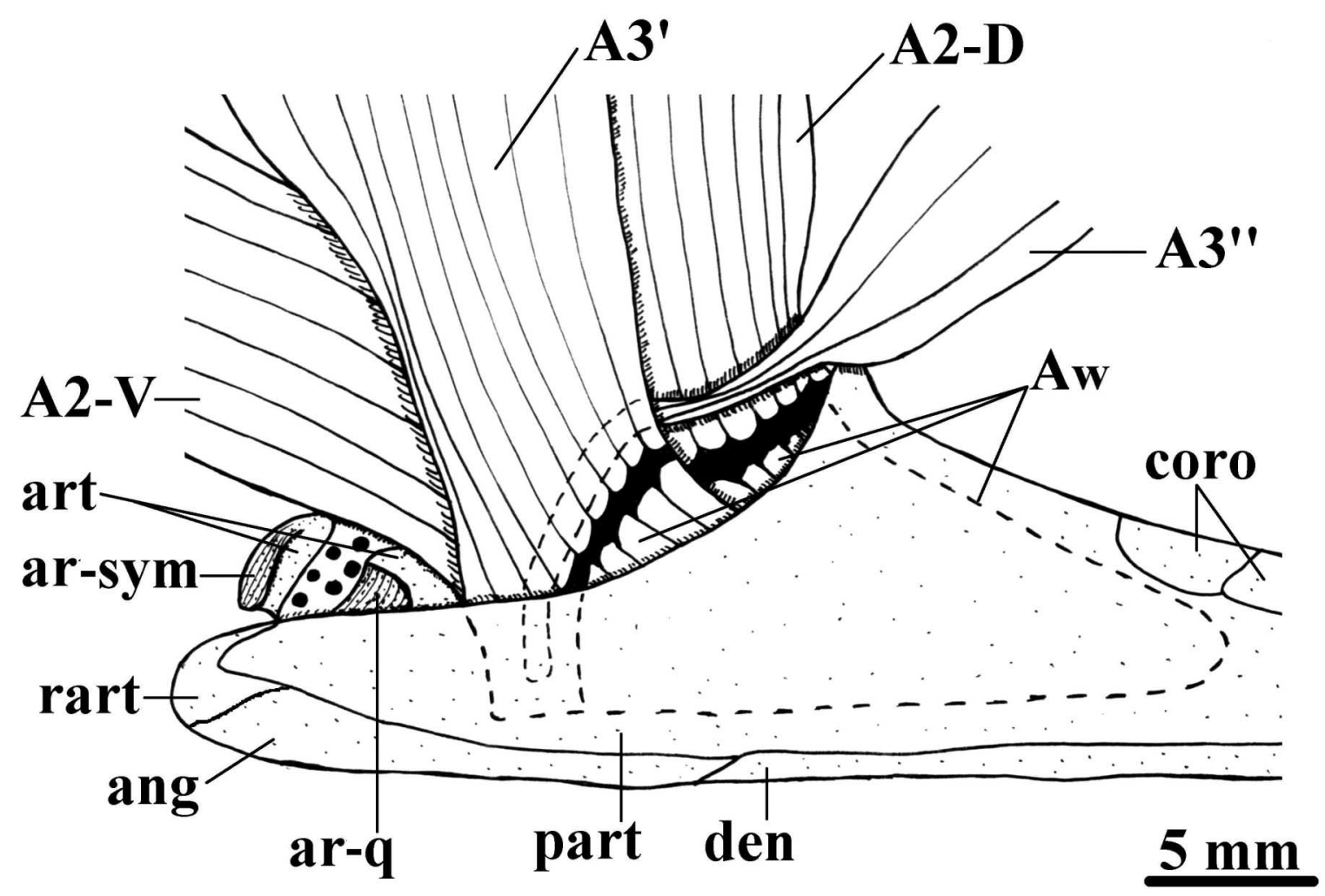

Fig. 31. Mesial view of the left mandible and adductor mandibulae of Amia calva, the levator maxillae superioris 3 and 4 are not shown; mandibular teeth were removed. A2-D, A2-V, A3', A3", Aw, sections of adductor mandibulae; ang, angular; ar-q, ar-sym, articular articulations for quadrate and for symplectic; art, articular; coro, coronoid; den, dentary bone; part, prearticular; rtart, retroarticular.

Xenocharax: $[140: 0 \rightarrow 1],[155: 1 \rightarrow 0],[193: 1 \rightarrow 0]$; Distichodus: $[1: 1 \rightarrow 0],[128: 0 \rightarrow 1],[133: 0 \rightarrow 1],[212: 0 \rightarrow 1]$, $[243: 0 \rightarrow 1]$; Citharinus: $[49: 0 \rightarrow 1],[67: 0 \rightarrow 1],[111: 1 \rightarrow 0]$, $[136: 0 \rightarrow 1],[165: 0 \rightarrow 1],[216: 0 \rightarrow 1] ;$ Brycon: $[43: 0 \rightarrow 1]$, $[88: 0 \rightarrow 1],[111: 1 \rightarrow 0],[128: 0 \rightarrow 1],[140: 0 \rightarrow 1],[155: 1 \rightarrow 0]$, $[165: 0 \rightarrow 1],[205: 1 \rightarrow 0],[206: 0 \rightarrow 1]$

Clade 49: $[34: 0 \rightarrow 1],[61: 0 \rightarrow 1],[79: 0 \rightarrow 1],[94: 0 \rightarrow 1]$, [190:0 $\rightarrow 1],[225: 0 \rightarrow 1]$

As can be seen in Figure 1, most researchers now agree that gymnotiforms and siluriforms are sister-groups. However, this sister-group relationship has been mostly supported by morphological evidence (e.g. Fink \& Fink 1981, 1996; Lauder \& Liem; this study). Some molecular cladistic analyses published in the last years support, instead, a sistergroup relationship between gymnotiforms and characiforms (e.g. Dimmick \& Larson; Saitoh et al.; Peng et al., 2006) or possibly between characiforms and siluriforms (e.g. Lavoué et al.). The present cladistic analysis does provide strong evidence for a clade including siluriforms and gymnotiforms (Fig. 2). This is because it did not only corroborated many of the synapomorphies provided by Fink \& Fink $(1981,1996)$ to support such a clade $(34: 0 \rightarrow 1 ; 61: 0 \rightarrow 1 ; 79: 0 \rightarrow 1 ; 94$ : $0 \rightarrow 1$ ), but also provided additional synapomorphies to support this clade, e.g. the ossification of the ligament connecting the suspensorium to the ethmoid region (190: $0 \rightarrow 1$ ) and the interhyal (ossified or not) being connected by ligaments to both the hyoid arch and the suspensorium (225: $0 \rightarrow 1$ ) (see Appendix 2). In fact, this clade C49 is supported by a bootstrap value of $93 \%$ (Fig. 2).

Clade 50: [39:0 $\rightarrow$ 1], [130:0 $\rightarrow \mathbf{1}],[140: 0 \rightarrow 1],[180: 0 \rightarrow 1]$, [216:0 $\rightarrow 1]$

This clade is expected (see Fig. 1) and is supported by a bootstrap value of $95 \%$. The second and third synapomorphies listed above (130: $0 \rightarrow 1$, levator arcus palatini markedly lateral to all bundles of adductor mandibulae; 140: $0 \rightarrow 1$, insertion of a significant part of adductor arcus palatini on lateral surface of suspensorium) concern muscular features that were not proposed as potential gymnotiform synapomorphies in previous works.

Brachyhypopomus: $[1: 1 \rightarrow 0],[174: 0 \rightarrow 1],[242: 0 \rightarrow 1]$ 


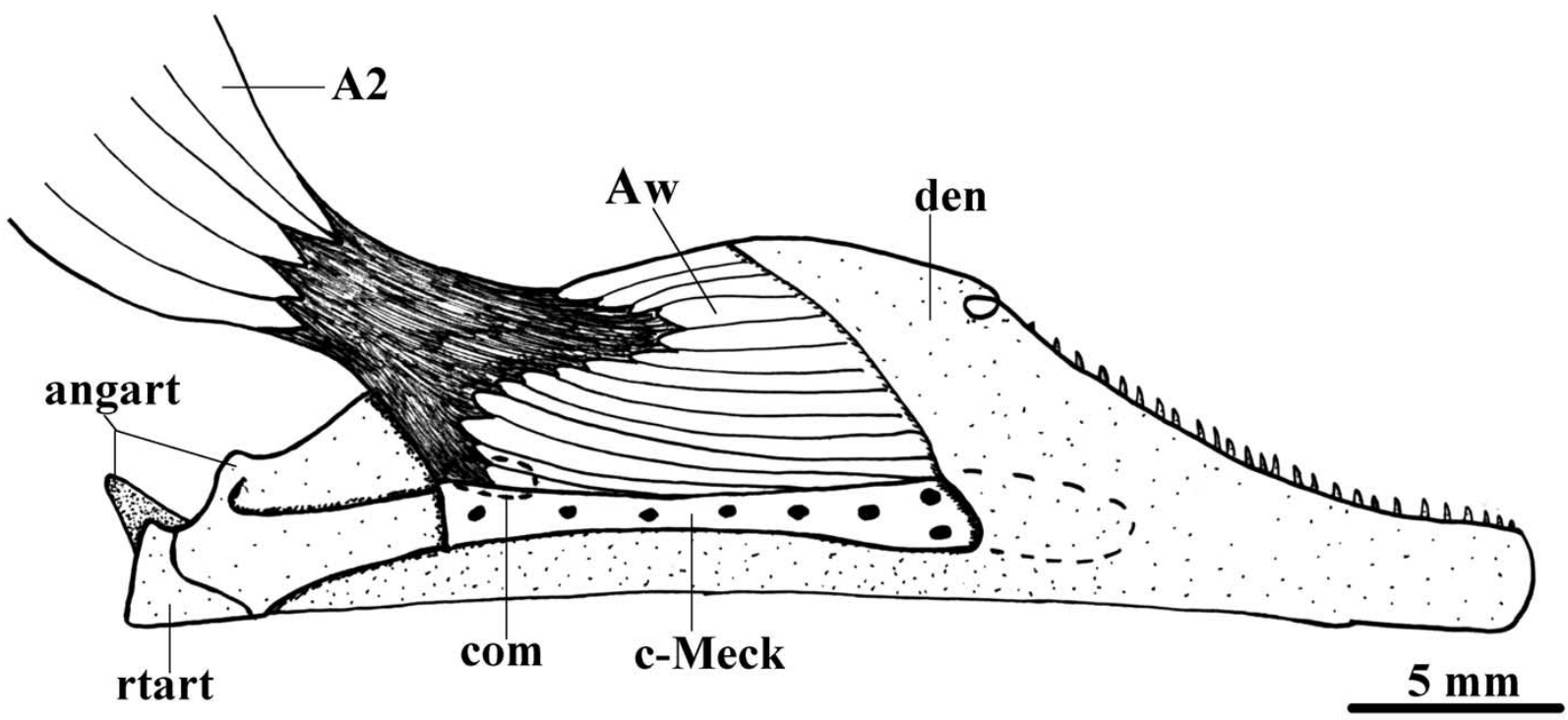

Fig. 32. Mesial view of the left mandible and adductor mandibulae of Alepocephalus rostratus. A2, Aw, sections of adductor mandibulae; angart, angulo-articular; c-Meck, Meckel's cartilage; com, coronomeckelian bone; den, dentary bone; rtart, retroarticular.

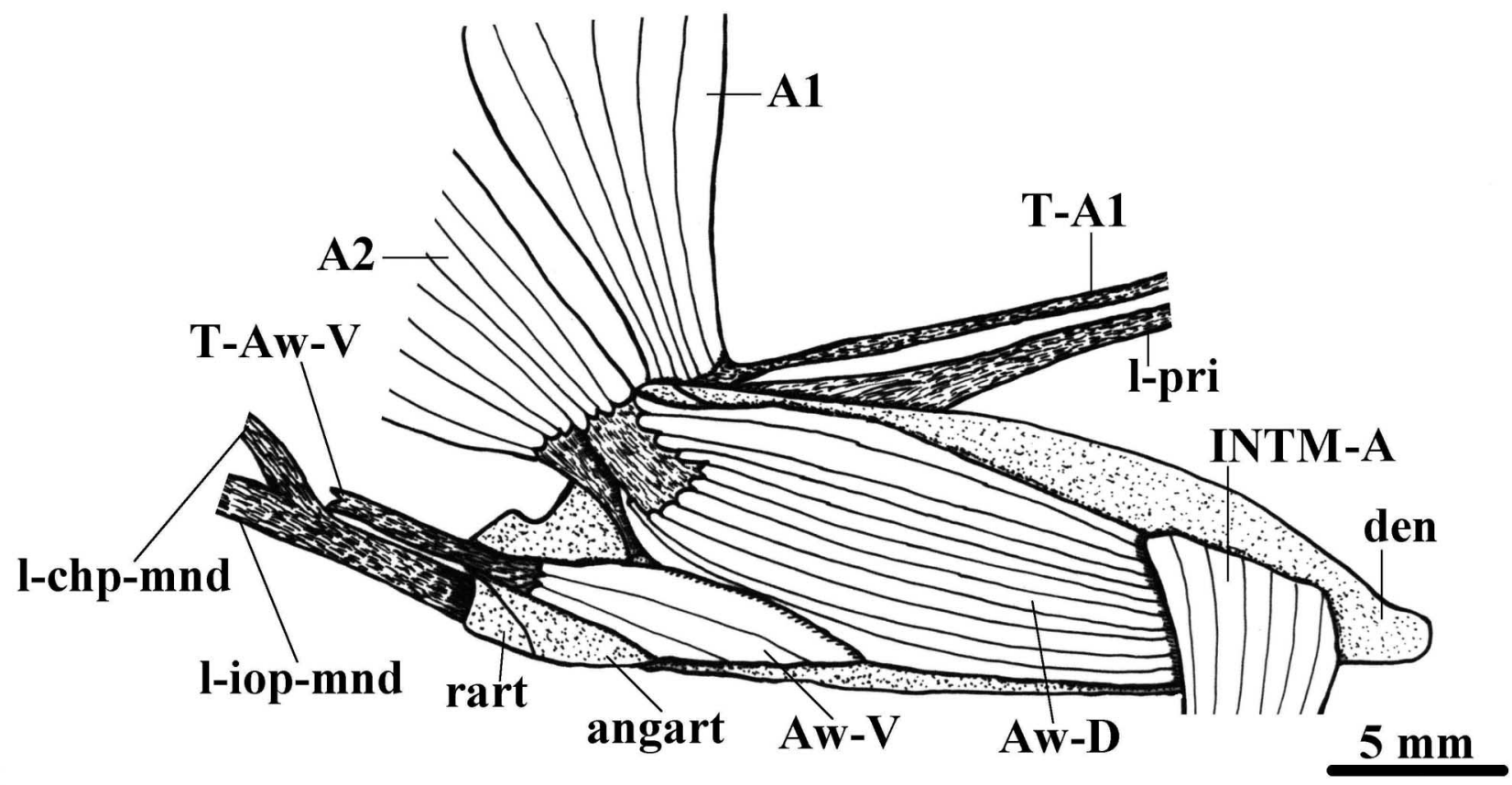

Fig. 33. Mesial view of the left mandible and adductor mandibulae of Aulopus filamentosus, the anterior intermandibularis and the primordial ligament, as well as the ligaments between the mandible, posterior ceratohyal and interopercle, are also shown; mandibular teeth were removed. A1, A2, Aw-D, Aw-V, sections of adductor mandibulae; angart, angulo-articular; den, dentary bone; l-chp-mnd, ligament between posterior ceratohyal and mandible; l-iop-mnd, ligament between interopercle and mandible; l-pri, primordial ligament; T-A1, tendon of A1; T- Aw-V, tendon of Aw-V; rtart, retroarticular. 


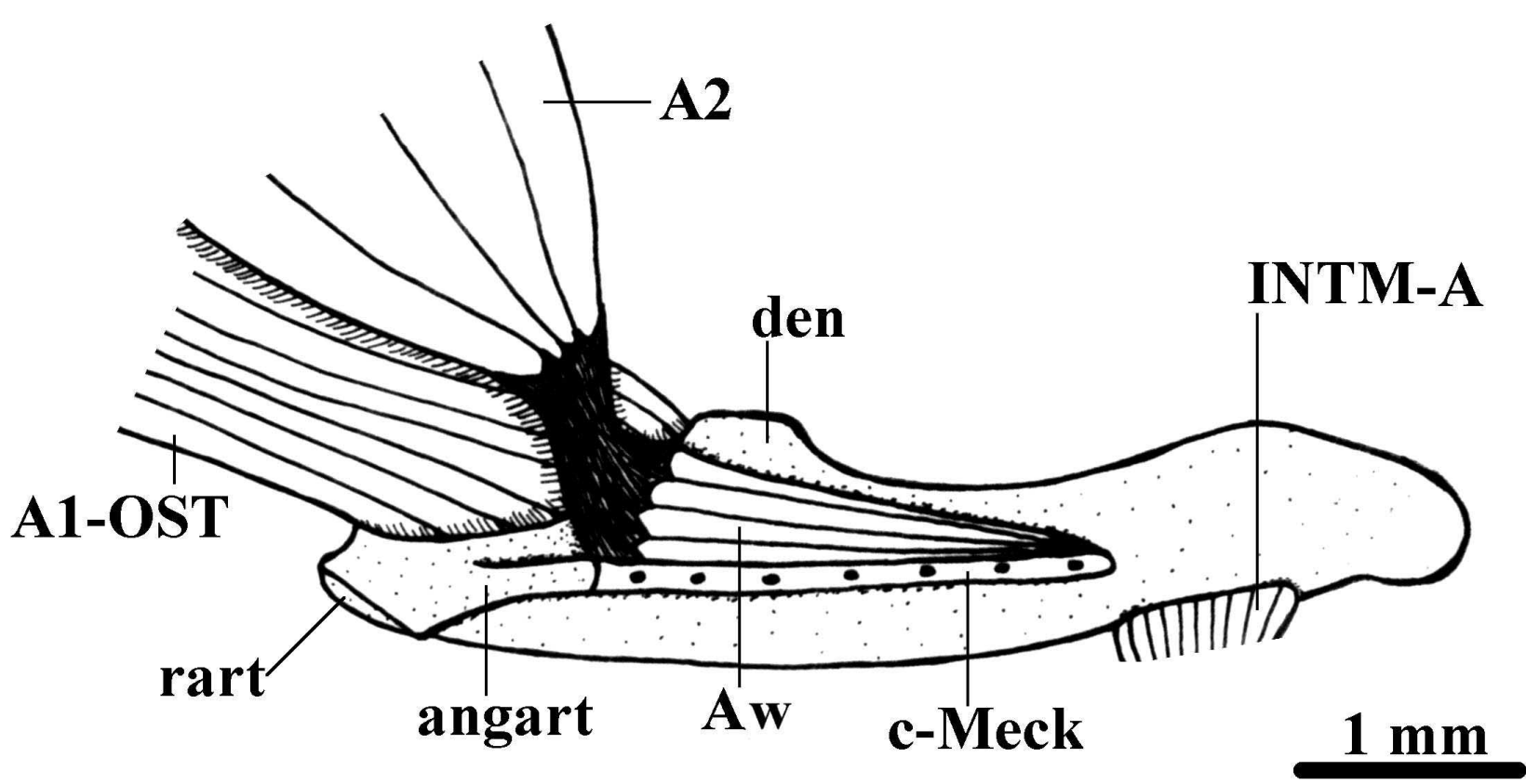

Fig. 34. Mesial view of the left mandible and adductor mandibulae of Danio rerio, the antertior intermandibularis is also shown; the adductor mandibulae A0 was removed. A1-OST, A2, Aw, sections of adductor mandibulae; angart, angulo-articular; c-Meck, Meckel's cartilage; den, dentary bone; INTM-A, anterior intermandibularis; rtart, retroarticular.

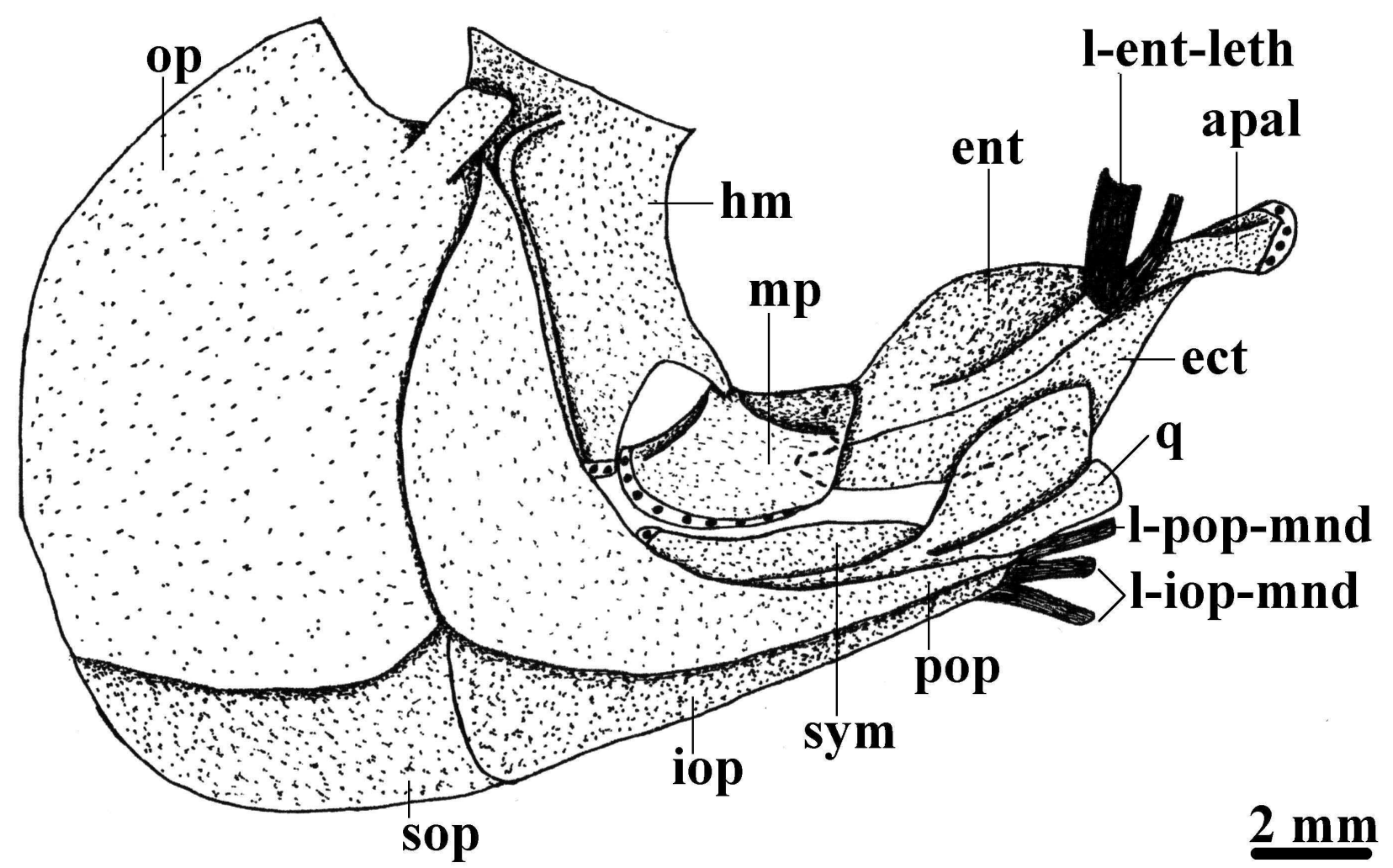

Fig. 35. Lateral view of the right suspensorium of Chanos chanos. apal, autopalatine; ect, ectopterygoid; ent, entopterygoid; hm, hyomandibula; iop, interopercle; l-ent-leth, ligament between entopterygoid and lateral-ethmoid; l-iop-mnd, ligament between interopercle and mandible; l-pop-mnd, ligament between preopercle and mandible; mp, metapterygoid; op, opercle; pop, preopercle; q, quadrate; sop, subopercle; sym, symplectic. 
Clade 51: $[13: 0 \rightarrow 1],[151: 0 \rightarrow 1]$

Authors such as De La Hoz (1974), Albert \& Campos-da-Paz (1998) and Albert (2001) defended that the sternopygid gymnotiforms are more closely related to hypopomids than to gymnotids. Authors such as Triques (1993), Gayet et al., (1994) and Alves-Gomez et al., (1995) have, instead, argued that hypopomids are more closely related to gymnotids than to sternopygids. Curiously, the two synapomorphies listed above, which concern muscular features that are homoplasy free within the fishes examined, support a closer relationship between the sternopygid Sternopygus and the gymnotid Gymnotus than between any of these taxa and the hypopomid Brachyhypopomus. This clade C51 is supported by a bootstrap value of $57 \%$ (Fig. 2).

Sternopygus: $[16: 0 \rightarrow 1],[193: 1 \rightarrow 0],[254: 0 \rightarrow 1]$; Gymnotus: [94:1 $\rightarrow 0]$

Clade 52: $[22: 1 \rightarrow 0],[48: 0 \rightarrow 1],[49: 0 \rightarrow 1],[\mathbf{5 9 : 0} \rightarrow \mathbf{1}]$, $[74: 0 \rightarrow 1],[86: 0 \rightarrow 1],[88: 0 \rightarrow 1],[92: 0 \rightarrow 1],[99: 0 \rightarrow 1]$, [100:0 $\rightarrow 1],[103: 0 \rightarrow 1],[111: 1 \rightarrow 0],[136: 0 \rightarrow 1],[201: 0 \rightarrow 1]$, [208:0 $\rightarrow 1],[247: 0 \rightarrow 1],[256: 0 \rightarrow 1],[\mathbf{2 6 6 : 0} \rightarrow \mathbf{1}]$

The assembly of the siluriform fishes examined is expected (see Fig. 1) and is supported by a bootstrap value of $100 \%$. Some of the features listed above have been listed in previous phylogenetic works as potential synapomorphies of the Siluriformes (e.g. 49: $0 \rightarrow 1 ; 59: 0 \rightarrow 1 ; 74: 0 \rightarrow 1 ; 86$ : $0 \rightarrow 1 ; 88: 0 \rightarrow 1$; 99: $0 \rightarrow 1 ; 100: 0 \rightarrow 1 ; 136: 0 \rightarrow 1 ; 247: 0 \rightarrow 1)$ 201: $0 \rightarrow 1 ; 208: 0 \rightarrow 1 ; 256.0 \rightarrow 1 ; 266: 0 \rightarrow 1$; see e.g. Regan, 1911; Chardon, 1968; Roberts, 1973; Lundberg, 1975; Howes, 1983ab; Fink \& Fink, 1981, 1996; Arratia, 1987; Schaefer, 1990; Mo, 1991; Arratia, 1992; De Pinna, 1993, 1998; Diogo, 2004) but others seemingly constitute additional potential synapomorphies to diagnose the order, such as: arrector dorsalis not subdivided into different sections $(22: 1 \rightarrow 0)$; frontal and autopterotic not contacting in dorsal view $(48: 0 \rightarrow 1)$; absence of 'ligament between posttemporal and posterior margin of neurocranium' (92: $0 \rightarrow 1$ ); presence of coracoid bridge (103: $0 \rightarrow 1)$; adductor mandibulae attaching exclusively on mandible and/or primordial ligament, near its mandibular insertion (111: $1 \rightarrow 0$ ). Within this clade C52, the phylogenetic scenario shown in Fig. 2 is essentially similar to that of Diogo's recent work. As Diogo has already provided a detailed discussion of the siluriform clades obtained in the present work, as well as a comparison with previous works on catfish phylogeny, we will only list the synapomorphies supporting these clades C53, C54, C55, C56, C57, C58 and C59, which are supported by bootstrap values of 51\%, 73\%, 63\%, 53\%, 66\%, 70\% and $54 \%$, respectively (Fig. 2).
Diplomystes: [137:1 $\rightarrow 0]$, [155:0 $\rightarrow 1$ ] Clade 53: $[16: 0 \rightarrow 1]$, [132:1 $\rightarrow 0]$, [138:1 $\rightarrow 0$ ]; Clade 54: [128:0 $\rightarrow 1],[133: 0 \rightarrow 1]$; Callichthys: $[12: 0 \rightarrow 1],[91: 0 \rightarrow 1],[101: 0 \rightarrow 2],[174: 0 \rightarrow 1]$, [256:1 $\rightarrow 0$ ], [257:0 $\rightarrow 1$ ]; Clade 55: [207:0 $\rightarrow 1]$, [216:0 $\rightarrow 1$ ], [220:0 $\rightarrow 1],[252: 0 \rightarrow 1]$; Nematogenys: $[103: 1 \rightarrow 0]$, [138:2 $\rightarrow 1],[140: 0 \rightarrow 1],[149: 0 \rightarrow 1],[230: 0 \rightarrow 1],[231: 0 \rightarrow 1]$, [267:0 $\rightarrow 1]$; Trichomycterus: $[145: 0 \rightarrow 1],[147: 0 \rightarrow 1]$; Clade 56: $[5: 0 \rightarrow 1],[25: 0 \rightarrow 1],[267: 0 \rightarrow 1]$; Cetopsis: $[51: 0 \rightarrow 1]$, [99:1 $\rightarrow 0],[122: 0 \rightarrow 1],[141: 0 \rightarrow 1],[144: 0 \rightarrow 1],[214: 1 \rightarrow 0]$; Clade 57: [26:0 $\rightarrow 1$ ]; Silurus: $[38: 0 \rightarrow 1]$, [48:1 $\rightarrow 0$ ], [256:1 $\rightarrow 0$ ]; Clade 58: [16:1 $\rightarrow 0$ ], [101:0 $\rightarrow 2$ ]; Chrysichthys: [193:1 $\rightarrow 0$ ]; Clade 59: [189:0 $\rightarrow 1$ ]; Bagrus: $[102: 0 \rightarrow 1]$; Pimelodus: $[42: 0 \rightarrow 1],[48: 1 \rightarrow 0],[152: 0 \rightarrow 1],[205: 0 \rightarrow 1]$

\section{CONCLUSIONS}

The elopomorphs appear grouped in a monophyletic clade, which is the sister-group of the clade including all the other teleosts included in the cladistic analysis. The osteoglossomorphs examined are also included in a monophyletic clade, which appears as the sister-group of the remaining non-elopomorph teleostean fishes examined. The clupeomorph and ostariophysan fishes are grouped together, thus contradicting the results of some recent molecular cladistic analyses placing the Alepocephaloidea inside the Otocephala. In fact, the monophyly of the Argentiniformes (Alepocephaloidea + Argentinoidea) is well supported in the cladistic analysis of the present work. This cladistic analysis also provides strong for the monophyly of the Alepocephaloidea, of the Argentinoidea, of the Galaxioidea + Osmeroidea, and of the Esociformes. However, it does not provide strong evidence to resolve the relationships between the Argentiniformes, Salmoniformes, Esociformes, Osmeriformes and Neoteleostei, although it does indicate that the salmoniforms might be closely related to the Neoteleostei and that the Esociformes and the Osmeriformes might constitute a monophyletic unit. The monophyly of the Cypriniformes + Characiformes + Gymnotiformes + Siluriformes, of the Characiformes + Gymnotiformes + Siluriformes and of the Gymnotiformes + Siluriformes is well supported.

\section{ACKNOWLEDGEMENTS}

We specially thank J. Snoeks, E. Vreven, and the late G.G. Teugels (Musée Royal de l'Afrique Centrale), P. Laleyé (Université Nationale du Bénin), R. Vari, J. Williams and S. Jewett (National Museum of Natural History), T. Grande (Field Museum of Natural History), D. Catania (California Academy of Sciences), M. Stiassny (American Museum of 
Natural History), Mark Sabad and J. Lundberg (Academy of Natural Sciences of Philadelphia), L. Page and M. Retzer (Illinois Natural History Survey) and P. Pruvost and G. Duhamel (Museum National d'Histoire Naturelle) for kindly providing a large part of the specimens analyzed for this study. We are particularly grateful to L. Taverne and Michel Chardon, who undertook a revision of a previous version of the paper and contributed to it with valuable comments and suggestions.

DIOGO, R.; DOADRIO, I. \& VANDEWALLE, P. Filogenia de teleosteos basada en características osteológicas y miológicas. Int. J. Morphol., 26(3):463-522, 2008.

RESUMEN: A pesar de los avances realizados en relación a la filogenia de los teleósteos en las últimas décadas, los estudios recientes siguen planteando cuestiones relativas a los altos niveles de relación de este notable grupo de diversos peces. El principal objetivo del presente trabajo es contribuir a aclarar los altos niveles de relación de teleósteos. Con este propósito, se llevó a cabo un análisis cladístico entre 70 taxones terminales de 20 órdenes diferentes y 271 caracteres morfológicos, principalmente en relación con estructuras osteológicas y miológicas de la región cefálica, cintura escapular y las aletas anteriores y vértebras. En el cladograma de consenso obtenido, los elopomorfos aparecen como los teleósteos más básicos existentes. Los osteoglosomorfos incluidos en el análisis se agrupan en un clado monofilético, que es el grupo hermano de los restantes teleósteos no elopomorfos. Los Otocephala, los clupeiformes, y los ostariofisios aparecen como clados monofiléticos, contradiciendo así los resultados de algunos análisis moleculares cladísticos recientes incluyendo los Alepocephalidae dentro Otocephala. De hecho, la monofilia de los Argentiniformes (Alepocephaloidea + Argentinoidea) está bien apoyada por el análisis cladístico del presente trabajo. Este análisis cladístico también proporciona apoyo para la monofilia de los Alepocephaloidea, de los Argentinoidea, de los Galaxioidea + Osmeroidea, y de los Esociformes. Sin embargo, no proporciona pruebas sólidas para resolver las relaciones entre los Argentiniformes, Salmoniformes, Esociformes, Osmeriformes y Neoteleostei, aunque indica que los salmoniformes podrían estar estrechamente relacionados con los Neoteleostei, y que los Esociformes y los Osmeriformes podrían constituir una unidad monofilética. La monofilia de los Cypriniformes + Characiformes + Gymnotiformes + Siluriformes, de los Characiformes + Gymnotiformes + Siluriformes y de los Gymnotiformes + Siluriformes está bien apoyada. Teleósteos.

PALABRAS CLAVE: Elopomorfo; Euteleósteos; Miología; Otocephala; Osteoglosomorfos; Osteología; Filogenia;

\section{Appendix 1: Material Examined}

A list of the specimens examined of the extant genera included in the cladistic analysis is given below; the trypsine-cleared and alizarine-stained (cands) or alcohol fixed (alc) condition of the studied fishes is given in parentheses following the number of specimens dissected (AMNH: American Museum of Natural History; ANSP: Academy of Natural Sciences of Philadelphia; CAS: California Academy of Sciences; FMNH: Field Museum of Natural History; INHS: Illinois Natural History Survey; LFEM: Laboratory of Functional and Evolutionary Morphology of the University of Liège; MNCN: Museo Nacional de Ciencias Naturales; MNHN: Museum National d'Histoire Naturelle; MRAC: Musée Royal de l'Afrique Centrale; UNB: Université Nationale du Bénin; USNM: National Museum of Natural History):

Outgroup: Amia calva: MNCN 35961, 2 (alc), 1 (cands). Lepisosteus osseus: ANSP 107961, 2 (alc); ANSP 172630, 1 (alc); MNCN 246557, 1 (cands). Lepisosteus platyrhincus: AMNH 74789, 2 (alc).

Osteoglossomorpha: Hiodon tergisus: MNCN 36019, 3 (alc). Mormyrus niloticus: LFEM, 1 (alc). Mormyrus tapirus: MNCN 80593, 3 (alc); MNCN 85283, 1 (alc). Pantodon buchholzi: MNCN 73493, 4 (alc). Xenomystus nigri: MNCN 227824, 25 (alc).

Elopomorpha: Albula vulpes: MNCN 52124, 2 (alc). Anguilla anguilla: MNCN 41049, 3 (alc). Elops lacerta: LFEM, 2 (alc). Elops saurus: MNCN 48752, 2 (alc). Conger conger: MNCN 1530, 5 (alc). Eurypharynx pelecanoides: AMNH 44315, 1 (alc); AMNH 44344, 1 (alc). Megalops cyprinoides: MNCN 48858, 3 (alc). Notacanthus bonaparte: MNCN 107324, 3 (alc).

Clupeomorpha: Denticeps clupeoides: MRAC 76-032-P-1, 2 (alc). Engraulis encrasicolus: MNCN 68048, 2 (alc); MNCN 65097, 8 (alc); MNCN 1099, 3 (alc). Engraulis sp: MNCN 48896, 3 (alc). Ethmalosa fimbriata: MNCN 48865, 3 (alc). Ilisha fuerthii: MNCN 49338, 8 (alc). Thryssa setirostris: MNCN 49294, 2 (alc).

Ostariophysi: Bagrus bajad: LFEM, 1 (alc), 1 (cands). Bagrus docmak: MRAC 86-07-P-512, 1 (alc). Barbus barbus: LFEM, 1 (cands). Barbus guiraonis: MNCN 245730, 3 (alc). Brachyhypopomus brevirostris: LFEM, 2 (alc). Brachyhypopomus $s p$ : INHS 89761, 2 (alc). Brycon guatemalensis: MNCN 180536, 3 (alc). Brycon henni: CAS 39499, 1 (alc). Callichthys callichthys: USNM 226210, 2 (alc). Catostomus commersonii: MNCN 36124, 10 (alc). Citharinus sp.: 86-016-P-72, 3 (alc). Cetopsis coecutiens: USNM 265628, 2 (alc). Chanos chanos: USNM 347536, 1 (alc), LFEM, 1 (alc). Chrysichthys auratus: UNB, 2 (alc). Chrysichthys nigrodigitatus: LFEM, 1 (cands). Cobitis paludica: MNCN 248076, 7 (alc). Cromeria nilotica: MRAC P.141098, 2 (alc). Danio rerio: LFEM, 5 (alc). Diplomystes chilensis: LFEM, 3 (alc). Distichodus notospilus: MRAC A0-048-P-2630, 3 (alc). Gonorynchus gonorynchus: LFEM, 2 (alc). Gonorynchus greyi: FMNH 103977 , 1 (alc). Grasseichthys gabonensis: MRAC 73-002-P-264, 3 (alc). Gymnotus carapo: ILNS 35493, 2 (alc); MNCN 115675, 2 (alc). 
Kneria wittei: MRAC P-33512, 2 (alc). Nematogenys inermis: USNM 084346, 2 (alc). Opsariichthys uncirostris: MNCN 56668, 3 (alc). Parakneria abbreviata: MRAC 99-090-P-703, 3 (alc). Phractolaemus ansorgii: MRAC P.137982, 3 (alc). Pimelodus blochii: LFEM, 2 (alc), 1 (cands). Silurus aristotelis: LFEM, 2 (alc). Silurus glanis: LFEM, 2 (alc). Sternopygus macrurus: CAS 48241, 1 (alc); INHS 62059, 2 (alc). Trichomycterus areolatus: LFEM, 2 (alc). Xenocharax spilurus: MRAC A0-048-P-2539, 3 (alc).

Euteleostei: Alepocephalus rostratus: MNCN 108199, 2 (alc). Argentina brucei: USNM 239005, 2 (alc). Argentina sphyraena: MNCN 001134, 12 (alc); MNCN 78530, 5 (alc). Astronesthes niger: MNCN 1102, 1 (alc). Aulopus filamentosus: MNCN 1170, 6 (alc). Bathylagus euryops: MNCN 124597, 1 (alc). Bathylagus longirostris: USNM 384823, 2 (alc). Bathylagus tenuis: MNHN 2005-1978, 2 (alc). Chlorophthalmus agassizi: MNCN 1193, 3 (alc); MNCN 1182, 5 (alc). Coregonus lavaretus: MNCN 75424, 1 (alc). Coregonus tugun: MNCN 75422, 2 (alc). Esox lucius: MNCN 197706, 5 (alc). Galaxias maculatus: USNM 344889, 2 (alc). Osmerus eperlanus: MNCN 193795, 11 (alc). Osmerus mordax: USNM 32565, 2 (alc). Plecoglossus altivelis: MNCN 192036, 1 (alc). Retropinna retropinna: AMNH 30890, 1 (alc). Salmo trutta: MNCN 136179, 2 (alc), 1 (cands); MNCN 16373, 2 (alc); MNCN 40685, 2 (alc). Salmo sp: MNCN 48863, 2 (alc). Searsia koefoedi: USNM 206896, 2 (alc). Stokellia anisodon: AMNH 31037, 1 (alc). Stomias boa: MNCN 74444, 8 (alc); MNCN 74456, 4 (alc). Thymallus thymallus: MNCN 115147, 1 (alc); MNCN 114992, 1 (alc). Umbra limi: MNCN 35672, 2 (alc); 36072, 2 (alc). Umbra krameri: MNCN 36659, 3 (alc). Xenodermichthys copei: MNCN 78950, 2 (alc); MNCN 1584, 2 (alc); USNM 215527, 2 (alc).

\section{Appendix 2: List of characters included in the cladistic analysis.}

A list of the characters included in the cladistic analysis is given below. Unless stated otherwise, the nomenclature of the morphological structures mentioned in this list follows that of Diogo. Due to limitations of size, this list of characters will be kept as short and simple as possible. Also, it is obviously not possible to include, in the present paper, anatomical drawings to illustrate all the numerous morphological features mentioned in this list. However, apart the numerous anatomical drawings provided in the present paper, an effort was made in order to supply, for most of the characters, references to figures provided in previous works in which the configuration corresponding to the derived states of these characters has been illustrated. In this way, we also want to pay a tribute to previous works done on teleostean comparative anatomy and phylogeny. It is important to note that, unless explicitly stated otherwise, all the morphological features mentioned in the list below refer exclusively to the adult configuration. It should also be noted that in the matrix shown in Table 1, inapplicable and missing character states for a certain taxon are indicated with '-' and with '?', respectively. Unless otherwise stated, inapplicable characters are used in cases in which for example a certain character refers to the shape of a bone that is not found in a certain taxon; missing character states are used in cases in which it was not possible to appropriately discern the respective state in a certain taxon (e.g. due to the poor preservation of the fossils or of the extant specimens dissected) (for more details see Diogo). As stressed by authors such as Hilton \& Bemis (1999), there are documented cases, within actinopterygian fishes, of remarkable morphological variation within a single genus, a single species, and even within a single population of the same species. As will be mentioned throughout the list of 271 characters given below, among these characters there are effectively cases in which different wild-type, adult members (examined by us and/or previously described in the literature) of a certain terminal taxon do seemingly exhibit different character states of a same character. Since in those cases one cannot assign the wild-type, adult members of the respective terminal taxon in which such a variation occurs to a single character state, the taxon is coded as '?' (see below).

\section{Ventral cephalic musculature.}

1. Two sections of intermandibularis (anterior and posterior intermandibularis). [0] Absent. [1] Present (e.g. Fig. 3; Greenwood, 1971: fig. 10). As shown in Edgeworth (1935), figure 271, in the members of the genus Albula dissected in the present work the intermandibularis is not subdivided into these two sections.

2. Posterior intermandibularis and interhyoideus (ordered multistate character). [0] Not associated to each other. [1] Posterior intermandibularis deeply associated with interhyoideus, forming the protractor hyoidei (e.g. Fig. 3), but also deeply associated with anterior intermandibularis. [2] Posterior intermandibularis deeply associated with interhyoideus, forming the protractor hyoidei, and not associated with anterior intermandibularis (e.g. Figs. 4, 5, 6; Greenwood, 1971: fig. 7). Greenwood (1971) stated that in osteoglossomorph notopterids, including the members of the genus Xenomystus, the posterior intermandibularis and the interhyoideus do not form a protractor hyoidei. However, in the Xenomystus specimens analyzed in the present work, it is not completely clear that this is effectively the case. This because the muscle named 'posterior intermandibularis' in Greenwood's (1971) page 21 does appear to have a myocommata dividing its anterior and posterior portions, which is very similar to the myocommata dividing the anterior and posterior portions (i.e. posterior intermandibularis and interhyoideus portions) of the protractor hyoidei in many other teleosts. Also, in the Xenomystus specimens examined, the muscle named 'interhyoideus' in Greenwood's (1971) page 21 is very similar to the 'hyohyoideus inferioris' (sensu Winterbottom's 1974 and the present works) of many other teleosts. Contrary to the interhyoideus of teleosts such as Albula and Mormyrus, the muscle named 'interhyoideus' in Greenwood's (1971) page 21 does not attach anteriorly to the lower jaw: instead, it fuses anteroventromesially with its counterpart and inserts onto the hypohyals through a short tendon, as is precisely the case with the hyohyoideus inferior of many other teleosts. Until more detailed data is available, Xenomystus will be prudently coded as '?'. 3. Interhyoideus. [0] Present (either as an independent element or included in the protractor hyoidei) (e.g. Fig. 3). [1] Missing. 4. Anterior intermandibularis. [0] Attaching partially or exclusively on dentary bones (e.g. Figs. 3, 4, 5, 6). [1] Not attaching on dentary bones (e.g. Howes, 1985: figs. 20, 21).

5. Peculiar differentiation of protractor hyoidei into pars dorsalis, pars ventralis and pars lateralis. [0] No differentiation (e.g. Figs. 3, 4, 5, 6). [1] Differentiation (e.g. Diogo, 2004: fig. 3-41).

6. Protractor hyoidei. [0] Not inserted high on mandibular coronoid process. [1] Inserted high on mandibular coronoid process (e.g. Howes, 1985: fig. 5). 
7. Hyohyoideus abductor. [0] Present (e.g. Figs. 3, 4, 5, 6). [1] Missing.

8. Hyohyoideus inferior and hyohyoideus abductor. [0] Blended to each other (e.g. Fig. 3). [1] Not blended to each other (e.g. Fig. 4; Diogo, 2004: fig. 3-44).

9. Presence of hyohyoidei adductores. [0] Not missing (e.g. Figs. 3, 4, 5, 6). [1] Missing.

10. Hyohyoideus abductor and hyohyoidei adductores. [0] Not highly modified (e.g. Figs. 3, 4, 5, 6). [1] Highly modified, being hypertrophied and deeply blended to each other (e.g. Greenwood, 1971: figs. 10, 12).

11. Hyohyoidei adductores. [0] Not covering a significant part of the lateral margin of the cranium. [1] Covering a significant part of the lateral margin of the cranium (e.g. Edgeworth: fig. 279).

12. Significant part of hyohyoideus abductor and/or hyohyoidei adductores. [0] Not attaching to pectoral girdle. [1] Attaching to pectoral girdle.

13. Hyohyoideus ventralis. [0] Absent (e.g. Figs. 3, 4, 5, 6). [1] Present (e.g. De la Hoz \& Chardon, 1984: fig. 16).

14. Branchiomandibularis. [0] Present (e.g. Lauder: fig. 3B). [1] Absent (e.g. Figs. 3, 4, 5, 6).

\section{Musculature associated with pectoral girdle and fins.}

15. Presence of sternohyoideus. [0] Present (e.g. Figs. 4, 5, 6). [1] Absent.

16. Anteroventromesial portion of hypoaxialis. [0] Not continuous with posteroventromesial portion of sternohyoideus (e.g. Lauder: figs. 2B, 3B). [1] Continuous with posteroventromesial portion of sternohyoideus (e.g. Diogo: fig. 3-113).

17. Sternohyoideus. [0] Not consolidated into a single median muscle (e.g. Lauder: figs. 2B, 3B). [1] Consolidated into a single median muscle (e.g. Figs. 4, 5, 6; Diogo, 2004: fig. 3-121).

18. Distinct muscle 'arrector 3'. [0] Absent (e.g. Figs. 7, 8A). [1] Present (e.g. Figs. 9, 10, 11, 12). This muscle was curiously not described in Winterbottom's 1974 work. One possible explanation is that this muscle is only found in some teleostean taxa examined, being absent in fishes such as elopomorphs and osteoglossomorphs, as well as in non-teleosts such as Amia and Lepisosteus (e.g. Figs. $7,8)$. The names of the pectoral girdle muscles used in works on catfishes such as Diogo et al. (2000) and Diogo do not fully correspond to the nomenclature proposed by Winterbottom. One of the main reasons for this is precisely due to the presence, in catfishes, of the muscle 'arrector 3', which was not described by Winterbottom and was tentatively named arrector ventralis by Diogo et al. (2001a) and Diogo. In the present work the nomenclature of the pectoral muscles essentially follows that used by Winterbottom. Thus, in order to facilitate comparisons with Diogo et al.' (2000) and Diogo' previous works on catfishes, it should be stressed that the "arrector ventralis" of those works corresponds to the 'arrector 3 ' of the present work; the "arrector dorsalis", "abductor superficialis 1 ", "abductor superficialis 2", "adductor superficialis 1", "adductor superficialis 2" and "abductor profundus" of those works correspond respectively to the arrector ventralis, abductor superficialis, abductor profundus, adductor superficialis, adductor profundus and arrector dorsalis of Winterbottom and of the present work.

19. Distinct muscle coracoradialis [0] Absent (e.g. Figs. 8B, 13, 14, 15, 16, 17, 18). [1] Present (e.g. Fig. 19; Winterbottom: fig. 38).
20. Distinct muscle arrector ventralis. [0] Absent (e.g. Fig. 7). [1] Present (e.g. Figs. 8A, 9, 10, 11, 12, 13, 14; Winterbottom: fig. 32). 21. Abductor superficialis and/or abductor profundus. [0] Not hypertrophied (e.g. Fig. 18). [1] Hypertrophied, a significant part also originating on mesial surface of pectoral girdle. (e.g. Greenwood \& Thompson, 1960: figs. 6, 8).

22. Arrector dorsalis (ordered multistate character). [0] Not subdivided (e.g. Fig. 16). [1] Subdivided into two well-developed sections (e.g. Fig. 8B). [2] Subdivided into three well-developed sections (e.g. Fig. 19).

23. Attachment of arrector dorsalis. [0] Not attaching on both the first and second pectoral rays (e.g. Fig. 16). [1] Attaching on both the first and second pectoral rays (e.g. Fig. 8B).

24. Protractor pectoralis. [0] Present: according to Greenwood \& Lauder the presence of a recognizable protractor pectoralis is seemingly the plesiomorphic condition for actinopterygians, being present in at least some extant members of e.g. the Acipenseriformes, Polypteriformes and Amiiformes (e.g. Fig. 11; Greenwood \& Lauder: fig. 2). [1] Absent as an independent element. As noted by these authors, in some members of the genus Galaxias this muscle is missing, while in others it is present as an independent element; this genus is thus coded as '?'.

25. Significant part of mesial portion of arrector ventralis. [0] Not passing through coracoid-cleithrum foramen. [1] Passing through coracoid-cleithrum foramen (e.g. Diogo: fig. 3-56).

26. Arrector ventralis divided into two distinct, well-developed bundles widely separated by large horizontal lamina of coracoid (or scapulo-coracoid). [0] Not divided (e.g. Fig. 8B). [1] Divided (e.g. Diogo: fig. 3-56).

27. Arrector ventralis peculiarly divided into well-developed posterodorsal and anteroventral bundles, both originating on ventrolateral surface of pectoral girdle. [0] Not divided (e.g. Fig. 8A). [1] Divided.

\section{Neurocranium, anterior vertebrae and related structures.}

28. 'Kinethmoid' bone. [0] Absent (e.g. Figs. 20, 21, 22, 23, 24). [1] Present (e.g. Fig. 10; Fink \& Fink, 1981: fig. 2A).

29. Rostrodermethmoids. [0] Not ossified and/or fused with median supraethmoid. [1] Ossified and not fused with median supraethmoid (e.g. Sanford 2000: figs. 10, 11, 12). According to authors such as Jollie (1975) and Wilson \& Veilleux (1982) the adults of genera as e.g. Esox and Umbra have paired rostrodermethmoids (sensu Sanford, 2000) fused with paired endoskeletal structures. However, as stressed by Sanford (2000), this does not invalidate the coding of Exox and Umbra as CS-1, since the specimens of these two genera examined in the present work do fulfill the two requirements needed to be coded as CS-1: their rostrodermethmoids are ossified and are not fused with a median supraethmoid (if the rostrodermethmoids were completely fused with a median, unpaired supraethmoid, the compound structure resulting from this fusion would not be constituted by two lateral, paired portions that never completely fuse in the midline, as is the case in the specimens examined of these two genera). According to authors such as Patterson (1973) the ossified 'pre-ethmoids' of Amia seemingly correspond to ventral ethmoid ossifications, and not to the rostrodermethmoids found in certain teleosts (see character below); therefore Amia is coded here as CS-0. 
30. Ventral ethmoids. [0] Not ossified and/or fused with prevomer (e.g. Fig. 21). [1] Ossified and not fused with prevomer (e.g. Sanford, 2000: figs. 10, 11, 12).

31. Mesethmoid. [0] If present, not fused with prevomer (e.g. Fig. 21). [1] Fused with prevomer (e.g. Ramaswami, 1953: fig. 1).

32. Anteroventral margin of prevomer. [0] Does not situate well posteriorly to anteroventral margin of mesethmoid (or of supraethmoid and/or rostrodermethmoids: see above) (e.g. Fig. 21). [1] Situates well posteriorly to anteroventral margin of mesethmoid (or of supraethmoid and/or rostrodermethmoids) (e.g. Taverne, 1974: figs. 2, 4; Fink \& Fink, 1981: figs. 2C,D, 4A).

33. Anterolateral processes of mesethmoid (or of supraethmoid and/ or rostrodermethmoids) supporting and/or articulating with premaxillae. [0] Not present (e.g. Fig. 21). [1] Present (e.g. Fig. 24; Fink \& Fink, 1981: fig. 3C,D, E, F). As pointed out by Gayet (1985: 109), it is difficult to discern this character appropriately in $\dagger$ Lusitanichthys characiformis. However, the illustrations provided in Gayet $(1981,1985)$ suggest that in the members of this species the anterolateral margins of the mesethmoid are mainly associated with the proximal surfaces of the maxillae, and not with the premaxillae ("anterolaterally, the mesethmoid presents a profound depression that receives the articular process of the maxilla": Gayet, 1981, p. 175). Thus $\nmid$ Lusitanichthys characiformis does not seem to exhibit CS-1.

34. Posterodorsal portion of mesethmoid (or of supraethmoid). [0] Not appearing markedly compressed transversally when seen in dorsal view. [1] Appearing markedly compressed transversally when seen in dorsal view (e.g. Fink \& Fink, 1981: fig. 3E, F).

35. 'Ethmoid endoskeleton'. [0] Not markedly reduced ossification of 'ethmoid endoskeleton' (sensu Patterson \& Johnson, 1996: p. 254) (e.g. Fig. 23). [1] Markedly reduced ossification of the 'ethmoid endoskeleton' (e.g. Fig. 24; Sanford, 2000: fig. 12). The Astronesthes specimens dissected exhibit a condition similar to that described for CS-1, while certain members of this genus appear to exhibit a condition similar to that described for CS-0 (see e.g. Weitzman, 1967a, b); this genus is thus coded as '?'.

36. Mesethmoid. [0] If present, not peculiarly shaped, markedly compressed anteroposteriorly and expanded transversally (e.g. Fig. 21). [1] Peculiarly shaped, being markedly compressed anteroposteriorly and expanded transversally (e.g. Thys van den Audenaerde, 1961: fig. 13).

37. Lateral ethmoids. [0] Not exhibiting remarkably large, peculiar lateral extensions (e.g. Fig. 22). [1] Exhibiting remarkably large, peculiar lateral extensions (e.g. Greenwood et al., 1966: fig. 6; Grande \& Poyato-Ariza: fig. 4B).

38. Thin, elongated lateral laminar projection of lateral ethmoid contacting autosphenotic. [0] Not present (e.g. Fig. 22). [1] Present (e.g. Bornbusch, 1995: fig. 5B).

39. Peculiar anteroventrolateral, anteroventrally pointed process of lateral ethmoid. [0] Not present (e.g. Fig. 22). [1] Present (e.g. De la Hoz \& Chardon, 1984: figs. 1, 4).

40. Prevomer. [0] Paired (e.g. Mayhew, 1924: fig. 3). [1] Unpaired (e.g. Taverne, 1974: fig. 4). As stressed by authors such as Patterson (1975) and De Pinna, some specimens of the genera Hiodon and Osmerus may exhibit CS-O, while others exhibit CS-1; these two genera are thus coded as '?'.

41. Large, strong 'pseudocartilaginous ligament' between prevomer, autopalatines and/or mandibles. [0] Not present. [1] Present (e.g. Thys van den Audenaerde, 1961: fig. 19).
42. Prevomerine teeth. [0] Present. [1] Absent (e.g. Fig. 21; Fink \& Fink, 1981: fig. 2). In Sanford's (2000) table II, this author states that the members of the genus Alepocephalus have prevomerine teeth. However, this seems to be an error, because all the Alepocephalus specimens examined in the present work and in the works of authors such as Gegenbaur (1878) and Gosline (1969) do not have prevomerine teeth.

43. Rhinosphenoid. [0] Absent (e.g. Fig. 21). [1] Present (e.g. Fig. 23; Fink \& Fink, 1981: fig. 2C). The presence/absence of a rhinosphenoid in $\nmid$ Lusitanichthys characiformis has been subject of controversy (see e.g. Gayet, 1985). In our opinion, the position of Gayet's $(1981,1985)$ 'rhinosphenoid' seems to be somewhat similar to that of the rhinosphenoid of some characiforms. Moreover, Cavin (1999) described a new species of $\nmid$ Lusitanichthys, $\dagger L$. Africans, which, according to this author, also appears to have a 'rhinosphenoid'. We therefore consider that we cannot simply discard a priori the hypothesis that the 'rhinosphenoid' of these authors might be homologous to the rhinosphenoid of certain characiforms. These structures will thus be tentatively coded here as primary homologues; this primary homology will be tested against the results of the cladistic analysis including all the available characters. Cavin ( p. 692) stated that he "observed a trace of a subrectangular bone behind the lateral ethmoid on several specimens of $†$ Clupavus maroccanus that could be interpreted as a rhinosphenoid'. Since in Taverne's (1977a, 1995) descriptions of $\dagger$ Clupavus maroccanus this author does not make any reference to the possible presence of a rhinosphenoid, we prefer to prudently code this latter species as '?'. 44. Independent orbitosphenoid. [0] Present (e.g. Fig. 21). [1] Absent (e.g. Fig. 22; Smith, 1989a: fig. 4). Authors such as Jollie (1975) and Arratia (1997, 1999) have described/coded the orbitosphenoid as present in Esox and/or Thymallus. However, the 'orbitosphenoid' of Jollie's (1975) figure 10 clearly does not seem to correspond to the orbitosphenoid of the present work; in the Esox and Thymallus specimens examined in the present work, as well as in works of other authors such as Norden (1961), Johnson \& Patterson (1996) and Sanford (2000), the orbitosphenoid is absent as an independent ossification.

45. Independent basisphenoid. [0] Present (e.g. Fig. 9). [1] Absent (e.g. Diogo: 3-66). Sanford (2000) coded Esox as not having a basisphenoid. However, all Esox specimens examined in the present work and in the works of other authors such as Jollie (1975) and Johnson \& Patterson do exhibit an independent basisphenoid.

46. Frontals. [0] Not markedly separated from each other along dorsal midline. [1] Markedly separated from each other along dorsal midline (e.g. Grande \& Poyato-Ariza: fig. 4B).

47. Autopterotic and dermopterotic. [0] At least one of these bones is not present as an independent ossification (e.g. Fig. 21). [1] Both these bones are present as independent, distinct ossifications (e.g. Gosline, 1969: fig. 6; Greenwood \& Rosen: figs. 22, 24). As explained by authors such as Patterson (1973) and Grande \& Bemis (1998), it is difficult to discern if both the autopterotic and dermopterotic are or not present as independent ossifications in Lepisosteus; this genus is thus coded as '?'.

48. Frontal and autopterotic (and/or dermospterotic). [0] Contacting in dorsal view (e.g. Fig. 20). [1] Not contacting in dorsal view (e.g. Diogo: fig. 3-67).

49. Vertical, complete laminar bony connection mesially to the eye between frontal, dorsally, and parasphenoid, ventrally. [0] Not present (e.g. Fig. 20). [1] Present (e.g. Fig. 10; Diogo: fig. 3-112). 
Some specimens of the genera Pantodon and Amia exhibit CS-0 (e.g. Taverne, 1978: fig. 31; Jollie, 1984a: fig. 13B), while others exhibit CS-1 (e.g. Kershaw, 1970: fig. 3; Patterson, 1973: fig. 9B); these genera are thus coded as '?'.

50. Frontals. [0] Not completely fused along midline. [1] Completely fused along midline (e.g. Smith, 1989b: fig. 505E). Forey et al. coded the elopomorph saccopharyngiforms as having the frontals fused along the midline. However, as explained by authors such as Regan (1912) and Tchernavin (1947a, b), this is not the case in Eurypharynx.

51. Peculiar anterodorsal process of pterosphenoid contacting posterodorsal process of lateral ethmoid. [0] Not present (e.g. Fig. 10). [1] Present (e.g. Diogo: fig. 3-46).

52. Prootic and/or pterotic bulla lodging diverticulum of swimbladder. [0] Not present (e.g. Fig. 25). [1] Present (e.g. Grande, 1986: fig. 31).

53. Sacculi and lagenae. [0] Not lying in a posterior position and/ or not lying near the midline. [1] Lying in a posterior position and near the midline (e.g. Rosen \& Greenwood, 1970: fig. 15B,C). Filleul \& Maisey reported a 'lagenar capsule' (see below) on the exoccipital and also the basioccipital of $\uparrow$ Santanichthys diasii; this seems to indicate that the members of this taxon exhibited CS- 1 . 54. Peculiar, large 'auditory foramen', which is usually an ovoid opening on the ventral face of the prootic through which the utricular otolith is visible. [0] Not present. [1] Present (e.g. Weitzman, 1962: fig. 4).

55. Markedly large, globular 'lagenar capsule'. [0] Not present (e.g. Fig. 26). [1] Present (e.g. Fig. 25; Weitzman, 1962: fig. 4). Gayet (1985) considered that it was not possible to discern the presence/ absence of this feature in the specimens of $\dagger$ Lusitanichthys characiformis that she analyzed. However, in Gayet's (1985) figure 23 the posterior portion of the basioccipital is illustrated, and a markedly large, globular 'lagenar capsule' such as that present in the taxa listed under CS-1 does not seem to be present.

56. Peculiar 'recessus lateralis'. [0] Absent (e.g. Fig. 20). [1] Present (e.g. Fig. 9; Forey, 1973a, b; Grande, 1986: figs. 27, 31; Di Dario, 2004: figs. 3, 4).

57. Exoccipitals. [0] Not markedly expanded posterolaterally (e.g. Fig. 26). [1] Markedly expanded posterolaterally, extending well over neural arch of first free vertebra (e.g. Poyato-Ariza, 1996; Grande \& Poyato-Ariza)

58. Exoccipitals and basioccipital. [0] Nor completely fused (e.g. Fig. 25). [1] Completely fused.

59. Parietals (or parieto-extrascapulars). [0] Not fused with supraoccipital (e.g. Fig. 21). [1] Fused with supraoccipital (e.g. Fink \& Fink, 1981: fig. 5D).

60. Main bodies of parietals (or of parieto-extrascapulars). [0] Not widely separated from each other in dorsal view (e.g. Fig. 21). [1] Widely separated from each other in dorsal view (e.g. Fig. 24; Sanford, 2000: fig. 27). Some members of the genera Esox, Thymallus and Coregonus exhibit CS-0, while others exhibit CS-1 (this study; see also descriptions of e.g. Norden, 1961; Shaposhnikova, 1967; Sanford, 2000; Grande et al., 2004); these genera are thus coded as '?'.

61. Intercalar. [0] According to authors such as Jollie (1986) the intercalar is primitively present as an independent ossification is neopterygians (e.g. Fig. 25). [1] Intercalar absent as independent ossification (e.g. Fig. 26; Patterson, 1973: fig. 11A).

62. Markedly enlarged, ventral 'pharyngeal process' of basioccipital (sensu Winterbottom, 1974). [0] Not present (e.g. Fig. 25). [1] Present (e.g. Vandewalle, 1975; Fink \& Fink, 1981: fig. 5D). 63. Markedly elongated, posteriorly pointed posterior process of parasphenoid. [0] Not present (e.g. Fig. 25). [1] Present (e.g. Ridewood, 1904a: fig. 122).

64. Teeth on parasphenoid. [0] Present. [1] Absent (e.g. Albert, 2001: fig. 2).

65. Basipterygoid process. [0] According to authors such as Patterson (1973: p. 254), the "loss of the basipterygoid process, as in Amia and most teleosts" is a "derived condition"; this view is supported by the recent work of Moritz \& Britz (2005). [1] Absence of 'basipterygoid process' (e.g. Taverne, 1974: fig. 4). Taverne (1977a) stated that a 'basipterygoid process' is missing in $\dagger$ Clupavus maroccanus, but Taverne (1995) stated that such a processus was in fact perhaps present in this taxon; until more data is available, we prefer to prudently code this taxon as '?'.

66. Supraoccipital. [0] Not ossified. [1] Ossified (e.g. Fig. 21; Patterson, 1973: fig. 3A,B).

67. 'Highly ossified triangular pars sustentaculum complex'. [0] Not present. [1] Present (e.g. Vari: fig. 32).

68. Anteroposterior elongation of anterior neural arches. In order to properly define this character, it should be mentioned that contrary to taxa of CS-0 [0] (e.g. Tchernavin, 1947a: fig-text 10) in the specimens examined of taxa of CS-1 [1] the length of at least part of at least one of the most anterior neural arches is almost equal, or even greater, than that of the centrum of the free vertebra to which it is associated (e.g. Fig. 27; Grande, 1994: figs. 6, 7).

69. Scaphium (ordered multistate character). [0] Not present (e.g. Fig. 27). As pointed out by authors such as Patterson (1984) and Fink \& Fink (1996), in the fishes of CS-1 [1] (e.g. Patterson, 1984: figs. 13-16) the scaphium does not seem to be as derived from the plesiomorphic condition found in fishes of CS- 0 as it is in the fishes of CS-2 [2] (e.g. Fink \& Fink, 1981: figs. 14-18).

70. Anterior margin of neural arch of third free vertebra. [0] Not closely approaching posterior border of neurocranium (e.g. Fig. 27). [1] Closely approaching posterior border of neurocranium (e.g. Fink \& Fink, 1981: figs. 15-18).

71. Claustrum. [0] Not present (e.g. Fig. 27). [1] Present (e.g. Fink \& Fink, 1981: figs. 14-17). According to authors such as De Pinna \& Grande (2003) and Grande \& De Pinna the claustrum of the fishes coded under CS-1 is homologous with the 'accessory neural arch' of some other teleosts. If this is effectively the case, the modification of this 'accessory neural arch' in the characteristic claustrum of the fishes of CS-1 will constitute a derived feature anyway.

72. Intercalarium (ordered multistate character) [0] Not present (e.g. Fig. 27). As pointed out by authors such as Patterson (1984) and Fink \& Fink (1996), in the fishes of CS-1 [1] (e.g. Patterson, 1984: figs. 13-16) the intercalarium does not seems to be as derived from the plesiomorphic condition found in those fishes coded under CS-0 as it is in the fishes coded under CS-2 [2] (e.g. Fink \& Fink, 1981: figs. 14-18).

73. Peculiar, prominent anterodorsal process of neural arch of third free vertebra. [0] Not present (e.g. Fig. 27). [1] Present (e.g. Fink \& Fink, 1981: fig. 15) [State 1].

74. Parapophyses of second free vertebra [0] Not markedly reduced in size or missing (nor completely fused with ribs) (e.g. Fig. 27). [1] Markedly reduced in size or missing (or occasionally completely fused with ribs) (e.g. Fink \& Fink, 1981: fig. 17) [State 1]. 
75. Parapophyses of two first free vertebrae. [0] Not fused to centra (e.g. Fig. 27). [1] At least some parapophyses of two first free vertebrae fused to centra. (e.g. Fink \& Fink, 1981: fig. 14).

76. Tripus (ordered multistate character). [0] Not present (e.g. Fig. 27). As pointed out by authors such as Patterson (1984) and Fink \& Fink (1996), in the fishes coded under CS-1 [1] (e.g. Patterson, 1984: figs. 13-16) the tripus does not seems to be as derived from the plesiomorphic condition found in the fishes coded under CS-0 as it is in the fishes coded under CS-2 [2] (e.g. Fink \& Fink, 1981: figs. 14-18).

77. Ribs/parapophyses of third free vertebra. [0] Not highly modified in relation to, and/or broader than, the ribs/parapophyses of the following free vertebrae. [1] Highly modified in relation to, and/or broader than, ribs/parapophyses of the following free vertebrae (e.g. Grande \& Poyato-Ariza: fig. 12). According to authors such as Rosen \& Greenwood, Fink \& Fink (1981, 1996), Patterson (1984) and Grande \& De Pinna the fishes exhibiting a tripus (see above) should be coded under CS-1 in a character such as this, because the tripus is seemingly at least partially constituted by enlarged ribs/parapophyses of the third free vertebra. Fink \& Fink (1996) suggested that Kneria and Parakneria might have a configuration such as that described for CS-1, although they recognized that in the members of these two genera the ribs/ parapophyses of the third free vertebral column are only slightly broader than those of the following free vertebrae. In the Kneria and Parakneria specimens examined by us, as well as in those specimens illustrated by Lenglet (1974: figs. 17-19), the ribs/ parapophyses of the third free vertebra are not considerably larger than those of the following free vertebrae. Also, Grande \& PoyatoAriza seem to suggest that Grasseichthys and Cromeria should be coded as CS-1, but the illustrations of Grande (1994: figs. 6, 9) seem to indicate that the ribs/parapophyses of the third free vertebra are not considerably broader than those of the following free vertebrae. Until more data is available, these four genera will be prudently coded here as '?'.

78.'Os suspensorium' (ordered multistate character). [0] Not present (e.g. Fig. 27). As pointed out by authors such as Patterson (1984) and Fink \& Fink (1996), in the fishes coded as CS-1 [1] (e.g. Patterson, 1984: figs. 13, 14, 16) the 'os suspensorium' does not seem to be as derived from the plesiomorphic condition found in the fishes coded as CS-0 as it is in the fishes coded as CS-2 [2] (e.g. Fink \& Fink, 1981: figs. 14-18).

79. Highly modified, ovoid peculiar anterolateral face of 'transverse process' of fourth free vertebra. [0] Not present (e.g. Fig. 27). [1] Present (e.g. Fink \& Fink, 1981: fig. 17, 18). Fink \& Fink (1981, 1996) did not mention the presence of this feature in cypriniforms, but the Danio and Barbus specimens examined by us do exhibit a highly modified, ovoid anterolateral face of the 'transverse process' of the fourth free vertebra that is similar to that found in many gymnotiforms and siluriforms.

80. Centrum of third free vertebra. [0] Not markedly shorter than surrounding centra (e.g. Fig. 27). [1] Markedly shorter than surrounding centra (e.g. Patterson, 1984: figs. 13, 14; Gayet, 1985: figs. 22-25).

81. Peculiar silvery peritoneal tunic of swimbladder covering at least part of its anterior portion. [0] Not present. [1] Present (e.g. Rosen \& Greenwood: fig. 4). As noted by these authors, the swimbladder is missing in Gonorynchus specimens, but these specimens do have remains of a silvery peritoneal tunic associated to the structures of the anterior free vertebrae.

82. Swimbladder. [0] Not markedly divided into peculiar anterior and posterior chambers. [1] Markedly divided into peculiar anterior and posterior chambers (e.g. Rosen \& Greenwood: fig. 4).

83. Perilymph system of inner ear. [0] Not peculiarly extended posteriorly. [1] Peculiarly extended posteriorly, constituting sinus impar (e.g. Chardon et al., 2003: fig. 3.4).

84. Peculiarly large, distinct 'precervical gap' filled mainly with connective tissue between first free vertebra and neurocranium. [0] Not present (e.g. Fig. 26). [1] Present (e.g. Rosen, 1985: figs. 14, 15). This character has been the subject of controversy. For example, authors such as Rosen (1985) stated that members of nonneoteleostean taxa as e.g. Osmerus might also have a large 'precervical gap'. This statement was however contradicted by authors such as Johnson \& Patterson (p. 278), which stated that "in osmeroids the articulation between the occipital condyle and V1 is normally close". Within the non-aulopiform and non-stomiiform taxa examined in the present work there were effectively some specimens that appeared to have a 'precervical gap', although this gap was not as peculiarly large as that found in the specimens examined of the genera Aulopus, Chlorophthalmus, Astronesthes and Stomias.

\section{Pectoral girdle and fins.}

85. Posttemporal. [0] Present (e.g. Fig. 28, 29). [1] Absent (e.g. Smith, 1989a: fig. 9).

86. Supracleithrum. [0] Present as independent ossification (e.g. Fig. 28). [1] Absent as independent ossification (e.g. Diogo, 346).

87. Main body of posttemporal (or posttemporo-supracleithrum). [0] Not lying considerably far from neurocranium (e.g. Fig. 23). [1] Lying considerably far from neurocranium, with almost no contact between these two structures. The association between the posttemporal (or posttemporo-supracleithrum) and the neurocranium is thus a rather feeble one made essentially through the 'ligament between the posttemporal and the posterior margin of the neurocranium' described below and/or occasionally through thin/small extrascapulars (e.g. Fig. 24; Monod: fig. 45).

88. Dorsomesial limb of posttemporal (or posttemporosupracleithrum). [0] Markedly thin and mesially extended (e.g. Fig. 21). [1] Not markedly thin and mesially extended (e.g. Figs. 9, 10, 23).

89. Scapula. [0] Ossified (e.g. Fig. 8). [1] Not ossified (e.g. Fig. 15; Jollie, 1984a: fig. 16).

90. Coracoid. [0] Ossified (e.g. Fig. 8). [1] Not ossified (e.g. Fig. 15; Jollie, 1984b: fig. 19).

91. Baudelot's ligament. [0] Present (e.g. Fig. 25). [1] Absent. Authors such as Patterson \& Johnson stated that gonorynchiforms do not have a Baudelot's ligament. However, most gonorynchiforms examined by us exhibit a well-developed, paired ossification that is usually named 'cephalic rib' but that is strikingly similar to the ossified Baudelot's ligament of teleosts such as catfishes, connecting the cleithrum and/or supracleithrum to the posteromesial surface of the neurocranium (usually exoccipital and/or basioccipital) (e.g. Fig. 26). A potential homology between such gonorynchiform peculiar 'cephalic rib' (e.g. Fig. 26) and the 'Baudelot's ligament' of other teleostean fishes (e.g. Fig. 25) has actually been already proposed by authors such as Ridewood (1905b). Until more detailed 
data is available on this subject, we prefer to code all the gonorynchiform fishes examined by us as '?', with exception to Grasseichthys, in which such peculiar 'cephalic ribs' are completely missing; this latter genus is thus coded as CS-0. Patterson \& Johnson stated that in the elopomorph Notacanthus the Baudelot's ligament is missing. However, the specimens of this genus examined by us do have a Baudelot's ligament, which is effectively peculiarly shaped, but is similar to that found in other elopomorph fishes such as Anguilla and Conger: it is markedly thin transversally and markedly broad anteroposteriorly, attaching to various free vertebrae.

92. 'Ligament between posttemporal and posterior region of neurocranium (usually intercalar)'. [0] Present (e.g. Figs. 21, 25, 28, 29). [1] Absent. This ligament corresponds to the 'posttemporalintercalar ligament' of authors such as Taverne (1974), but because in some cases (e.g. when the intercalar is missing) it may attach to other bones such as the autopterotic, we prefer to use the less restrictive name 'ligament between posttemporal and posterior margin of neurocranium'.

93. Baudelot's ligament. [0] Contacting mesially with anterior free vertebrae, being exclusively attached to neurocranium. [1] Not contacting mesially with anterior free vertebrae, being exclusively attached to neurocranium (e.g. Fig. 25; Fink \& Fink, 1981: fig. 19B,C,D).

94. Ossification of Baudelot's ligament. [0] Not ossified (e.g. Fig. 25). [1] At least partially ossified (e.g. Fink \& Fink, 1981: fig. 19C,D). Some Hiodon specimens exhibit CS-0 while others exhibit CS-1 (see e.g. Taverne, 1977b); this genus is thus coded as '?'.

95. 'Ligament between posttemporal and posterior region of neurocranium'. [0] At least partially ossified (e.g. Fig. 25). [1] Not ossified. Taverne $(1972,1977 \mathrm{~b}, 1978)$ stated that in the osteoglossomorphs Hiodon, Xenomystus and Mormyrus there is no "process of the posttemporal for the intercalar" (that is, there is no ossification of the ligament mentioned in the present character). However, in the specimens examined of these three genera the ligament is, in fact, ossified (e.g. Fig. 29; see also Figs. 21, 28). The presence of an ossified ligament in the specimens of these three genera can be effectively overlooked, for example in analyses that do not include the observation of soft structures. This because these specimens display a peculiar configuration in which the anteroventrolateral surface of the posttemporal is bifurcated anteriorly into a shorter, lateral arm that is essentially a tubular structure carrying a sensorial canal, and a longer, mesial arm that extends well anteriorly to the lateral one and that is attached by a thick ligament to the intercalar (or occasionally the autopterotic in Mormyrus, in which the interhyal is missing) (e.g. Fig. 29; see also Fig. 21). This latter arm thus clearly seems to be homologous to the ossified 'ligament between the posttemporal and the posterior region of neurocranium' found in many other teleosts. In the Pantodon specimens examined by us the ligament is very thick, but is not ossified.

96. Posttemporal. [0] As explained above, although many other taxa may have an ossified 'ligament between the posttemporal and the posterior margin of the neurocranium', their posttemporal is not peculiarly bifurcated anteroventrolaterally in a shorter, lateral arm carrying a sensorial canal and a longer, mesial arm that corresponds to the ossified 'ligament between posttemporal and posterior margin of neurocranium' of the present work. [1] Such a peculiar configuration of the posttemporal is only found in the specimens examined of the osteoglossomorph genera Hiodon, Xenomystus and Mormyrus (see e.g. Figs. 21, 29).

97. Cleithrum. [0] Present as independent ossification (e.g. Fig. 20). [1] Absent as independent ossification (e.g. Tchernavin, 1947a: text-fig. 14).

98. Deep, long, curved fossa on lateral surface of cleithrum (e.g. Fig. 20). [0] Not present. [1] Present.

99. Bifurcation of cleithrum. [0] Not markedly bifurcated dorsally into well-developed anterodorsal and posterodorsal arms for articulation with supracleithrum (or posttemporo-supracleithrum) (e.g. Fig. 28). [1] Markedly bifurcated dorsally into well-developed anterodorsal and posterodorsal arms for articulation with supracleithrum (or posttemporo-supracleithrum) (e.g. Taverne, 1972: fig. 1; 1978: fig. 44; Diogo, fig. 3-58).

100. Compound bone scapulocoracoid. [0] Not present (e.g. Fig. 28). [1] Present (e.g. Gosline, 1977; Diogo et al., 2001a: fig. 12). 101. Mesial limb of coracoids (or scapulo-coracoids) (ordered multistate character). [0] Not broad and anteroposteriorly elongated (e.g. Fig. 8B). [1] Broad and anteroposteriorly elongated, but does not meet its counterpart in a strong median interdigitation (e.g. Brosseau, 1978a: fig. 1). [2] Broad and anteroposteriorly elongated, meeting its counterpart in a strong median interdigitation (e.g. Fig. 28; Diogo, fig. 3-56). Some specimens of the genus Galaxias exhibit CS-0, while others seemingly exhibit CS-1 (see e.g. Swinnerton, 1903; McDowall, 1969); this genus is thus coded as '?'.

102. Prominent posteroventral process on ventral surface of coracoid. [0] Not present (e.g. Fig. 28). [1] Present (e.g. Fig. 17; Diogo: fig. 3-40A) (such a process, found in a few teleosts, should not be confused with the posterior process that is present on the posterolateral surface of the coracoid (or scapulo-coracoid) of numerous teleostean fishes: see e.g. Brosseau, 1987b: fig. 8).

103. 'Coracoid bridge'. [0] Not present (e.g. Fig. 28). [1] Present (e.g. Diogo, fig. 3-56).

104. Mesocoracoid arch. [0] Present (ossified or not) (e.g. Fig. 28). [1] Either undifferentiated or completely fused anteriorly with the posterior margin of the coracoid and/or scapula (e.g. Fig. 19; Smith, 1989a: fig. 9).

105. Ossification of mesocoracoid arch. [0] Among those fishes examined with a mesocoracoid arch (see above), in fishes such as Lepisosteus and Amia this structure is not ossified (e.g. Fig. 16); this is also the case in other basal Actinopteri such as many members of the extant genera Acipenser, Psephurus and Polyodon (e.g. Jollie, 1980; Mabee \& Noordsy, 2004; Hilton, pers. comm.). [1] Mesocoracoid arch ossified (e.g. Fig. 28; Taverne, 1974: 23).

106. Mesocoracoid arch and coracoid and/or scapula. [0] Among those fishes examined by us exhibiting an ossified mesocoracoid arch, the plesiomorphic condition is seemingly that in which this arch is not firmly and rigidly attached, through suture or complete fusion, to the coracoid and/or scapula. This is the case in e.g. elopomorph fishes such as Elops, Megalops and Albula and osteoglossomorph fishes such as Hiodon and Mormyrus, in which the mesocoracoid arch articulates ventrally with the coracoid and/ or scapula and, thus, in which this arch has some mobility in relation to these latter bones (e.g. Fig. 8B; 28; Taverne, 1974: fig. 23). This is also the case in e.g. some basal Actinopteri such as some members of the acipenseriform genus Acipenser with an ossified mesocoracoid arch (Hilton, pers. comm.). [1] The taxa coded as CS-1 have an ossified mesocoracoid arch that is firmly and rigidly associated, often through suture or complete fusion, to the coracoid 
and/or scapula (or scapulo-coracoid) (e.g. Fig. 18; Diogo et al., 2001a: fig. 12).

107. Length of mesocoracoid arch. [0] Not markedly elongated dorsoventrally (e.g. Fig. 28). [1] Markedly elongated dorsoventrally (e.g. Taverne, 1978: figs. 30, 44).

108. Shape of mesocoracoid arch. [0] Not markedly enlarged transversally (e.g. Fig. 28). [1] Markedly enlarged transversally (e.g. Taverne, 1978: figs. 30, 44). Some specimens of Mormyrus exhibit CS-0, while others display CS-1 (Taverne, 1972; this study); this genus is thus coded as '?'.

109. 'Pectoral splints'. [0] Present (e.g. Figs. 7, 8). [1] Absent (e.g. Fig. 11; Gosline, 1980: fig. 2).

110. First pectoral ray. [0] Not articulating directly with scapula and/or occasionally with coracoid. [1] Articulating directly with scapula and/or occasionally with coracoid (e.g. Fig. 8B; Jessen, 1872; Gosline, 1980: fig. 3).

\section{Lateral cephalic musculature.}

111. Adductor mandibulae. [0] Attaching only on mandible and/ or primordial ligament, near its mandibular insertion (e.g. Fig. 9). [1] Attaching not only on mandible and/or primordial ligament, near its mandibular insertion, but also on other structures (e.g. maxilla, lacrimal and/or other bones) (e.g. Fig. 10; Bishai, 1967: fig. 2; Kershaw, 1976: fig.23).

112. Adductor mandibulae insertion on bones other than the mandible. [0] When most lateral bundles of the adductor mandibulae attach also, or exclusively, on bony structures other than the mandible, the non-mandibular insertions include only the maxilla (e.g. Fig. 10). [1] When most lateral bundles of adductor mandibulae attach also, or exclusively, on bony structures other than the mandible, the non-mandibular insertions include bones other than maxilla, such as those of the infraorbital series and/or the dermopalatine/autopalatine (e.g. Greenwood, 1977: figs. 10, 11, 21).

113. Adductor mandibulae A1-OST. [0] Not present (e.g. Fig. 9, 24, 30, 31, 32, 33). [0] Present (e.g. Figs. 10, 22, 23, 34; Diogo \& Chardon, 2000: figs. 1-11; Diogo \& Vandewalle, fig. 2.3).

114. Well-developed, dorsolateral bundle A1 of the adductor mandibulae. [0] Not present (e.g. Fig. 9). [1] Presence of welldeveloped, dorsolateral bundle A1 of the adductor mandibulae (sensu Diogo \& Chardon; not to be confused with the adductor mandibulae A1-OST of these authors: see above) (e.g. Fig. 33; Diogo \& Chardon, fig. 1).

115. Distinct adductor mandibulae A3-MAX. [0] Not present (e.g. Fig. 9). [1] The name adductor mandibulae A3-MAX as not been used so far, but the use of this new name for this adductor mandibulae section seems to be the best option, because there has been much confusion concerning its nomenclature and homologies in the literature. The adductor mandibulae A3-MAX corresponds to the 'A1-b' of authors such as Greenwood (1977: e.g. figs. 3, 10, 11, 12), Winterbottom and $\mathrm{Wu} \&$ Shen (e.g. Fig. 2). However, as stressed by these authors, many other names have been used to designate this adductor mandibulae section in the literature, as e.g. 'pterygo-maxillaire', 'pterygo-maxillaris', or 'levator maxillae superior'. The position and origin of this section is actually somewhat similar to that of the A3'/A3" of other fishes examined in the present work (see below), the main difference being that the A3-MAX attaches on the maxilla and not on the mandible. That is why, in order to differentiate this section from the A3'/A3" of other teleosts, we use the name A3-MAX.

116. Adductor mandibulae sections 'palatomandibularis minor' and 'palatomandibularis major'. [0] Not present (e.g. Fig. 9). [0] Present (e.g. Fig. 30; Lauder fig. 2A). In Lauder's table II it is suggested that the adductor mandibulae sections 'palatomandibularis minor' and 'palatomandibularis major' of Lepisosteus are likely homologous to the 'levator maxillae superioris 3 and 4' of Amia, because all these structures represent an 'anterior division' of the adductor mandibulae. However, the overall shape, position and attachments of the 'palatomandibularis minor' and 'palatomandibularis major' of Lepisosteus are markedly different from those of the 'levator maxillae superioris 3 and 4' of Amia. Just to give an example, the 'palatomandibularis minor' and 'palatomandibularis major' of Lepisosteus originate dorsally on the ectopterygoid/entopterygoid and insert ventrally on the mandible, while the section 3 of the 'levator maxillae superioris 3 and 4' of Amia originates dorsally on the neurocranium and orbital bones and inserts ventrally mainly on the autopalatine (e.g. Lauder, fig. 3A).

117. Adductor mandibulae sections 'levator maxillae superioris 3 and 4'. [0] Not present (e.g. Fig. 9). [0] Present (e.g. Lauder, fig. 3A) (see character above).

118. 'Abductor mandibulae'. [0] Not present (e.g. Fig. 9). [1] In Eurypharynx a part of the adductor mandibulae has differentiated into an 'abductor mandibulae' (e.g. Tchernavin, 1947a: figs. 4, 5), which inserts on the posterior end of the mandible behind the mandibulo-quadrate articulation, its contraction thus helping to open, and not to close, the mouth.

119. Peculiar bundle of adductor mandibulae markedly extended anteriorly in order to attach to the anterodorsal surface of mandible. [0] Not present (e.g. Fig. 30). [1] Present (e.g. Bishai, 1967: figs. 1-3).

120. Quite peculiar configuration of A1-OST, its anterior portion being almost perpendicular to its posterior portion. [0] Not present (e.g. Fig. 22). [0] Present (e.g. Howes, 1985: figs. 18, 19).

121. Several small, peculiar tendons branching off from A2. [0] Not present (e.g. Fig. 9). [1] Present (e.g. Howes, 1985: figs. 18, 19).

122. Origin of adductor mandibulae A1-OST. [0] Not extending to neurocranium (e.g. Fig. 22). [1] Extending to neurocranium (e.g. Diogo, 2004: fig. 3-43).

123. Peculiar, well-differentiated bundle A1-OST-m running from anteroventral surface of quadrate to maxilla. [0] Not present (e.g. Fig. 22). [1] Present ('a1i' of Howes's 1985 figs. 11, 12, 16).

124. Attachment of mainly undivided A2 on mesial surface of mandible. [0] Not accomplished by means of two welldistinguished, thick tendons (e.g. Fig. 30). [1] Accomplished by means of two well-distinguished, thick tendons, the most lateral one usually attaching to the coronomeckelian and the most mesial one usually attaching posteriorly to the Aw (e.g. Fig. 33). It should be noted that we consider 'Inapplicable' not only those cases in which there is no 'mainly undivided A2' but also in which there is a 'mainly undivided A2 not attaching on the mesial surface of the mandible by means of two well-distinguished tendons' but not an A3'. This is because the A3 may well be the result of the differentiation of a dorsal part of the A2 plus the incorporation of one of those two ventral tendons attaching on the mesial surface of the mandible in fishes coded as CS-1. 
125. Insertion of adductor mandibulae A2. [0] Not directly inserted on anteromesial surface of dentary bone (e.g. Fig. 30). [1] Directly inserted on anteromesial surface of dentary bone s (e.g. Sanford, 2000: figs. 95, 96).

126. Recognizable dilatator operculi. [0] Not present (e.g. Fig. 22). [1] Present (e.g. Tchernavin, 1947: text-figs. 4, 5).

127. Recognizable adductor operculi. [0] Not present (e.g. Fig. 22). [1] Present (e.g. Tchernavin, 1947: text-figs. 4, 5).

128. Dilatator operculi. [0] Not markedly lateral to A2 (e.g. Fig. 22). [1] Markedly lateral to A2 (e.g. Fig. 23; Diogo, fig. 3-88).

129. Adductor mandibulae A2. [0] Not exhibiting strong tendon that is perpendicular to its main body and that connects this bundle to the anteroventral surface of quadrate (e.g. Fig. 22). [1] Exhibiting strong tendon that is perpendicular to its main body and that connects this bundle to the anteroventral surface of quadrate (e.g. Howes, 1985: fig. 16).

130. Levator arcus palatini. [0] Not markedly lateral to all bundles of adductor mandibulae (e.g. Fig. 22). [1] Markedly lateral to all bundles of adductor mandibulae (e.g. De la Hoz \& Chardon: fig. 13).

131. Well-differentiated section A3' of adductor mandibulae. [0] As explained by Lauder (1980: table II), the plesiomorphic condition for actinopterygians is seemingly that in which there are two 'mesial adductor mandibulae divisions', as is the case in the Amia and Lepisosteus specimens examined by us (e.g. Lauder: figs. 2A, 3A). The two mesial adductor mandibulae divisions found in Amia and Lepisosteus correspond to the A3' and A3" of Diogo \& Chardon and of the present work (see Figs. 30, 31), and thus the presence of A3' and A3" is accordingly coded here as CS-0. [1] No welldifferentiated section A3' (e.g. Fig. 32). Sanford (fig. 94) reported an A3' in members of Galaxias. However, in the Galaxias specimens examined by us some fibers of the A2 lie mesial to the levator arcus palatini but ventrally these fibers meet, and deeply blend with, the remaining fibers of the A2. Galaxias is thus coded here as '?'. It should be noted that we consider that one of the adductor mandibulae bundles attaching on the coronomeckelian bone in the members of the genus Albula corresponds to an A3', and, thus, this genus is coded here as CS-0.

132. Well-differentiated, separated section A3" of adductor mandibulae. [0] Present (e.g. Fig. 30, 31). [1] Absent (e.g. Fig. 23) (see character above).

133. Adductor mandibulae Aw. [0] Present (e.g. Fig. 31). [1] Absent (e.g. Fig. 30; Howes 1985: fig. 16). The bundle named 'Aw' in Vari's (1979) figure 42 of Distichodus corresponds to part of the A1-OST of Diogo \& Chardon and not to an Aw.

134. Division of Aw. [0] Not divided into well-developed, distinct Aw-D and Aw-V bundles (e.g. Fig. 31). [1] Divided into welldeveloped, distinct Aw-D and Aw-V bundles, with the Aw-V attaching anteriorly to the suspensorium and/or opercular series (e.g. Fig. 33). Gosline (1986, 1989) described the adductor mandibulae section Aw of Aulopus japonicus as an undivided section that does not attach to the suspensorium and/or the opercular series. The Aulopus specimens examined by us do have an Aw divided into a well-developed dorsal Aw-D bundle and a welldeveloped Aw-V bundle (e.g. Fig. 33) attaching posteriorly on the opercular series. This is also the case of the specimens examined of the other aulopiform genus analyzed, Chlorophthalmus, as well as of several other aulopiform and non-aulopiform eurypterygians (see Fig. 1) described in the literature, which exhibit a configuration strikingly similar to that found in the Aulopus specimens examined by us (see e.g. Winterbottom, 1974; Gosline, 1986; Sato \& Nakabo, 2002; Wu \& Shen). We thus consider that it is very likely that Gosline $(1986,1989)$ failed to recognize the Aw-V in the Aulopus specimens examined by him. In fact, in our first observations of the Aulopus specimens we also failed to recognize the Aw-V. Not because this bundle was small or really absent, but because when one separates the mandible from the other cephalic structures, this bundle tends to remain attached to the opercular series. Therefore, when one then analyses the separated mandible and the structures attached to it, one can effectively easily fail to recognize the Aw-V. 135. Small bundle of adductor mandibulae attaching to lateral ethmoid by means of a thin, long tendon. [0] Not present (e.g. Fig. 22). [1] Present.

136. Adductor arcus palatini and autopalatine and/or dermopalatine. [0] Adductor arcus palatini, or muscle differentiated from it, not inserting on autopalatine and/or dermopalatine (e.g. Fig. 22). [1] Adductor arcus palatini, or muscle differentiated from it, inserting on autopalatine and/or dermopalatine (e.g. Takahasi, 1925: figs. 8, 9, 12).

137. Adductor arcus palatini. [0] Part of adductor arcus palatini and/or of muscle differentiated from it not deeply blended with ligaments connecting the anterior region of the suspensorium and the ethmoid region. [1] Part of adductor arcus palatini and/or of muscle differentiated from it deeply blended with ligaments connecting the anterior region of the suspensorium and the ethmoid region (e.g. Diogo, fig. 3-73).

138. Extensor tentaculi (ordered multistate character). [0] Whiting those fishes in which there an insertion of the adductor arcus palatini or of a part differentiated from it on the autopalatine and/or dermopalatine (see above), the plesiomorphic condition is to lack an extensor tentaculi. [1] Some fibers of the extensor tentaculi are blended with those of the adductor arcus palatini (e.g. Diogo, fig. 3-89). [2] Extensor tentaculi completely separated from adductor arcus palatini (e.g. Diogo et al., 2003: fig. 7-7, 7-8, 7.9).

139. Adductor arcus palatini and preopercle. [0] No significant attachment of adductor arcus palatini to preopercle (e.g. Fig. 22). [1] Significant part of adductor arcus palatini inserting to preopercle (see e.g. Howes, 1985).

140. Adductor arcus palatini and lateral surface of suspensorium. [0] No significant attachment of adductor arcus palatini to lateral surface of suspensorium (e.g. Fig. 24). [1] Significant part of adductor arcus palatini inserting on lateral surface of suspensorium (e.g. Fig. 23; Diogo, fig. 3-20).

141. Anterior and posterior sections of levator arcus palatini. [0] Not peculiarly differentiated into well-developed anterior and posterior sections (e.g. Fig. 22). [1] Peculiarly differentiated into welldeveloped anterior and posterior sections (e.g. Greenwood, 1977: fig. 11).

142. Dorsolateral and ventromesial sections of levator arcus palatini. [0] Not differentiated into a well-developed dorsolateral and a well-developed ventromesial sections (e.g. Fig. 22). [1] Differentiated into well-developed dorsolateral and well-developed ventromesial sections (e.g. Fig. 24; Kirchhoff, 1958: figs. 38, 39; Greenwood, 1968: fig. 34).

143. Levator arcus palatini and metapterygoid. [0] The plesiomorphic condition seems to be that in which the levator adductor arcus palatini inserts not only on the hyomandibula but also on the metapterygoid, as is the case for example in Amia, 
Lepisosteus and many teleosts examined (e.g. Fig. 24; Lauder, fig. 2A). [1] Does not insert on metapterygoid.

144. Origin of levator arcus palatini. [0] No attachment of significant part of levator arcus palatini to dorsal surface of cranial roof (e.g. Fig. 22). [1] Significant part of levator arcus palatini originated on dorsal surface of cranial roof (see e.g. Diogo).

145. Origin of dilatator operculi. [0] No attachment of significant part of dilatator operculi to dorsal surface of cranial roof (e.g. Fig. 22). [1] Significant part of dilatator operculi originated on dorsal surface of cranial roof (see e.g. Diogo).

146. Dilatator operculi [0] Not almost completely covered in lateral view by dorsal surface of preopercle. (e.g. Fig. 22). [1] Almost completely covered in lateral view by dorsal surface of preopercle. Such a peculiar configuration of the dilatator operculi is found in Denticeps (e.g. Fig. 9) and has led some authors such as Greenwood (1968) to incorrectly state that this muscle is absent in the members of this genus.

147. Differentiation of dilatator operculi. [0] Not differentiated into two well-developed, distinct divisions. [1] Differentiated into two well-developed, distinct divisions (see e.g. Diogo).

148. Levator operculi. [0] As stated by authors such as Schaeffer \& Rosen and Lauder the plesiomorphic condition for actinopterygians is seemingly that found in most basal actinopterygians and in fishes such as Lepisosteus, in which there is no recognizable levator operculi. [1] A recognizable levator operculi is found in those fishes coded as CS-1 (e.g. Fig. 22; Lauder, fig. 3A).

149. Levator operculi and lateral surface of opercle. [0] No insertion of significant part of levator operculi on lateral surface of opercle. [1] Significant part of levator operculi inserted on lateral surface of opercle (e.g. Diogo: fig. 3-88).

150. Levator arcus branchialis $V$ (ordered multistate character). [0] Not hypertrophied. [1] Hypertrophied. [2] Still more enlarged and voluminous than in CS-1 (e.g. Matthes, 1963: plate 9c).

151. Division of levator operculi. [0] Not peculiarly divided into an anterior, mesial bundle and a posterior, lateral bundle. [1] Peculiarly divided into an anterior, mesial bundle and a posterior, lateral bundle (e.g. De la Hoz \& Chardon, fig. 13a; Aguilera, 1986: fig. 1).

152. Drumming muscle of swimbladder. [0] Not present. [1] Present (e.g. Ladich, 2001; Diogo, fig. 3-100).

153. Fibers of hypaxialis and/or epaxialis. [0] Not peculiarly covering great part of neurocranial floor. [1] Peculiarly covering great part of neurocranial floor (e.g. Fig. 24; Günther \& Deckert, 1959: figs. 11, 12; Gosline, 1969: fig. 8; Fink \& Fink, 1986).

\section{Splanchnocranium.}

154. Maxilla and infraorbitals. [0] Not forming peculiar, long compound structure (e.g. Fig. 20). [1] Maxilla and infraorbitals fused, forming peculiar, long compound structure (e.g. Arratia \& Schultze, 1991: fig. 19).

155. Maxillary teeth. [0] Present (e.g. Fig. 20). [1] Absent (e.g. Fig. 22; Greenwood, 1977: fig. 21). We agree with the interpretation of authors such as Belouze in that the upper jaw of Eurypharynx is at least partially constituted by the maxilla. The presence of a welldefined, proximal head of the toothed element constituting the upper jaw in the Eurypharynx specimens examined, the presence of a strong ligament between the distal surface of this element and the mandible, and its overall position and shape, combined with the developmental data of Orton (1963), strongly support this interpretation. Some members of the genus Alepocephalus have maxillary teeth (e.g. Gosline, 1969; Sanford) while others not (e.g. Fig. 24; see also Begle, 1991, 1992); this genus is thus coded as '?'. As stressed by authors such as Greenwood (1968), the Denticeps specimens dissected by us have numerous odontodes in various bones of the skull, and is effectively difficult to discern, in certain specimens, if the 'teeth' present in some of these bones are or not exclusively odontodes. Until more detailed, conclusive data is available, we prudently code this genus as '?'.

156. Peculiar, deep lateral fossa on distal margin of maxilla, in which attaches significant part of adductor mandibulae. [0] Not present (e.g. Fig. 22). [1] Present (e.g. Howes, 1985: figs. 18, 19) 157. Premaxillae. [0] Present as independent ossifications (e.g. Fig. 20). [1] Not present as independent ossifications (e.g. Belouze, fig. 2A).

158. Supramaxillae. [0] Present as independent ossifications (e.g. Fig. 20). [1] Not present as independent ossifications (e.g. Fig. 22; Patterson, 1973: fig. 5A). Some members of the genus Astronesthes have supramaxillary bones, while others not (see e.g. Weitzman 1967b); this genus is thud coded as '?'.

159. Maxillae. [0] Markedly ankylosed with neurocranium. [1] Not markedly ankylosed with neurocranium (e.g. Fig. 20; Patterson, 1973: fig. 5A).

160. Distinct, strong ligaments connecting the anterior surfacelanterior cartilage of autopalatines and/or dermopalatines and maxilla and/or premaxillae. [0] Not present. [1] Present (e.g. Fig. 10; Vrba, 1968: fig. 3).

161.Well-developed 'rostral' cartilaginous or cartilaginous-like structures associated with posterior surface of well-developed premaxillary dorsomedial processes attached to/articulating with ethmoid region. [0] Not present. [1] Present. The presence/absence and homologies of these structures have been the subject of controversy in the literature. For example, authors such as Fink and Weitzman (1982) and Fink (1984) stated that some fishes of the orders Stomiiformes and Aulopiformes have 'rostral' premaxillary cartilages similar to those present in members of more derived neoteleostean groups. However, authors such as Hartel \& Stiassny (1986) and Stiassny $(1986,1996)$ questioned such an interpretation. Stiassny (1996: p. 455) called the attention to the fact that some of the structures that are often considered to be 'rostral' cartilages are in fact "not composed of hyaline cartilage"; they are, instead, "of an essentially fibrous composition of minimal matrix secretion". We thus prefer to define CS-1 in a way that it includes all the cases in which we have found "well-developed rostral cartilaginous or cartilaginous-like structures associated with the posterior surface of well-developed premaxillary dorsomesial processes attached to/articulating with the ethmoid region". In fact, whether these structures are paired or not, or are completely cartilaginous or not, among all the specimens examined we have only seen such well-developed structures in those few specimens coded as CS-1 (see e.g. Rosen, 1985: figs. 40A,C, 41A,B,C).

162. Premaxillae. [0] Not peculiarly fused in a single median structure (e.g. Fig. 20). [1] Peculiarly fused in a single median structure (e.g. Taverne, 1972: fig. 6; 1978: fig. 36).

163. Premaxillae and neurocranium. [0] Marked ankylosis (but not complete fusion) between these structures. [1] No marked ankylosis (nor complete fusion) between these structures (e.g. Fig. 20; Vrba, 
figs. 2, 3; Patterson, 1973: fig. 5C).

164. Maxilla. [0] Not exhibiting peculiar, somewhat $\wedge$-shaped overall configuration (e.g. Fig. 20). [1] Exhibiting peculiar, somewhat $\wedge$-shaped overall configuration (e.g. D'Aubenton, 1961: fig. 8; Lenglet, figs. 12, 13)

165. Peculiar mesial interdigitations between premaxillae. [0] Not present (e.g. Fig. 20). [1] Present (e.g. Weitzman, 1962: figs. 2, 4). 166. Prominent, well-defined, roundish anterior process of maxilla for articulation with posterior/mesial surface of premaxilla. [0] Not present (e.g. Fig. 10). [1] Present (e.g. Fig. 22; Sulak, 1977: figs. 3A, 7A).

167. Primordial ligament. [0] As the primordial ligament of Amia (e.g. Lauder, fig. 3A) and many teleosts examined connects the maxilla to the dorsal surface of the coronoid process, we are tentatively coding such a configuration as CS-0 for the fishes included in this cladistic analysis. [1] In the specimens examined of the genera coded as CS-1 the primordial ligament connects the maxilla to the posterolateral surface of the mandible, somewhat near its articulation with the quadrate (e.g. Fig. 23; Vrba, fig. 3). 168. Strong, well-defined ligament between premaxilla and proximal surface of maxilla. [0] Not present. [1] Present (e.g. Diogo, fig. 3-55). Some specimens of the genus Albula do not seem to have such a ligament (e.g. those examined in the present work) while others seemingly do (e.g. those described by Greenwood, 1977); this genus is thus coded as '?'

169. Peculiar ventromesial, roughly circular process of each premaxilla to articulate with its counterpart. [0] Present. [1] Not present (e.g. Monod, fig. 11, 'bouton articulaire median interpremaxillaires').

170. Prominent, roughly triangular anterolateral processes of premaxillae. [0] Not present (e.g. Fig. 21). [1] Present (e.g. Greenwood \& Rosen, fig. 24).

171. Premaxillae. [0] Not syndesmotically attached to proximal head of maxillae in adults (e.g. Fig. 21). [1] Syndesmotically attached to proximal head of maxillae in adults (e.g. Howes \& Sanford 1987: fig. 2).

172. Peculiar lateral excavation of upper and lower jaws, in which are anchored numerous outer, epithelially implanted comb-teeth. [0] Not present (e.g. Fig. 21). [1] Present (e.g. Howes \& Sanford, fig. 2).

173. Large, peculiar tooth-bearing interpremaxillary pad between premaxillae in adults. [0] Not present (e.g. Fig. 21). [1] Present (e.g. Howes \& Sanford, fig. 2).

174. Premaxillary teeth. [0] Present (e.g. Fig. 21). [1] Absent (e.g. Fig. 22). Contrary to Eurypharynx, which is coded here as '?' because it is difficult to discern if the premaxillae are present (e.g. fused with mesethmoid and/or prevomer) or not (in this case, this character would be inapplicable), there is a good amount of evidence suggesting that in the members of Anguilla and Conger the premaxillae are fused to the mesethmoid and prevomer and that these fishes do have premaxillary teeth (see e.g. Belouze, fig. 2D). 175. Long, strong ligament between premaxilla and anteromesial surface of mandible. [0] Not present. [1] Present (e.g. Thys van den Audenaerde, fig. 18).

176. 'Rictal cartilages' between upper jaws and between lower jaws. [0] Not present. [1] Present (e.g. Thys van den Audenaerde, fig. 18).

177. 'Gingival teeth' on upper jaw. [0] Not present. [1] As explained by authors such as Grande \& Poyato-Ariza (p. 210) the 'gingival teeth' reported by Monod (1993) in Gonorynchus are non-osseous "fringes on the soft issue of the premaxillae".

178. Toothed dermopalatine. [0] Present (e.g. Fig. 21), occasionally fused to other structures (e.g. ectopterygoids: see below). [1] Absent (e.g. Figs. 22, 35; Lauder \& Liem, fig. 38B; Arratia, 1992: fig. 8B). We agree with Johnson \& Patterson in that in members of the genera Retropinna and Stokellia the toothed structure situated ventrally and posteroventrally to the autopalatine is very likely the result of the fusion of the dermopalatine with the ectopterygoid; these genera are thus coded here as CS- 0 , and as CS- 1 in the character below.

179. Compound, dermopalatine-ectopterygoid toothed structure. [0] Not present (e.g. Fig. 21). [1] Present (e.g. Johnson \& Patterson, fig. 4A). Authors such as Ridewood (1905a), Kershaw (1970), Taverne (1978), Hilton and Moritz \& Britz (2005) stated that Xenomystus and Pantodon exhibit a compound dermopalatineectopterygoid toothed structure. The observations of the present work support such a statement. However Arratia \& Schultze,'s figure 20A seems to suggest that in certain Pantodon specimens these two bones are not fused; this latter genus is thus coded as '?'.

180. Autopalatine. [0] Well ossified (e.g. Fig. 35). [1] Very poorly ossified or completely unossified (e.g. Fig. 21; De la Hoz \& Chardon, 1984: fig. 2).

181. Articulation, either direct or indirect, between autopalatine/ dermopalatine and maxilla. [0] Not present. [1] Present. (e.g. Fig. 10; Vrba, 1968: fig. 3). It should be noted that, despite being poorly developed, there is a maxillary articulatory facet for the autopalatine/ dermopalatine in the specimens examined of the osteoglossomorph genera Hiodon, Pantodon and Xenomystus (it was however not possible to discern if this is also the case, or not, in the Mormyrus specimens dissected).

182. Peculiar, large, deep anterodorsal concavity of entopterygoid for articulation with ventral surface of lateral ethmoid. [0] Not present (e.g. Fig. 21). [1] Present (e.g. Vandewalle, 1975: fig. 51). 183. Pars autopalatina. [0] Not peculiarly separated from pars pterygoquadrata (e.g. Fig. 35). [1] Peculiarly separated from pars pterygoquadrata (e.g. Arratia, 1992: figs. 16, 17; Diogo et al., 2001b: fig. 1).

184. Large anteroventral expansion of laminar bone of autopalatine. [0] Not present (e.g. Fig. 35). [1] Present (e.g. Monod, fig. 30; Pasleau, 1974: fig. 23).

185. Anterior portion and/or anterior cartilage of autopalatine. [0] Not forming peculiar 'broad hook' that covers a great portion of the proximal portion of maxilla in lateral view (e.g. Fig. 24). [1] As noted by authors such as Sanford, although in a few fishes coded as CS-0 the anterior portion and/or anterior cartilage of the autopalatine may be significantly elongated anteroposteriorly and/or occasionally form a 'small hook', such a peculiar 'broad wook' covering a great portion of the proximal portion of the maxilla in lateral view is only found, within the specimens examined, in those fishes coded as CS2 (e.g. Stiassny, 1986: fig. 5A; Sanford, fig. 32).

186. Well-developed, peculiar 'processus dorsomedialis' of autopalatine. [0] Not present (e.g. Fig. 35). [1] Present (e.g. Fig. 10; Fink \& Fink, 1981: figs. 3B, 9).

187. Semimovable articulation between entopterygoid and posterior portion and/or posterior cartilage of autopalatine. [0] Not present (e.g. Fig. 35). [1] As explained by authors such as Fink \& Fink (1981, 1996), although some fishes of CS-0 could occasionally exhibit a somewhat similar articulation between the anterior 
pterygoid bones and the autopalatine (e.g. some gonorynchiforms), only in those fishes of CS-1 such an articulation is made between a characteristic, concave facet of the entopterygoid and the posterior portion and/or posterior cartilage of the autopalatine.

188. Peculiar dorsoventral enlargement of posterior portion of autopalatine. [0] Not present (e.g. Fig. 35). [1] Present (e.g. Fig. 24; Gosline, 1969: figs. 4A, 5).

189. Strong, long ligament connecting anterior surface of pterygoid bones to maxilla. [0] Not present (e.g. Fig. 24). [1] Present (e.g. Diogo, fig. 3-39C).

190. Ossification of ligament connecting anterior margin of suspensorium to ethmoid region. [0] No ossification (e.g. Fig. 24). [1] Partial or complete ossification (e.g. Chapmam, 1942: fig. 3; De la Hoz \& Chardon, 1984: fig. 8; Diogo, fig. 3-73).

191. Large metapterygoid-quadrate fenestra. [0] Not present (e.g. Fig. 35). [1] Present (e.g. Fink \& Fink, 1981: figs. 9, 10).

192. Peculiar configuration of anterior portion of suspensorium, the main bodies of the entopterygoid and ectopterygoid being widely separated by the quadrate, with almost no contact, or no contact at all, between the entopterygoid and ectopterygoid. [0] Absence of such peculiar configuration (e.g. Fig. 35). [1] Presence of such peculiar configuration (e.g. Lekander, 1949: fig. 67).

193. Teeth on pterygoid bones. [0] Present. [1] Absent (e.g. Fig. 35). Some Alepocephalus specimens dissected by us have teeth on the pterygoid region while others not. Also, the Distichodus specimens examined by us have no teeth on this region, but Buckup stated that in the specimens examined by him there were teeth on both the entopterygoid and the ectopterygoid. These two genera are thus coded as '?'.

194. Peculiar, stout posteromesial process of ectopterygoid for articulation with ethmoid region. [0] Not present (e.g. Fig. 21). [1] Present (e.g. Thys van den Audenaerde, fig. 17).

195. Prominent dorsal process of ectopterygoid abutting in infraorbitals. [0] Not present (e.g. Fig. 21). [1] Present (e.g. Ridewood, 1904b; Forey et al., 1996).

196. Peculiar, prominent hyomandibular lateral spur at or below the level of the opercular process, projecting caudally to contact the preopercle. [0] Not present (e.g. Fig. 35). [1] Present (e.g. Johnson \& Patterson, 1996: fig. 4B). In Johnson \& Patterson's (p. 326) appendix 1, these authors coded this character as an unordered multistate character: for example, Plecoglossus was coded as CS-1 ("short vertical crest fitting against preopercular"), Osmerus as CS2 ("triangular spur"), and Galaxias as CS-3 ("obliquely oriented spurlike crest"). We usually agree with Johnson \& Patterson's criticism of Begle's (1992) coding. However, in this case we prefer to follow Begle's (1992) coding for this character, because we do not think that the 'peculiar lateral hyomandibular spur at or below the level of the opercular process projecting caudally to contact the preopercle' found in the fishes of CS-1 being e.g. little bit more (as e.g. in Plecoglossus) or a little bit less (as e.g. in Galaxias) vertical is enough to exclude, a priori, the possibility that this feature constitutes a primary homology between these fishes.

197. Prominent, long, thin and posteroventrally directed posterior process of hyomandibula. [0] Not present (e.g. Fig. 35). [1] Present (e.g. Monod, figs. 36, 37).

198. Prominent anteroventromesial process of quadrate. [0] Not present (e.g. Fig. 35). [1] Present (e.g. Lenglet, fig. 12).

199. Prominent, thin, anterodorsally directed anteroventrolateral process of quadrate. [0] Not present (e.g. Fig. 35). [1] Present (e.g.
Thys van den Audenaerde, fig. 17).

200. Metapterygoid. [0] Present as independent ossification (e.g. Fig. 35). [1] Absent as independent ossification (e.g. Smith, 1989a: fig. 6). In some specimens of Bathylagus the metapterygoid, although small, is present, while in others it is missing; this genus is thus coded as '?'.

201. Symplectic. [0] Present as independent ossification (e.g. Fig. 35). [1] Not present as independent ossification (e.g. Smith, 1989a: fig. 6).

202. Quadratojugal as independent ossification. [0] Present as independent ossification. [1] Not present as independent ossification (e.g. Fig. 35; Arratia \& Schultze, fig. 23).

203. Two articulatory points between ventral portion of suspensorium and mandible. [0] The ventral portion of the suspensorium and the mandible do not articulate by means of two distinct articulatory points (e.g. Fig. 30). [1] The ventral portion of the suspensorium and the mandible articulate by means of two distinct articulatory points (e.g. Fig. 31; Patterson, 1973: fig. 6B).

204. Toothed 'dermometapterygoids'. [0] Not present (e.g. Fig. 35). [1] Present (e.g. Arratia \& Schultze, fig. 42B).

205. Broad, deep, roughly circular fossa on anteroventromesial surface of quadrate. [0] Not present. [1] Present (e.g. Diogo et al., 1999: fig. 4).

206. Two articulatory heads of hyomandibula for neurocranium. [0] In Lepisosteus and Amia, as well as in most teleosts examined by us, the hyomandibula exhibits a single, continuous dorsal articulatory head for the neurocranium (e.g. Arratia \& Schultze, fig. 23) (note: although in some taxa coded as CS-0, e.g. Megalops, it might seem that there two hyomandibular cartilaginous heads for the neurocranium, these cartilaginous structures are in fact continuous). [1] Two articulatory heads for neurocranium (e.g. Arratia \& Schultze, fig. 23).

207. Prominent posterodorsal projection of hyomandibula (or hyomandibulo-metapterygoid) firmly attached to neurocranium by strong, short connective tissue. [0] Not present. [1] Present (e.g. Diogo).

208. Subopercle. [0] Present as independent ossification (e.g. Fig. 35). [1] Absent as independent ossification (e.g. Taverne, 1978: figs. 41, 104).

209. Subopercle and hyoid arch. [0] Subopercle not articulating directly with hyoid arch by a peculiar, prominent anterior spine. [1] Subopercle articulating directly with hyoid arch by a peculiar, prominent anterior spine (e.g. Ridewood, 1904a: fig. 135C).

210. Opercle. [0] Present as independent ossification (e.g. Fig. 35). [1] Not present as independent ossification (e.g. Tchernavin, 1947a: text-figs. 2, 3).

211. Peculiar, dorsoventrally elongated mesial crest of opercle for articulation with subopercle. [0] Not present. [1] Present (e.g. Monod, fig. 16).

212. Large fenestra on anterodorsal surface of opercle. [0] Not present (e.g. Fig. 35). [1] Present (e.g. Vari, fig. 19B).

213. Preopercle. [0] Present as independent ossification (e.g. Fig. 35). [1] Not present as independent ossification (e.g. Tchernavin, 1947a: text-figs. 2, 3).

214. Opercle. [0] Not with characteristic triangular shape (e.g. Fig. 35). [1] With characteristic triangular shape (e.g. Fink \& Fink, 1981: figs. 11, 12).

215. Several peculiar thin spiny structures on posterior and/or posteroventral portions of opercle. [0] Not present (e.g. Fig. 35). 
[1] Present (e.g. Fig. 24). Some specimens of the genera Elops, Megalops, Galaxias and Esox have such peculiar spiny structures (e.g. Fig. 20; Taverne, 1974), while others not (e.g. Ridewood, 1904; Vrba; Winterbottom, 1974); these genera are thus coded as '?'.

216. Prominent, thin, dorsally/anterodorsally oriented anterodorsal projection of opercle. [0] Not present (e.g. Fig. 20). [1] Present (e.g. Fig. 35; De la Hoz \& Chardon, 1984: fig. 13C; Diogo, fig. 389).

217. Prominent, broad posteroventral spine-like process of preopercle. [0] Not present (e.g. Fig. 35). [1] Present (e.g. Fig. 9; Greenwood, 1968: fig. 7).

218. Preopercles. [0] Not markedly expanded ventrally (e.g. Fig. 4). [1] Markedly expanded ventrally, one preopercle overlapping the other along ventral midline (e.g. This van den Audenaerde, fig. 14).

219. Large anterolateral articulatory facet of interopercle for articulation with quadrate. [0] Not present (e.g. Fig. 35). [1] Present. 220. Well-defined, long, strong ligament running from anterodorsal surface of interopercle to posterodorsal surface of preopercle. [0] Not present. [1] Present (e.g. Diogo).

221. Interopercle. [0] Not a markedly thin and long structure (e.g. Fig. 35). [1] A markedly thin and long structure (e.g. Thys van den Audenaerde, fig. 20).

222. Opercle/subopercle. [0] Not widely separated from interopercle (e.g. Fig. 35). [1] Widely separated from interopercle (e.g. Gosline, 1969: fig. 3A).

223. Interhyal. [0] As noted by authors such as Patterson (1977, 1982) and Jollie (1980, 1984ab, 1986), in Amia and Lepisosteus, as well as in other basal Actinopteri such as Acipenser and Polyodon and in many teleosts, the interhyal (sensu these authors) is not ossified (see e.g. Fig. 4). [1] Presence of ossified interhyal (e.g. Fig. 5; Arratia \& Schultze, fig. 2D). Some members of the genera Chanos, Gonorynchus, Phractolaemus, Nematogenys and Catostomus do not have an ossified interhyal (e.g. Fig. 6), while others have (see e.g. Weisel, 1960; Arratia, 1992; Grande \& PoyatoAriza; Diogo). These genera are thus coded as '?'.

224. Length of interhyal. [0] Interhyal (ossified or not) not markedly elongated dorsoventrally (e.g. Fig. 4). [1] Interhyal (ossified or not) markedly elongated dorsoventrally, such a peculiar elongation being seemingly related to a rather peculiar mechanism of mouth opening/ closure (e.g. Tchernavin, 1953; Günther \& Deckert, figs. 26, 33). 225. Interhyal, hyoid arch and suspensorium. [0] Interhyal (ossified or not) not connected by ligaments to both hyoid arch and suspensorium (e.g. Fig. 5). [1] Interhyal (ossified or not) connected by ligaments to both hyoid arch and suspensorium and thus not articulating directly with these structures. Arratia (1992) described this derived feature for catfishes. However the gymnotiform of the genera Sternopygus, Gymnotus and Brachyhypopomus examined by us and by authors such as De la Hoz \& Chardon (e.g. fig. 8) also have ligaments between the interhyal and both the hyoid arch and the suspensorium.

226. Shape of interhyal. [0] Interhyal (ossified or not) not with peculiar, somewhat dumbbell shape (e.g. Fig. 4). [1] Interhyal (ossified or not) with peculiar, somewhat dumbbell shape. The original definition of this character by Begle was 'interhyal short, dumbbell-shaped'. However, as stressed by Johnson \& Patterson, in specimens such as those of the genus Bathylagus the interhyal is not significantly shorter than in certain other fishes coded as CS-0. Therefore, we prefer to use the less restricting terms 'interhyal with peculiar, somewhat dumbbell shape': such a description does effectively apply to the condition found all in the specimens examined of those taxa coded as CS-1.

227. Distinct mandibulo-hyoid ligament. Present (e.g. Fig. 24; Lauder, fig. 3A, 18). [1] Not present.

228. Mandibulo-hyoid and mandibulo-interopercular ligaments. [0] Within those fishes having mandibulo-hyoid and mandibulointeropercular ligaments, plesiomorphically these ligaments are well-separated from each other (e.g. Vrba, fig. 5; Lauder, fig. 3A). [1] In the specimens examined of the taxa coded as CS-1 one of these three conditions, or a combination of them, occurs: the two ligaments are deeply mixed anteriorly, giving the appearance that there is a single ligament attaching anteriorly on the mandible (e.g. Fig. 33); a significant portion of the mandibulo-interopercular ligament attaches also on the posterior ceratohyal (e.g. Figs. 5, 24); a significant portion of the mandibulo-hyoid ligament attaches also on the interopercle. It should be noted that some authors referred to a 'shift in insertion of the mandibulo-hyoid ligament to the interopercle' as a synapomorphy of the Eurypterygii (e.g. Lauder \& Liem; Johnson, 1992) or of the Neoteleostei (e.g. Rosen, 1985). Thus, according to Rosen (1985) fishes such as the basal Neoteleostei stomiiforms, as well as basal Eurypterygii such as the aulopiforms (see Fig. 1), seemingly exhibit such a feature, while according to Lauder \& Liem and Johnson (1992) the stomiiforms lack this feature. However, Stiassny (1996) and Sato \& Nakabo stressed that such a feature is not present in stomiiforms nor in numerous aulopiforms. The observations of the present study support the statement of these latter authors. The stomiiform and aulopiform fishes examined by us exhibit a condition similar to that found in many non-neoteleostean taxa of CS-1: the mandibulohyoid and mandibulo-interopercular ligaments are both present, but are deeply blended anteriorly, giving the appearance that there is a single ligament attaching anteriorly on the mandible (e.g. Fig. 33). 229. Well-developed, posterodorsally pointed dorsal process of posterior ceratohyal. [0] Not present (e.g. Fig. 5). [1] Present (e.g. Thys van den Audenaerde, fig. 17).

230. Well-developed ventrolateral laminar expansion of anterior ceratohyal. [0] Not present (e.g. Figs. 5, 6). [1] Present (e.g. Diogo). 231. Prominent, broad anteroventral lamina of anterior ceratohyal. [0] Not present (e.g. Figs. 5, 6). [1] Present (e.g. Diogo).

232. Peculiar tooth plates associated with anterior and/or posterior ceratohyals. [0] Not present (e.g. Figs. 5, 6). [1] Present (e.g. Arratia \& Schultze, fig. 2C,D). Apart Elops and Amia, the Megalops specimens examined by us also exhibit such tooth plates (Megalops was not included in the list of fishes analyzed in Arratia \& Schultze's work).

233.Peculiar articulation between prominent anteromesial process of anterior ceratohyal and broad, deep, circular concavity formed by the lateral margins of both urohyal and basihyal. [0] Not present (e.g. Fig. 6). [1] Present (e.g. Taverne, 1972: figs. 9, 10).

234. Broad, deep, roughly circular concavity in each of the anterodorsolateral margins of the urohyal for lodging the anteroventral surface of anterior ceratohyals. [0] Not present (e.g. Fig. 6). [1] Present (e.g. Belouze, fig. 37).

235. Branchiostegal rays. [0] Present (e.g. Fig. 6). [1] Absent (e.g. Tchernavin, 1947a: text-figs. 2, 3; McAllister, 1968).

236. Ossified urohyal/parurohyal. [0] Not present. [1] Present (e.g. Fig. 6; Arratia \& Schultze, fig. 13).

237. Peculiar long and thin cartilages of branchiostegal rays for 
articulation with hyoid arch. [0] Not present (e.g. Fig. 6). [1] Present.

238. Branchiostegal photophores. [0] Absence of several peculiar branchiostegal photophores. [1] Presence several peculiar branchiostegal photophores (e.g. Fink, 1985; Harold \& Weitzman, 1996).

239. Ossification of ventral and dorsal hypohyals. [0] At least one ossified hypohyal present (e.g. Fig. 6). [1] Absence of ossified hypohyals (e.g. Smith, 1989a: fig. 7; Baldwin \& Johnson, 1996: fig. 12B). As explained by authors such as Taverne (1972) and Hilton, Mormyrus apparently has hypohyals, although they are very small.

240. Branchiostegal rays and hypohyals. [0] Not articulating with hypohyals (e.g. Fig. 6). [1] Some branchiostegal rays articulating with hypohyals (e.g. Weitzman, 1967b: fig. 11).

241. Ossified gular plate. [0] Present (e.g. Fig. 20). [1] Absent (e.g. Fig. 4; Gosline 1963: fig. 26B; Jessen 1968: fig. 1). Forey et al. (1996) coded Albula as having an ossified gular plate, but the specimens of this genus examined by us do not seem to have such an ossified gular plate; this genus is thus prudently coded as '?'.

242. Mandibular teeth. [0] Present (e.g. Fig. 21). [1] Absent (e.g. Fig. 10; Vandewalle figs. 1, 2). In some members of the genus Coregonus there are small mandibular teeth while in others such teeth are apparently missing (e.g. Shaposhnikova; Nelson, 1973; Sanford); this genus is thus coded as '?'. Mandibular teeth were drawn in Gayet's (1981) figure 4 of $\uparrow$ Lusitanichthys characiformis but were not drawn in Gayet's (1985) figure 18 of the same species. Cavin described a new species of $\dagger$ Lusitanichthys, $\dagger$ L. africanus, which, according to the latter author, does not have mandibular teeth, suggesting that these teeth might effectively be missing in $\dagger L$. characiformis. However, until more conclusive information is available, we prefer to prudently code $\dagger L$. characiformis as '?'.

243. Peculiar articulation between dentary bone and posterior portion of mandible. [0] Not present (e.g. Fig. 34). [1] Present (e.g. Vari, fig. 42).

244. Coronoid bones. [0] Present as independent ossifications (e.g. Fig. 31). [1] Absent as independent ossifications (e.g. Fig. 32; Patterson, 1973: fig. C).

245. Prearticulars. [0] Present as independent ossifications (e.g. Fig. 31). [1] Absent as independent ossifications (e.g. Fig. 32; Patterson, 1973: fig. C).

246. Articulars. [0] Not mainly fused with angulars (and/or retroarticulars) (e.g. Fig. 30). [1] Mainly fused with angulars (and/ or retroarticulars) (e.g. Fig. 32; Nelson 1973: fig. 6H). According to the descriptions of authors such as Nelson (1973), Taverne (1974) and Hilton the articulars of the members of the genera Megalops and Elops are not fused with the angulo-retroarticulars (see e.g. Fig. 20). However, Arratia (1999: pp. 275, 289) coded Megalops as having articulars "fused with angular and retroarticular bones". Megalops is thus coded here as '?'. Concerning Elops, Arratia (1999: pp. 275, 289) coded this genus as having articulars "partially fused with anguloretroarticulars late in ontogeny". Elops is coded here under CS-0, since, even if in some adult specimens of this genus the articulars are occasionally 'partially' fused with the anguloretroarticulars, as stated Arratia (1999), they are not 'mainly' fused with these latter structures, as described for CS-1.

247. Retroarticulars. [0] Present as independent ossifications (e.g. Fig. 31). [1] Absent as independent ossifications (e.g. Fig. 20; Nelson, 1973: fig. 3K). According to authors such as Nelson (1973) and Hilton in Hiodon the retroarticulars are fused with the angulars, but this is seemingly not always the case, since the Hiodon specimens illustrated by Arratia (1997: fig. 85B) and Taverne (1977b: fig. 15) appear to have independent retroarticulars (see e.g. Fig. 21). This genus is thus coded as '?'.

248. Retroarticular and quadrato-mandibular joint. [0] Retroarticular not excluded from quadrato-mandibular joint (e.g. Fig. 30). [1] Retroarticular excluded from quadrato-mandibular joint (e.g. Nelson, 1973: fig. 6D) [State 1]. Arratia (1992) stated that adult gymnotiforms display a configuration such as CS-0. This is effectively the case for the Gymnotus and Brachyhypopomus specimens that we have dissected. However, this is not the case for the Sternopygus specimens examined in the present work and in works such as De la Hoz \& Chardon (figs. 2, 8). Nelson (1973: 340) stated that in the notopterid osteoglossomorphs (which include Xenomystus), as well as in the osteoglossomorph Pantodon, the retroarticular is not included in the quadrato-mandibular joint. But Hilton questioned this statement because, according to him, the retroarticular of Pantodon is included in quadrato-mandibular joint. Concerning Xenomystus, Hilton stated that in members of this genus the retroarticular lies close to the quadrato-mandibular joint. In the Xenomystus and Pantodon specimens analyzed by us the retroarticular is included in the joint. So, there is seemingly a variation of this character within the members of these two latter genera, and they are thus coded as '?' (it should be noted that the fishes in which the retroarticular is not present as an independent ossification - see above - were coded as 'Inapplicable').

249. Lower jaw. [0] Not highly modified, i.e. dentary bone not roughly perpendicular to remaining of mandible (e.g. Fig. 32). [1] Highly modified, with dentary bone roughly perpendicular to remaining of mandible (e.g. Howes, figs. 6, 19C).

250. Various peculiar, prominent lateral, mesial and dorsal processes of mandible. [0] Not present (e.g. Fig. 32). [1] Present (e.g. Howes, fig. 13).

251. Right and left halves of lower jaw. [0] Firmly attached to each other at midline (e.g. Fig. 4). [1] Not firmly attached to each other at midline (e.g. Howes \& Sanford).

252. Dorsal tip of coronoid process. [0] Not markedly curved mesially (e.g. Fig. 34). [1] Markedly curved mesially (e.g. Fig. 30; Diogo, fig. 3-91).

253. Prominent, posterodorsally pointed anterolateral spine of dentary bone in adults. [0] Not present (e.g. Fig. 9). [1] Present (e.g. Fig. 10).

254. Prominent, stout, dorsoventrally elongated posterolateral and anterodorsally pointed process of angulo-articular. [0] Not present (e.g. Fig. 9). [1] Present (e.g. De la Hoz \& Chardon, fig. 2).

255. 'Interdentary'. [0] Not present. [1] The Plecoglossus specimens examined by us exhibit a 'mandibular postsymphysial element with ossified tips', which was named 'interdentary' by Howes \& Sanford (1987b: fig. 3). Howes \& Sanford and Johnson \& Patterson found, in a specimen of Osmerus mordax, a spherical, partially ossified body lying posterior to the mandibular symphysis that, according to Howes \& Sanford, appears to be somewhat similar to the 'interdentary' of Plecoglossus. Such a structure was not found in the Osmerus specimens examined by us; this genus is thus coded as '?'.

256. Characteristic 'ascending portion' of Meckel's cartilage. [0] Not present (e.g. Fig. 32). [1] Present (e.g. Mo, 1991: fig. 37; Arratia, 1992; Diogo, fig. 3.36). 
257. Ossified coronomeckelian bone. [0] Not present (e.g. Nelson 1973: fig. 1). [1] Present (e.g. Fig. 32; Nelson, 1973: fig. 2). 258. Dorsal margin of coronomeckelian bone. [0] Not situating significantly dorsal to upper margin of other mandibular bones (e.g. Fig. 32). [1] Situating significantly dorsal to upper margin of other mandibular bones (e.g. Howes, fig. 13).

259. Prominent, roughly circular articulatory surface on dorsomesial margin of angulo-articular for articulation with quadrate and/or ectopterygoid. [0] Not present (e.g. Fig. 32). [1] Present.

\section{Miscellaneous}

260. 'Saclike bioluminescent organ' at posterior margin of pectoral fin. [0] Not present. [1] As noted by authors such as Parr (1951, 1960), Matsui \& Rosenblatt (1987), Begle and Johnson \& Patterson, the fishes coded as CS-1 exhibit a 'saclike bioluminescent organ' at the posterior margin of the pectoral fin.

261. 'Tongue-bite mechanism' with dorsal teeth on parasphenoid and occasionally on other bones. [0] Not present. [1] Present (e.g. Sanford \& Lauder, fig. 2). As explained by authors such as Sanford, a few other teleosts, e.g. some salmoniforms, may exhibit a mechanism roughly similar to that of fishes of CS-1. But there are significant differences between the two mechanism and only the mechanism of fishes of CS-1 involves the presence of dorsal teeth on the parasphenoid.

262. Peculiar muscle retractor dorsalis. [0] Not present. [1] Present (e.g. Winterbottom, 1971: fig. 19, 23). As noted by authors such as Johnson (1992: p. 11), "although musculature between the free vertebral column and dorsal gill arch elements occurs in a few lower teleosts (e.g. Pantodon, some muraenid, some cyprinids, siluriforms)", this muscle has been interpreted by most authors as "nonhomologous with the retractor dorsalis of neoteleosts". According to this author, the peculiar neoteleostean muscle retractor dorsalis is associated with an also peculiar "modification of the dorsal gill arch muscles" of fishes such as stomiiforms and aulopiforms, namely the "insertion of the third internal levator on the fifth upper pharyngeal toothplate". As also stressed by Johnson (p. 11), "Fink (1984) noted the presence of a 'retractor dorsalis' in Lepidogalaxias", a genus not included in the present study that is nowadays usually included in the Galaxioidea. According to Johnson the configuration found in the members of the genus Lepidogalaxias is unlike that found in fishes such as stomiiforms and aulopiforms, since the former "retain insertion of the third internal levator on the fourth pharyngobranchial cartilage", this "lack of the associated neoteleostean modification" being "at least consistent with an independent origin of the 'retractor dorsalis' of Lepidogalaxias".

263. Pair of well-developed 'nasal tubes' in anterolateral surfaces of head. [0] Not present. [1] Present (e.g. Thys van den Audenaerde, 1961: fig. 1).

264. Peculiar 'accessory cartilage of the fifth ceratobranchial'. [0] Not present. [1] As explained by authors such as Nelson (1967, 1969, 1970), the fishes coded as CS-1 have a peculiar 'accessory cartilage of the fifth ceratobranchial', which forms part of the 'crumeral organ' of these fishes (e.g. Greenwood \& Rosen, figs. 1A, 2A, 4A, 6B).

265. Characteristic multicuspid teeth. [0] Not present (e.g. Fig. 21). [1] Present (e.g. Fig. 23; Weitzman, 1962: fig. 10, 1964) [State 1]. 266. Characteristic maxillary barbels moved by palatine-maxillary system. [0] Not present. [1] Present (e.g. Alexander, 1965: fig. 8; Gosline, 1975: fig. 1; Diogo et al., 2000, 2003; Diogo \& Chardon) 267. Paired 'mandibular barbels' associated with peculiar basal cartilages. [0] Not present. [1] Present (e.g. Diogo et al., 2003: fig. 7.3A,B).

268. 'Leptocephalus larva'. [0] Not present. [1] Present (e.g. Inoue et al., 2004: figs. 1, 5). Authors such as Gosline (1973) have stated that a 'leptocephalus larva' is also found in fishes other than those usually included in the clade Elopomorpha (see Fig. 1), and that the character state described as CS-1 might be a plesiomorphic feature for teleosts. However, authors such as Forey (1973b) and Forey et al. (1996) pointed out that the 'leptocephalus larva' of fishes included in the 'Elopomorpha' exhibits, in fact, several peculiar, derived features in relation to the larvae of other lower teleosts (see e.g. Forey, 1973b, for more details on these features). In the present work the use of the term 'leptocephalus larva' follows the more restrictive definition given by authors such as Forey (1973b) and Forey et al. (1996).

269. 'Symphysial barbel'. [0] Not present. [1] Present (e.g. Howes, fig. 7).

270. 'Luminous chin barbel'. [0] Not present. [1] Present (e.g. Weitzman, 1967b: fig. 1).

271. One or more 'abdominal scutes', each of a single element which crosses the ventral midline of the fish. [0] Not present. [1] As explained by authors such as Grande (1985) the fishes coded as CS-1 present such peculiar 'abdominal scutes'. As noted by Hilton (p. 68), some osteoglossomorphs, e.g. Xenomystus, have somewhat similar 'abdominal scutes', but "the abdominal scutes found in clupeoids are formed as single median elements, whereas those of notopterids are paired, and therefore do not pass the test of similarity in the establishment of (primary) homology". Xenomystus is thus coded as CS- 0 .

\section{REFERENCES}

Aguilera, O. La musculatura estriada en los peces Gymnotiformes (Teleostei-Ostariophysi): musculatura facial. Acta. Biol. Venez., 12:13-23, 1986.

Albert, J. S. Species diversity and phylogenetic relationships of American Knifefishes (Gymnotiformes, Teleostei). Misc. Publ. Mus. Zool. Univ. Mich., 190:1-127, 2001.

Albert, J. S. \& Campos-da-Paz, R. Phylogenetic systematics of Gymnotiformes with diagnoses of 58 clades: a review of available data. In LR Malabarba, RE Reis, RP Vari, ZM Lucena, CAS Lucena, eds. Phylogeny and Classification of Neotropical Fishes. Porto Alegre, Edipucrs, 1998. pp.410-46.

Alexander, R. McN. Structure and function in catfish. J. Zool. (Lond.), 148:88-152, 1965.

Alves-Gomez, J. A., Orti, G., Haygood, M., Heiligenberg, W. \& Meyer, A. Phylogenetic analysis of the South American electric fishes and the evolution of their electrogenic system: a synthesis based on morphology, electrophysiology and mitochondrial data. Mol. Biol. Evol., 12:298-318, 1995. 
Arratia, G. Development and variation of the suspensorium of primitive catfishes (Teleostei: Ostariophysi) and their phylogenetic relationships. Bonn. zool. Monogr., 32:1-148, 1992.

Arratia, G. Basal teleosts and teleostean phylogeny. Paleo Ichthyologica, 7:5-168, 1997.

Arratia, G. The monophyly of Teleostei and stem-group teleosts. Consensus and disagreements. In Arratia, G. \& Schultze, H. P. Eds. Mesozoic fishes 2 - Systematic and Fossil Record. München, Verlag Dr. F. Pfeil, 1999. pp.265-334.

Arratia, G. Phylogenetic relationships of Teleostei. Past and present. Estud. Oceanol., 19:19-51, 2000.

Arratia, G. Mesozoic halecostomes and the early radiation of teleosts. In Arratia, G. \& Tintori, A. eds. Mesozoic fishes 3 Systematic, Paleoenvironments and Biodiversity. München, Verlag Dr. F. Pfeil, 2004. pp.279-315.

Arratia, G. \& Schultze, H. P. The urohyal: development and homology within osteichthyans. J. Morphol., 203:247-82, 1990.

Begle, D. P. Relationships of the osmeroid fishes and the use of reductive characters in phylogenetic analysis. Syst. Zool., 40:3353, 1991.

Begle, D. P. Monophyly and relationships of the argentinoid fishes. Copeia, 1992:350-66, 1992.

Belouze, A. Compréhension morphologique et phylogénétique des taxon actuels et fossiles rapportés aux Anguilliformes (poissons, téléostéens). Doc. Lab. Geo. Lyon, 158:1-401, 2002.

Bishai, R. M. Cranial muscles of Mormyrus caschive (L.). Anat. Anz. Bd., 121:12-25, 1967.

Brosseau, A. R. The pectoral anatomy of selected Ostariophysi, II - the Characiformes. J. Morphol., 148:89-136, 1978.

Buckup, P. A. Relationships of the Characidiinae and phylogeny of characiform fishes (Teleostei: Ostariophysi). In LR Malabarba, RE Reis, RP Vari, ZM Lucena, CAS Lucena, eds. Phylogeny and Classification of Neotropical Fishes. Porto Alegre, Edipucrs, 1998. pp.123-44.

Cavin, L. A new Clupavidae (Teleostei, Ostariophysi) from the Cenomanian of Daoura (Morocco). C. R. Acad. Sci. Paris, 329:689-95, 1999.

Chapman, W. M. The osteology and relationships of the Argentinidae, a family of oceanic fishes. J. Wash. Acad. Sci., 32:104-17, 1942.

Chardon, M., Parmentier, E. \& Vandewalle, P. Morphology, development and evolution of the Weberian apparatus in catfish. In Arratia, G.; Kappor, B. G.; Chardon, M. \& Diogo, R. Eds. Catfishes. Enfield, Science Publishers, 2003. pp.71-120.
Cloutier, R. \& Arratia, G. Early diversification of actinopterygians. In Arratia, G. \& Tintori, A. eds. Mesozoic fishes 3 - Systematic, Paleoenvironments and Biodiversity. München, Verlag Dr. F. Pfeil, 2004. pp.217-70.

D'Aubenton, F. Morphologie du crâne de Cromeria nilotica occidentalis Daget 1954. Bull. Inst. Fr. Afr. Noire., Sér A, 23:187-249, 1961.

De la Hoz, E. Définition et classification des poissons Gymnotoidei sur la base de la morphologie comparée et fonctionnelle du squélette et des muscles. Unpublished $\mathrm{PhD}$ thesis, University of Liège, 1974.

De la Hoz, E. \& Chardon, M. Skeleton, muscles, ligaments and swim-bladder of a gymnotid fish, Sternopygus macrurus Bloch \& Schneider (Ostariophysi: Gymnotoidei). Bull. Soc. R. Sci. Liège, 53:9-53, 1984.

De Pinna, M. C. C. A phylogenetic analysis of the Asian catfish families Sisoridae, Akysidae and Amblycipitidae, with a hypothesis on the relationships of the Neotropical Asprenidae (Teleostei, Ostariophysi). Fieldiana (Zool.), 84:1-82, 1996.

De Pinna, M. C. C. \& Grande, T. Ontogeny of the accessory neural arch in pristigasteroid clupeomorphs and its bearing on the homology of the otophysan claustrum (Teleostei). Copeia, 2003:938-845, 2003.

Di Dario, F. Evidence supporting a sister-group relationship between Clupeoidea and Engrauloidea (Clupeomorpha). Copeia, 2002:496-503, 2002.

Di Dario, F. Homology between the recessus lateralis and cephalic sensory canals, with the proposition of additional synapomorphies for the Clupeiformes and the Clupeoidei. Zool. J. Linn. Soc., 141:257-70, 2004.

Dimmick, W. W. \& Larson, A. A molecular and morphological perspective on the phylogenetic relationships of the othophysan fishes. Mol. Phylogenet. Evol., 6:120-33, 1996.

Diogo, R. Morphological evolution, aptations, homoplasies, constraints, and evolutionary trends: catfishes as a case study on general phylogeny and macroevolution. Enfield, Science Publishers, 2004.

Diogo, R. \& Chardon, M. Homologies between different adductor mandibulae sections of teleostean fishes, with a special regard to catfishes (Teleostei: Siluriformes). J. Morphol., 243:193-208, 2000.

Diogo, R.; Oliveira, C. \& Chardon, M. On the osteology and myology of catfish pectoral girdle, with a reflection on catfish (Teleostei: Siluriformes) plesiomorphies. J. Morphol., 249:10025, 2001a.

Diogo, R.; Oliveira, C. \& Chardon, M. On the homologies of the skeletal components of catfish (Teleostei: Siluriformes) suspensorium. Belg. J. Zool., 131:93-109, 2001 b. 
Diogo, R.; Chardon, M. \& Vandewalle, P. Morphological description of the cephalic region of Bagrus docmak, with a reflection on Bagridae (Teleostei: Siluriformes) autapomorphies. Neth. J. Zool., 49:207-32, 1999.

Diogo, R.; Chardon, M. \& Vandewalle, P. Functional morphology of catfishes: movements of barbels. In Arratia, G.; Kappor, B. G.; Chardon, M. \& Diogo, R. Eds. Catfishes. Enfield, Science Publishers, 2003. pp.203-20.

Edgeworth, F. H. The cranial muscles of vertebrates. Cambridge, University Press, 1935.

Elmerot, C., Arnason, U., Gojobori, T. \& Janke, A. The mitochondrial genome of the pufferfish, Fugu rubripes, and ordinal teleostean relationships. Gene, 295:163-72, 2002.

Farris, J. S. Hennig 86, version 1.5. Distributed by the author, New York, Port Jefferson Station, 1988.

Filleul, A. Analyse critique des synapomorphies des Élopomorphes et analyse phylogénétique du groupe. Cybium, 24:75-83, 2000.

Filleul, A. \& Lavoué, S. Basal teleosts and the question of elopomorph monophyly: morphological and molecular approaches. C. R. Acad. Sci. Paris, 324:393-9, 2001.

Filleul, A. \& Maisey, J. G. Redescription of Santanichthys diasii (Otophysi, Characiformes) from the Albian of the Santana formation and comments on its implications for Otophysan relationships. Am. Mus. Novit., 3455:1-21, 2004.

Fink, W. L. Basal euteleosts: relationships. In Moser, H. G.; Richards, W. J.; Cohen, D. M.; Fahay, M. P.; Kendall, A. W. \& Richardson, S. L. eds. Ontogeny and systematics of fishes - Am. Soc. Ichthyol. Herpet., Special Publ. num. 1, 1984. pp.202-6.

Fink, W. L. Phylogenetic interrelationships of the stomiid fishes (Teleostei: Stomiiformes). Misc. Publ. Mus. Zool. Univ. Mich., 171:1-127, 1985 .

Fink, S. V. \& Fink, W. L. Interrelationships of the ostariophysan fishes. Zool. J. Linn. Soc. (Lond.), 72:297-353, 1981.

Fink, S. V. \& Fink, W. L. Interrelationships of ostariophysan fishes (Teleostei). In Stiassny, M. L. J.; Parenti, L. R. \& Johnson, G. D. eds. Interrelationships of Fishes. New York, Academic Press, pp. 209-49, 1996.

Fink, S. V., Greenwood, P. H. \& Fink, W. A critique of recent works on fossil ostariophysan fishes. Copeia, 4:1033-41, 1984.

Fink, W. L. \& Weitzman, S. H. Relationships of the stomiiform fishes (Teleostei), with a description of Diplophos. Bull. Mus. Comp. Zool., 150:31-93, 1982.

Forey, P. L. A revision of the elopiform fishes, fossil and recent. Bull. British Mus. (Nast. Hist.), Geol., suppl., 10:1-222, 1973a.
Forey, P. L. Relationships of Elopomorpha. In Greenwood, P. H.; Miles, R. S. \& Patterson, C. eds. Interrelationships of Fishes - Zool. J. Linn. Soc. 53, Suppl. 1. London, Academic Press, 1973b. pp.351-368.

Forey, P. L.; Littlewood, D. T. J.; Ritchie, P. \& Meyer, A. Interrelationships of elopomorph fishes (Teleostei). In Stiassny, M. L. J., Parenti, L. R. \& Johnson, G. D. eds. Interrelationships of Fishes. New York, Academic Press, 1996. pp.175-91.

Gayet, M. Contribuition à l'etude anatomique et systématique de l'ichthyofaune Cénomanienne du Portugal, deuxième partie: les ostariophysaires. Comun. Serv. Geol. Portugal, 67:17390, 1981.

Gayet, M. Contribuition à l'etude anatomique et systématique de l'ichthyofaune Cénomanienne du Portugal, troisième partie: complèment à l'ètude des ostariophysaires. Comun. Serv. Geol. Portugal, 71:91-118, 1985.

Gayet, M. About ostariophysan fishes: a reply to S.V. Fink, P.H. Greenwood and W.L. Fink's criticisms. Bull. Mus. Natl. Hist. Sec. C., 8:393-409, 1986

Gegenbaur, C. Ueber das Kopfskelet von Alepocephalus rostratus Risso. Morphol. Jahrb., 4:1-42, 1878.

Gosline, W. A. The morphology and systematic position of the alepocephaloid fishes. Bull. Br. Mus. Nat. Hist., Zool., 18:183$218,1969$.

Gosline, W. A. Jaw musculature configuration in some higher teleostean fishes. Copeia, 1986:705-13, 1986.

Gosline, W. A. The structure and function of the dermal pectoral girdle in bony fishes with particular reference to ostariophysines. J. Zool. (Lond.), 183:329-38, 1977.

Gosline, W. A. The evolution of some structural systems with reference to the interrelationships of modern lower teleostean fish groups. Jap. J. Ichthyol., 27:1-27, 1980.

Grande, L. Recent and fossil clupeomorph fishes with materials for revision of the subgroups of clupeoids. Bull. Amer. Mus. Nat. Hist., 181:231-372, 1985.

Grande, T. Phylogeny and paedomorphosis in an African family of freshwater fishes (Gonorynchiformes: Kneriidae). Fieldiana (Zool.), 78:1-20, 1994.

Grande, L. \& Bemis, W. E. A comprehensive phylogenetic study of amiid fishes (Amiidae) based on comparative skeletal anatomy. An empirical search for interconnected patterns of natural history. J. Vert. Paleontol., 18(1):1-690, 1998.

Grande, T. \& De Pinna, M. C. C. The evolution of the Weberian apparatus: a phylogenetic perspective. In Arratia, G. \& Tintori, A. eds. Mesozoic fishes 3 - Systematic, Paleoenvironments and Biodiversity. München, Verlag Dr. F. Pfeil, 2004. pp.429-48. 
Grande, T., Laten, H. \& Lopez, J. A. Phylogenetic relationships of extant esocid species (Teleostei: Salmoniformes) based on morphological and molecular characters. Copeia, 2004:74357, 2004.

Grande, T. \& Poyato-Ariza, F. J. Phylogenetic relationships of fossil and recent gonorynchiform fishes (Teleostei: Ostariophysi). Zool. J. Linn. Soc., 125:197-238, 1999.

Greenwood, P. H. Hyoid and ventral gill arch musculature in osteoglossomorph fishes. Bull. Brit. Mus. Nat. Hist. Zool., 22:1-55, 1971.

Greenwood, P. H. Interrelationships of osteoglossomorphs. In Greenwood, P. H., Miles, R. S., Patterson, C. eds.. Interrelationships of Fishes - Zool. J. Linn. Soc. 53, Suppl. 1.. London, Academic Press, 1973. pp.307-32.

Greenwood, P. H. Notes on the anatomy and classification of elopomorph fishes. Bull. Br. Mus. Nat. Hist. (Zool.), 32:65$103,1977$.

Greenwood, P. H. \& Rosen, D. E. Notes on the structure and relationships of the alepocephaloid fishes. Amer. Mus. Novit., 2473:1-41, 1971.

Greenwood, P. H. \& Lauder, G. V. The protractor pectoralis muscle and the classification of teleost fishes. Bull. Br. Mus. Nat. Hist. (Zool.), 41:213-34, 1981.

Greenwood, P. H.; Rosen, D. E.; Weitzman, S. H. \& Meyers, G. S. Phyletic studies of teleostean fishes, with a provisional classification of living forms. Bull. Am. Mus. Natl. Hist., 131:339-456, 1966.

Günther, K. \& Deckert, K. Morphologie und Funktion des Kieferund Kiemenapparates von Tiefseefischen der Gattungen Malacosteus und Photostomias (Teleostei, Isospondyli, Stomiatoidea, Malacosteidae). Dana. Rep., 49:1-54, 1959.

Harold, A. S. \& Weitzman, S. H. Interrelationships of the Stomiiformes. In Stiassny, M. L. J., Parenti, L. R. \& Johnson, G. D. eds. Interrelationships of Fishes. New York, Academic Press, 1996. pp. 333-53.

Hillis, D.M. \& Bull J. J. An Empirical Test of Bootstrapping as a Method for Assessing Confidence in Phylogenetic Analysis. Syst. Biol., 42:182-92, 1993.

Hilton, E. J. Comparative osteology and phylogenetic systematics of fossil and living bony-tongue fishes (Actinopterygii, Teleostei, Osteoglossomorpha). Zool. J. Linn. Soc., 137:1-100, 2003.

Hilton, E. J. \& Bemis, W. E. Skeletal variation in shortnose sturgeon (Acipenser brevirostrum) from the Connecticut River: implications for comparative osteological studies of fossil and living fishes. In Arratia, G. \& Schultze, H.-P. eds. Mesozoic fishes 2 - Systematic and Fossil Record. München, Verlag Dr. F. Pfeil, 1999. pp.69-94.
Howes, G. J. Cranial muscles of gonorynchiform fishes, with comments on generic relationships. Bull. Br. Mus. Nat. Hist. (Zool.), 49:273-303, 1985.

Howes, G. J. \& Sanford, C. P. J. Oral ontogeny of the ayu, Plecoglossus altivelis and comparison with the jaws of other salmoniform fishes. Zool. J. Linn. Soc., 89:133-69, 1987.

Inoue, J. G.; Miya, M.; Tsukamoto, K. \& Nishida, M. Basal actinopterygian relationships: a mitogenomic perspective on the phylogeny of the "ancient fish". Mol. Phylogenet. Evol., 26:110-20, 2003.

Inoue, J. G.; Miya, M.; Tsukamoto, K. \& Nishida, M. Mitogenomic evidence for the monophyly of elopomorph fishes (Teleostei) and the evolutionary origin of the leptocephalus larva. Mol. Phylogenet. Evol., 32:274-86, 2004.

Ishiguro, N. B.; Miya, M. \& Nishida, M. Basal euteleostean relationships: a mitogenomic perspective on the phylogenetic reality of the "Protacanthopterygii". Mol. Phylogenet. Evol., 27:476-88, 2003.

Jessen, H. The gular plates and branchiostegal rays in Amia, Elops and Polypterus. Nobel. Symp. 4, Cur. Probl. Low. Vert. Phyl., 429-38, 1968.

Jessen, H. Schultergürtel und Pectoralflosse bei Actinopterygiern. Fossils Strata, 1:1-101, 1972.

Johnson, G. D. Monophyly of the euteleostean clades Neoteleostei, Eurypterygii, and Ctenosquamata. Copeia, 1992:8-25, 1992.

Johnson, G. D. \& Patterson, C. Relationships of lower euteleostean fishes. In Stiassny, M. L. J., Parenti, L. R. \& Johnson, G. D. eds. Interrelationships of Fishes. New York, Academic Press, 1996. pp.251-332.

Jollie, M. Development of the head skeleton and pectoral girdle in Esox. J. Morphol., 147:61-88, 1975.

Jollie, M. Development of head and pectoral girdle skeleton and scales in Acipenser. Copeia, 1980:226-49, 1980.

Jollie, M. Development of the head and pectoral skeleton of Amia with a note on the scales. Gegenbaurs. Morphol. Jahrb., 130:315-51, 1984a.

Jollie, M. Development of head and pectoral girdle bones of Lepisosteus with a note on scales. Copeia, 1984:476-502, 1984b.

Jollie, M. A primer of bone names for the understanding of the actinopterygian head and pectoral girdle skeleton. Can. J. Zool., 64:365-79, 1986.

Kershaw, D. R. The cranial osteology of the 'Butterfly Fish', Pantodon buchholzi Peters. Zool. J. Linn. Soc., 49:5-19, 1970. 
Kershaw, D. R. A structural and functional interpretation of the cranial anatomy in relation to the feeding of osteoglossoid fishes and a consideration of their phylogeny. Trans. Zool. Soc. Lond., 33:179-252, 1976.

Kirchhoff, H. Functionell-anatomische untersuchung des visceralapparates von Clupea harengus L. Zool. Jahrb., 76:461-540, 1958.

Ladich, F. Sound-generating and -detecting motor system in catfish: design of swimbladder muscles in doradids and pimelodids. Anat. Res., 263:297-306, 2001.

Lauder, G. V. Evolution of the feeding mechanism in primitive actinopterygian fishes: a functional anatomical analysis of Polypterus, Lepisosteus, and Amia. J. Morphol., 163:283-317, 1980.

Lauder, G. V. \& Liem, K. F. The evolution and interrelationships of the actinopterygian fishes. Bull. Mus. Comp. Zool., 150:95197, 1983.

Lavoué, S. \& Sullivan, J. P. Simultaneous analysis of five molecular markers provides a well-supported phylogenetic hypothesis for the living bony-tongue fishes (Osteoglossomorpha: Teleostei). Mol. Phylogenet. Evol., 33:171-85, 2004.

Lavoué, S.; Miya, M.; Inoue, J. G.; Saitoh, K.; Ishiguro, N. B. \& Nishida, M. Molecular systematics of the gonorynchiform fishes (Teleostei) based on whole mitogenome sequences: implications for higher-level relationships within the Otocephala. Mol. Phylogenet. Evol., 37:165-77, 2005.

Lecointre, G. Molecular and morphological evidence for a Clupeomorpha-Ostariophysi sister-group relationship (Teleostei). Geobios, 19:205-10, 1995.

Lekander, B. The sensory line system and the canal bones in the head of some Ostariophysi. Acta Zool., 30:1-131, 1949.

Lenglet, G. Contribution à l'étude ostéologique des Kneriidae. Ann. Soc. R. Zool. Belg., 103:239-70, 1974.

Li, G. Q. A new species of Late Cretaceous osteoglossid (Teleostei) from the Oldman Formation of Alberta, Canada, and its phylogenetic relationships. In Arratia, G. \& Viohl, G. eds. Mesozoic fishes - Systematic and Paleoecology. München, Verlag Dr. F. Pfeil, 1996. pp.285-98.

Li, G. Q. \& Wilson, M. V. H. Phylogeny of Osteoglossomorpha. In Stiassny, M. L. J.; Parenti, L. R. \& Johnson, G. D. eds. Interrelationships of Fishes. New York, Academic Press, 1996. pp.163-74.

Liu, H. Phylogenetic relationships of the Cypriniformes tested by mtDNA $12 \mathrm{~S}$ rRNA sequence variations. Acta Gen. Sinica, 31:137-42, 2004.
Liu, H; Tzeng, C. S. \& Teng H. Y. Sequence variations in the mitochondrial DNA control region and their implications for the phylogeny of the Cypriniformes. Can. J. Zool., 80:569-81, 2002.

López, J. A.; Chen, W. J. \& Orti, G. Esociform phylogeny. Copeia 2004:449-64, 2004.

Mabee, P. M. \& Noordsy, M. Development of the paired fins in the paddlefish, Polyodon spathula. J. Morphol., 261:334-44, 2004.

Matthes, H. A comparative study of the feeding mechanisms of some African Cyprinidae (Pisces, Cypriniformes). Bijdr. Dierk., 33:3$35,1963$.

Mayhew, R. L. The skull of Lepisosteus ptatostomus. J. Morphol., 38:315-46, 1924.

McAllister, D. E. The evolution of branchiostegals and associated opercular, gular, and hyoid bones and the classification of teleostome fishes, living and fossil. Bull. Nat. Mus. Can., 221:1239, 1968.

McDowall, R. M. Relationships of galaxioid fishes with a further discussion of salmoniform classification. Copeia, 1969:796-824, 1969.

Mo, T. Anatomy, relationships and systematics of the Bagridae (Teleostei: Siluroidei) with a hypothesis of siluroid phylogeny. Theses Zoologicae, 17:1-216, 1991.

Monod, T. Sur quelques points de l'anatomie de Gonorhynchus gonorhynchus (Linné 1766). Melanges Ichthyol., 68:255-313, 1963.

Moritz, T. \& Britz, R. Ontogeny and homology of the basipterygoid articulation in Pantodon buchholzi (Teleostei: Osteoglossomorpha). Zool. J. Linn. Soc., 144:1-13, 2005.

Nelson, G. J. Gill arches of teleostean fishes of the division Osteoglossomorpha. J. Linn. Soc. (Zool.), 47:261-77, 1968.

Nelson, G. J. Relationships of clupeomorphs, with remarks on the structure of the lower jaw in fishes. In Greenwood, P. H., Miles, R. S., Patterson, C. eds. Interrelationships of Fishes - Zool. J. Linn. Soc. 53, Suppl. 1. London, Academic Press, 1973. pp.333-49.

Nelson, J. S. Fishes of the World. Third edition. New York, John Wiley \& Sons, 2004.

Nelson, J. S. Fishes of the World. Fourth edition. New York, John Wiley \& Sons, 2006.

Nixon, K. C. Nona \& Winclada, version 1.00.08. Published by the author, New York, Ithaca, 2002.

Norden, C. R. Comparative osteology of representative salmonid fishes, with particular reference to the grayling (Thymallus articus) and its phylogeny. J. Fish. Res. Bd. Canada, 18:679791, 1961. 
Obermiller, L. E. \& Pfeiler, E. Phylogenetic relationships of elopomorph fishes inferred from mitochondrial ribosomal DNA sequences. Mol. Phylogenet. Evol., 26:202-14, 2003.

Orti, G. \& Meyer, A. The radiation of characiform fishes and the limits of resolution of mitochondrial ribosomal DNA sequences. Syst. Biol., 46:75-100, 1997.

Orton, G. L. Notes on larval anatomy of fishes of order Lyomeri. Copeia, 1963:6-15, 1963.

Pasleau, F. Recherches sur la position phylétique des téléostéens Gonorynchiformes, basées sur l'étude de l'ostéologie et de myologie céphalique. Bachelor's thesis, University of Liège, 1974.

Patterson, C. Interrelationships of holosteans. In Greenwood, P. H.; Miles, R. S. \& Patterson, C. eds. Interrelationships of Fishes Zool. J. Linn. Soc. 53, Suppl. 1. London, Academic Press, pp. 233-305, 1973.

Patterson, C. The braincase of pholidophorid and leptolepid fishes, with a review of the actinopterygian braincase. Philos. Trans. R. Soc. Lond., Ser. B, 269:275-579, 1975.

Patterson, C. The contribution of paleontology to teleostean phylogeny. In Hecht, P. C., Goody, P. C. \& Hecht, B. M. eds. Major patterns in vertebrate evolution. New York, Plenum Press, pp. 579-643, 1977.

Patterson, C. Chanoides, a marine Eocene otophysan fish (Teleostei: Ostariophysi). J. Vert. Paleont., 4:430-56, 1984.

Patterson, C. \& Rosen, D. E. Review of ichthyodectiform and other Mesozoic fishes and the theory and practice of classifying fossils. Bull. Amer. Mus. Nat. Hist., 158:85-172, 1977.

Patterson, C. \& Johnson, G. D. The intermuscular bones and ligaments of teleostean fishes. Smithson. Contrib. Zool., 599:183, 1995.

Peng, Z.; Shunping, H.; Wang, J.; Wang, W. \& Diogo, R. Mitochondrial molecular clocks and the origin of the major otocephalan clades (Pisces, Teleostei): a new insight. Gene, 370:113-24, 2006.

Poyato-Ariza, F. J. A revision of the ostariophysan fish family Chanidae, with special reference to the Mesozoic forms. Palaeo Ichthyologica, 6:1-52, 1996.

Ramaswami, L. S. Skeleton of cyprinoid fishes in relation to phylogenetic studies. V, the skull and gasbladder capsule of the Cobitidae. Proc. Nat. Inst. Sci. India, Biol. Sci., 19:323-47, 1953.

Regan, C. T. The anatomy and classification of the teleostean fishes of the order Lyomeri. Ann. Mag. Nat. Hist., 8:347-9, 1912.

Ridewood, W. G. On the cranial osteology of the clupeoid fishes. Proc. Zool. Soc. Lond., 29:448-93, 1904a.
Ridewood, W. G. On the cranial osteology of the fishes of the families Elopidae and Albulidae, with remarks on the morphology of the skull in the lower teleostean fishes generally. Proc. Zool. Soc. Lond., 2:35-81, 1904b.

Ridewood, W. G. On the cranial osteology of the fishes of the families Osteoglossidae, Pantodontidae, Phractolaemidae. J. Linn. Soc. Lond. (Zool.), 29:252-82, 1905a.

Ridewood, W. G. On the skull of Gonorynchus greyi. Ann. Mag. Nat. Hist., 7:361-72, 1905 b.

Rokas, A.; Williams, B. L.; King, N. \& Carroll, S. B. Genome-scale approaches to resolving incongruence in molecular phylogenies. Nature, 425:798-804, 2003.

Rosen, D. E. Interrelationships of higher euteleostean fishes. In Greenwood, P. H.; Miles, R. S.; Patterson, C. Eds. Interrelationships of Fishes - Zool. J. Linn. Soc. 53, Suppl. 1. London, Academic Press, 1973. pp.397-513.

Rosen, D. E. Phylogeny and zoogeography of salmoniform fishes and relationships of Lepidogalaxias salamandroides. Bull. Am. Mus. Nat. Hist., 153:265-326, 1974.

Rosen, D. E. An essay on euteleostean classification. Am. Mus. Novit., 2827:1-45, 1985.

Rosen, D. E. \& Greenwood, P. H. Origin of the Weberian apparatus and the relationships of the ostariophysan and gonorynchiform fishes. Am. Mus. Novit., 2428:1-25, 1970.

Saitoh, K., Miya, M., Inoue, J. G., Ishiguro, N. B. \& Nishida, M. Mitochondrial genomics of ostariophysan fishes: perspectives on phylogeny and biogeography. J. Mol. Evol., 56:464-72, 2003.

Sanford, C. P. J. Salmonoid fish osteology and phylogeny (Teleostei: Salmonoidei). Theses Zoologicae, 33:1-264, 2000.

Sato, T. \& Nakabo, T. Paraulopidae and Paraulopus, a new family and genus of aulopiform fishes with revised relationship within the order. Ichthyol. Res., 49:25-46, 2002.

Shaposhnikova, G. Comparative morphology of the whitefishes (Coregoninae) from the URSS. Trudy. Zool. Inst. Akad., 46:207256, 1967.

Schaeffer, B. \& Rosen, D. E. Major adaptive levels in the evolution of the actinopterygian feeding mechanisms. Am. Zool., 1:187204, 1961.

Shen, M. Fossil "osteoglossomorphs" in East Asia and their implications in teleostean phylogeny. In Arratia, G. \& Viohl, G. eds. Mesozoic fishes - Systematic and Paleoecology. München, Verlag Dr. F. Pfeil, 1996. pp.261-72.

Siebert, D. J. Interrelationships among families of the order Cypriniformes (Teleostei). Unpublished Ph. D. Dissertation, City University of New York, 1987. 
Smith, D. G. Family Anguillidae. In: Fishes of the Western North Atlantic, Mem. Sears Found. Mar. Res. 1, part 9:25-47, 1989a.

Smith, D. G. Family Congridae. In: Fishes of the Western North Atlantic, Mem. Sears Found. Mar. Res. 1, part 9:460-567, 1989b.

Springer, V. G. \& Johnson, G. D. Study of the dorsal gill-arch musculature of teleostome fishes, with special reference to the Actinopterygii. Bull. Biol. Soc. Wash., 11:1-236, 2004.

Stiassny, M. L. J. The limits and relationships of the acanthomorph fishes. J. Zool. (Lond.), B, 1:411-60, 1986.

Stiassny, M. L. J. Basal ctenosquamate relationships and the interrelationships of the myctophiform (scopelomorph) fishes. In Stiassny, M. L. J.; Parenti, L. R. \& Johnson, G. D. Eds. Interrelationships of Fishes. New York, Academic Press, 1996. pp.405-36.

Stiassny, M. L. J.; Wiley, E. O.; Johnson, G. D. \& de Carvalho, M. R. Gnathostome fishes. In Donaghue, M. J. \& Cracraft, J. eds. Assembling the tree of life. New York, Oxford University Press, 2004. pp. 410-29.

Sulak, K. J. The systematics and biology of Bathypterois (Pisces, Chlorophthalmidae) with a revised classification of benthic myctophiform fishes. Galathea Rep., 14:49-108, 1977.

Swinnerton, H. H. The osteology of Cromeria nilotica and Galaxias attenuatus. Zool. Jahr., 18:58-70, 1903.

Takahasi, N. On the homology of the cranial muscles of the cypriniform fishes. J. Morphol., 40:1-109, 1925.

Taverne, L. Ostéologie des genres Mormyrus Linné, Mormyrops Muller, Hyperopisus Gill, Myomyrus Boulenger, Stomatorhinus Boulenger et Gymnarchus Cuvier. Ann. Mus. R. Afr. Centr. 200:1-194, 1972.

Taverne, L. Ostéologie d'Elops Linné, C., 1766 (Pisces, Elopiformes) et son intérêt phylogénétique. Acad. R. Belg. Mem. Classe Sci., 41:1-96, 1974.

Taverne, L. Ostéologie de Clupavus maroccanus (Crétacé Supérieur du Maroc) et considérations sur la position systématique et des relations des Clupavidae au sein de l'ordre des Clupeiformes sensu stricto (Pisces, Teleostei). Geobios, 10:697-722, 1977a.

Taverne, L. Ostéologie, phylogénèse, et systématique des téléostéens fossiles et actuels du super-ordre des ostéoglossomorphes, première partie. Ostéologie des genres Hiodon, Eohiodon, Lycoptera, Osteoglossum, Scleropages, Heterotis et Arapaima. Acad. R. Belg. Mem. Classe Sci., 41:1$235,1977 \mathrm{~b}$

Taverne, L. Ostéologie, phylogénèse, et systématique des téléostéens fossiles et actuels du super-ordre des ostéoglossomorphes, deuxième partie. Ostéologie des genres
Phareodus, Phareoides, Brychaetus, Musperia, Pantodon, Singida, Notopterus, Xenomystus et Papyrocranus. Acad. R. Belg. Mem. Classe. Sci., 42:1-212, 1978.

Taverne, L. Description de l'appareil de Weber du téléosteen crétacé marin Clupavus maroccanus et ses implications phylogénétiques. Belg. J. Zool., 125:267-82, 1995.

Taverne, L. Les poissons cretacés de Nardò, $8^{\circ}$ - Sorbininardus apuliensis, gen. nov., sp. nov. (Teleostei, Ostariophysi, Anatophysi, Sorbininardiformes, nov. ord.). Studi e Richerche sui giacimenti terziari di Bolca VIII, Spec Vol L Sorbiri, Mus. Civ. St. Nat. Verona, 23:77-103, 1999.

Tchernavin, V. V. Six specimens of Lyomeri in the British Museum (with notes on the skeleton of the Lyomeri). J. Linn. Soc. Lond. Zool., 41:287-350, 1947a.

Tchernavin, V. V. Further notes on the structure of the bony fishes of the order Lyomeri (Eurypharynx). J. Linn. Soc. Lond. Zool., 41:387-93, 1947b.

Triques, M. L. Filogenia dos géneros de Gymnotiformes (Actinopterygii, Ostariophysi), com base em caracteres esqueléticos. Comun. Mus. Ciênc. PUCRS, série zool., 6:85-130, 1993.

Thys van den Audenaerde, D. F. E. L'anatomie de Phractolaemus ansorgei Blgr. et la position systématique des Phractolaemidae. Ann. Mus. R. Afr. Centr., 103:101-67, 1961.

Vandewalle, P. Contribution à l'étude anatomique et fonctionnelle de la région céphalique de Gobio gobio (L.) (Pisces, Cyprinidae), 3, les os, les muscles et les ligaments. Forma et Functio, 8:33160,1975

Vandewalle, P. Particularités anatomiques de la tête de deux Poissons Cyprinidés Barbus barbus (L.) et Leuciscus leuciscus (L). Bull. Acad. R. Belg., 5:469-79, 1977.

Vari, R. P. Anatomy, relationships and classification of the families Citharinidae and Distichodontidae (Pisces, Characoidea). Bull. Br. Mus. Nat. Hist. (Zool.), 36:261-344, 1979.

Vrba, E. S. Contributions to the functional morphology of fishes Part V, the feeding mechanism of Elops saurus Linnaeus. Zool. Afr., 3:211-36, 1968.

Wang, C. H.; Kuo, C. H.; Mok, H. H. \&Lee, S. C. Molecular phylogeny of elopomorph fishes inferred from mitochondrial $12 \mathrm{~S}$ ribosomal RNA sequences. Zool. Scripta, 32:231-41, 2003.

Waters, J. M.; Lopez, J. A. \& Wallis, G. P. Molecular phylogenetics and biogeography of galaxiid fishes (Osteichthyes: Galaxiidae) dispersal, vicariance, and the position of Lepidogalaxias salamandroides. Syst. Biol., 49:777-95, 2000.

Weisel, G. F. The osteocranium of the catostomid fish, Catostomus macrocheilus - a study in adaptation and natural relationship. $J$. Morphol., 106:109-29, 1960. 
Weitzman, S. H. The osteology of Brycon meeki, a generalized characid fish, with an osteological definition of the family. Stanford Ichthyol. Bull., 8:1-77, 1962.

Weitzman, S. H. The origin of stomiatoid fishes with comment on the classification of salmoniform fishes. Copeia, 1967:50740, 1967a.

Weitzman, S. H. The osteology and relationships of the Astronesthidae, a family of oceanic fishes. Dana. Rep., 71:154, 1967b.

Wilga, C. D.; Wainwright, P. C. \& Motta, P. J. Evolution of jaw depression mechanisms in aquatic vertebrates: insights from Chondrichthyes. Biol. J. Linn. Soc., 71:165-85, 2000.

Wilson, M. V. H. \& Veilleux, P. Comparative osteology and relationships of the Umbridae (Pisces: Salmoniformes). Zool. J. Linn. Soc., 76:321-5, 1982.

Wu, K. Y. \& Shen, S.C. Review of the teleostean adductor mandibulae and its significance to the systematic position of the Polymixiiformes, Lampridiformes, and Triacanthoidei. Zool. Stud., 43:712-36, 2004.

Winterbottom, R. A descriptive synonymy of the striated muscles of the Teleostei. Proc. Acad. Nat. Sci. (Phil.), 125:225-317, 1974.

Zaragüeta-Bagils, R.; Lavoué, S.; Tillier, A.; Bonillo, C. \& Lecointre, G. Assessment of otocephalan and protacanthopterygian concepts in the light of multiple molecular phylogenies. C. R. Biologies, 325:1191-207, 2002.
Correspondence to:

Dr. Rui Diogo

Department of Anthropology,

The George Washington University, 2110 G St. NW, Washington, DC 20052, USA

Phone: 202-248-1440

Email: ruidiogo@gwmail.gwu.edu

Received: 29-03-2008

Accepted: 07-07-2008 